\title{
Emotion and Autobiographical Memory
}

\author{
Alisha C. Holland and Elizabeth A. Kensinger \\ Boston College, Department of Psychology, Chestnut Hill, MA 02467
}

\section{Abstract}

Autobiographical memory encompasses our recollections of specific, personal events. In this article, we review the interactions between emotion and autobiographical memory, focusing on two broad ways in which these interactions occur. First, the emotional content of an experience can influence the way in which the event is remembered. Second, emotions and emotional goals experienced at the time of autobiographical retrieval can influence the information recalled. We discuss the behavioral manifestations of each of these types of interactions and describe the neural mechanisms that may support those interactions. We discuss how findings from the clinical literature (e.g., regarding depression) and the social psychology literature (e.g., on emotion regulation) might inform future investigations of the interplay between the emotions experienced at the time of retrieval and the memories recalled, and we present ideas for future research in this domain.

\section{Keywords}

affect; autobiography; consolidation; encoding; fMRI; mood; neuroimaging; retrieval

\section{Introduction}

A large proportion of memory research has followed the "verbal learning tradition" (e.g., Underwood, 1954, 1964), assessing the number of unrelated words that individuals can learn and the period of time over which they can retain the information. Yet when we use the word "memory" colloquially, we are generally referring not to our ability to intentionally memorize disconnected bits of information but rather to our ability to remember past experiences in a coherent fashion. "Autobiographical memory" is a term that fits well with this colloquial use of the word "memory," being defined as "memory for the events of one's life" (Conway \& Rubin, 1993, pg. 103). As those authors note, autobiographical memory "constitutes a major crossroads in human cognition where considerations relating to the self, emotion, goals, and personal meanings all intersect" (Conway \& Rubin, 1993, p. 103), and it is the behavioral and neurobiological nature of this intersection that is the focus on the current review.

In this article, we begin by briefly reviewing the qualitative characteristics, functions, and neural underpinnings of autobiographical memory (Section 2). We give particular attention to the constructivist nature of autobiographical memory and describe how recent neuroimaging studies have clarified some of the mechanisms that support this reconstruction process and yield memories of varying levels of specificity. We then turn our attention to the

Publisher's Disclaimer: This is a PDF file of an unedited manuscript that has been accepted for publication. As a service to our customers we are providing this early version of the manuscript. The manuscript will undergo copyediting, typesetting, and review of the resulting proof before it is published in its final citable form. Please note that during the production process errors may be discovered which could affect the content, and all legal disclaimers that apply to the journal pertain. 
main focus of the review, examining the interactions between emotion and autobiographical memory. We discuss how the emotional content of an experience can influence the way in which the event is retained and recalled (Section 3). We describe how emotional experiences can be remembered with high confidence even when the events are not remembered in a highly consistent fashion, and we discuss the features of an emotional experience that may lead to these influences. We also describe how some aspects of an emotional experience can be remembered more accurately and vividly than others, resulting in a "memory trade-off" or in "tunnel memory" for restricted details of an event. After presenting the behavioral evidence that such effects occur, we describe the neural interactions that give rise to these effects, discussing the way in which emotion can influence the encoding, consolidation, and retrieval of autobiographical memories. We then describe how experienced emotion and activated emotion regulation goals at the time of autobiographical retrieval can influence the way in which past emotions and prior experiences are recalled (Section 4). We discuss how memories of the emotions experienced during a specific event are often reconstructed in light of current emotional states. We review how emotions experienced at the time of retrieval can influence which autobiographical information is most accessible and therefore most likely to be retrieved, such as in mood congruent memory. We also describe how individuals' emotion regulation goals at the time of retrieval can bias which memories are likely to be retrieved, and we discuss how the details of prior events can be construed and even biased based on emotion regulation goals. We describe what has been learned about the neural processes affected by mood states (i.e., depression) and by emotion regulation, exploring how that literature might inform future investigations of the interplay between the emotions experienced at the time of retrieval and the memories recalled. In the final section (Section 5), we propose conclusions that can be drawn about the intersection of emotion and autobiographical memory and suggest ideas for future research in this domain.

\section{Autobiographical Memory}

The term autobiographical memory encompasses a rich database of knowledge about oneself and as such it is difficult to pinpoint a precise definition for it (e.g., Brewer, 1996; Conway \& Pleydell Pearce, 2000; Rubin, Schrauf, \& Greenberg, 2003). In large part due to Tulving's $(1972,1983)$ suggested division of episodic and semantic memory systems, autobiographical memory has broadly been conceptualized to be divided into personal semantic information (i.e., facts about the self, such as knowing where one was born) and personal episodic information (i.e., unique events, such as remembering a first day of school) (see Brewer, 1996; Baddeley, 1992 for discussions). Recalling personal semantic information does not depend on retrieving particular experiences, but rather is linked to feelings of "knowing" or familiarity; on the other hand, recalling personal episodic information requires re-experiencing and recollecting particular past events (Wheeler, Stuss \& Tulving, 1997) and integrating information from a number of different subsystems (e.g., sensory information, language, emotion, narrative, etc.; Rubin, 2006). Recalling each type of information seems to rely on differential patterns of neural activation (e.g., Maguire, Mummery \& Buchel, 2000). Although autobiographical memory includes both personal semantic and episodic information (Wheeler et al., 1997), for the purposes of this review we will be focusing on individuals' memories for particular episodes or events.

Autobiographical memory is usually elicited in the laboratory by asking individuals to report specific personal episodes. One of the most popular ways to do so is to present individuals with a series of cue words (e.g., table) and ask them to retrieve a specific memory that somehow relates to each word (e.g., Galton, 1879; Crovitz \& Schiffman, 1974; see also Rubin, Wetzler \& Nebes, 1986; Brewer, 1996; Rubin \& Wenzel, 2004, for reviews). Cue words can be emotional in nature, such as in the Autobiographical Memory Test developed by Williams and Broadbent (1986) to examine memory in depressed individuals. The cue 
word technique allows for measurement of both objective measures of autobiographical memory (e.g., latencies to recall negative vs. positive events, recent vs. remote events, etc.) as well as subjective, phenomenological characteristics of those events (e.g., ratings of valence and arousal, confidence in accuracy, vividness, etc.; see Brewer, 1996). A similar technique involves asking individuals to recall self-nominated events that meet some predetermined criteria, such as being highly negative vs. positive (e.g., Bohanek, Fivush \& Walker, 2005; Berntsen, 2002) or coming from a particular lifetime period (e.g., first week of classes in college; Holland, Tamir \& Kensinger, submitted). Other researchers have relied on guided autobiographical memory interviews that ask individuals to recall typical life events from various lifetime periods (e.g., Levine et al., 2002) or to create narratives of critical lifetime events (e.g., McAdams et al., 1996). A growing number of studies ask individuals to recall the details of unique, emotional, public events ("flashbulb" events; Brown \& Kulik, 1977; see Section 3 for an in-depth review).

One criticism of the study of autobiographical memory is the difficulty in controlling for factors like accuracy in retrospective reports (see, e.g., Bell, 1992). Therefore, some have turned to prospective studies of autobiographical memory by asking participants to keep diaries and subjective ratings of everyday events and then to recall a random subset of those memories after some delay (e.g., Barclay \& Wellman, 1986; Burt, Kemp \& Conway, 2003; see also Larsen \& Conway, 1997; Wagenaar, 1986, for examples of researchers who kept diaries of their own memories). Although diary studies do allow for more objective measures of accuracy, they still lack experimental control over which events participants record everyday (Bell, 1992). More recently, Cabeza et al. (2004) developed a task in which undergraduates were asked to take photographs of their college campus and later discriminate between the photos they took and those that other undergraduates captured. This technique affords greater control over the encoding conditions of specific visual and spatial episodic details, accuracy measures, and the age of the memories (Cabeza et al., 2004). With the advent of neuroimaging technologies over the past two decades, there has also been an upsurge of studies that utilize such techniques to examine autobiographical memory, usually in conjunction with one of the behavioral methodologies outlined above (see Cabeza \& St. Jacques, 2007, for a review; see also Section 2.2 below).

\subsection{Characteristics and Functions}

Autobiographical memory serves a number of functions in our everyday lives. Recent reviews by Bluck (2003) and Bluck et al. (2005) suggest that these functions can broadly be organized into three categories: self, social, and directive. The self category pertains to autobiographical memory's role in personality development (see also Woike et al., 1999; Woike \& Polo, 2001; Woike, 2008; McAdams, 1996) and maintaining a coherent sense of self over time (see also Conway, 2005). The social category includes functions such as providing material for conversation and social bonding (reviewed by Bluck, 2003; Bluck et al., 2005; see also Fivush, Haden \& Reese, 1996; Fitzgerald, 1996 for perspectives on social functions of autobiographical memory on either end of the lifespan). Finally, the directive category encompasses autobiographical memory's role in problem solving and guiding future behavior (see also Pillemer, 2003).

Autobiographical memories for events are associated with a number of phenomenological characteristics. For one, they are often recalled with great feelings of vividness and rich sensory and perceptual detail (e.g., Brewer, 1996; Rubin \& Kozin, 1984; Wright \& Gaskell, 1992; Conway, 1990). Indeed, retrieving such vivid details can lead to the feeling that one has mentally time traveled to the past and is re-experiencing an event (Rubin, 2005), a phenomenon termed autonoetic memory by Tulving (1985). The vantage point from which we re-experience autobiographical events can vary between a field perspective, in which we "see" a scene from the same viewpoint that we originally experienced it, and an observer 
perspective, in which we see the mental images of a scene-often including ourselves—as an outside observer would have (Freud 1899/1953; Robinson, 1996; Robinson \& Swanson, 1993). Recent memories tend to be remembered from a field experience (Nigro \& Neisser, 1983; Talarico, LaBar \& Rubin, 2004), as do emotional memories (D'Argembeau, Comblain \& Van Der Linden, 2003; Berntsen \& Rubin, 2006a). In addition to these visual features, our autobiographical memories for personal episodes are often organized into coherent narratives or stories complete with contextual details (e.g., Larsen, 1992). The ability to create such narratives develops through co-constructions of past events with primary caregivers in early childhood (Fivush \& Reese, 1992; Fivush, Haden \& Reese, 1996; Nelson $\&$ Fivush, 2004) and is further honed during adolescence (Habermas \& Bluck, 2000).

Another characteristic of autobiographical memories is that they can vary in their levels of specificity (e.g., Barsalou, 1988; Conway \& Pleydell-Pearce, 2000). A popular model in the field is Conway \& Pleydell-Pearce's (2000) self-memory system, which proposes that autobiographical knowledge is arranged hierarchically. According to this model, overarching lifetime periods or themes (e.g., when I was in college) are positioned at the top of the hierarchy. At the intermediary level of the hierarchy are general autobiographical events, including either repeated categories of events (e.g., every Thanksgiving) or temporally extended events (e.g., a picnic or a vacation). The bottom of the hierarchy is comprised of event specific knowledge, including particular sensory and perceptual details from general events (e.g., the spatial layout of the food on the blanket at a picnic). It has been proposed that when we are cued to retrieve an autobiographical memory, we begin our search at the intermediate, general level and then move to retrieving more specific information with the support of a central executive (Conway \& Pleydell-Pearce, 2000). Importantly, current conceptualizations of autobiographical retrieval propose that our memories are not stored as perfect records of specific events, but rather that they are constructed from our vast autobiographical knowledge stores (Conway, 1996; Conway \& Pleydell-Pearce, 2000). The constructivist approach to autobiographical retrieval predicts that multiple retellings of the same autobiographical event will not be identical and might differ depending on an individuals' goals and motivations (reviewed by Conway, 1996). This theme of the reconstruction of autobiographical memory will be carried throughout the review.

\subsection{Neuroanatomy and Regional Connectivity}

In 1957, Brenda Milner and William Scoville published a manuscript that would fundamentally alter the way that scientists thought about memory. They described the dense amnesia that resulted after an experimental medial temporal-lobe resection was performed to cure a patient's intractable epilepsy (Scoville \& Milner, 1957). Following the operation, the patient - known as "H.M." in the scientific literature - could not form new, long-term memories. His resulting anterograde amnesia provided strong evidence that the ability for the present to become entered into a roster of past experiences requires processes implemented by the medial temporal-lobe.

A plethora of research has confirmed the importance of the medial temporal-lobe in establishing and retrieving autobiographical memory. When the medial temporal-lobe is damaged, such as in Alzheimer's disease, there are noticeable deficits in registering events into long-term memory. The medial temporal-lobe is not only essential for the creation of new long-term memories; many believe these regions are equally important for piecing together the sights, sounds, smells, and other contextual details of past experiences into coherent recollections (discussed in Kensinger \& Corkin, 2008). In fact, the medial temporal-lobe - and the hippocampal complex more specifically - is often referred to as the "hub" of the autobiographical memory system (Moscovitch et al., 2005). It is believed that the hippocampal complex can serve as a "pointer system" to the cortical regions that have 
stored the various features of past experiences (Nadel \& Moscovitch, 1997). Thus, damage to the hippocampal complex does not prevent information from being processed but rather it prevents the organized binding and indexing of event features. Hippocampal damage, therefore, results in anterograde amnesia (the inability to form new long-term memories) by preventing new information from becoming bound together and indexed in a fashion that allows it to later be retrieved. It also results in retrograde amnesia because the damage destroys the indices that would have pointed to components of past experiences; without those hippocampal "pointers", the coordinated re-experiencing of previous live events is impaired.

The metaphor of the medial temporal-lobe system as an index or "pointer" system emphasizes that the medial temporal-lobes do not act alone to encode or to retrieve an autobiographical experience. It is necessary not only to have the index of the cortical regions that may have processed the events but also to have a preservation of function within those cortical regions that initially processed the event. Indeed, extensive research has revealed that memories are not stored within any single area of the brain, but rather result from a distributed network of activity throughout the cortex (see recent review by Cabeza \& St. Jacques, 2007). Moreover, the particular cortical regions that are activated during autobiographical retrieval have a strong tie to those that were engaged during the initial processing of the event, an overlap that has led researchers to propose that memory retrieval reflects the recapitulation of activity that was engaged during an event's initial processing. For instance, after learning a series of word-sound or word-picture pairs, participants will show retrieval-related activity in the auditory cortex when presented with a word that had been paired with a sound and will display activity in visual cortex when presented with a word that had been paired with a picture (see Kohler et al., 1998; Wheeler et al., 2000; Vaidya et al., 2002; Wheeler and Buckner, 2003, 2004; Kahn et al., 2004; Slotnick and Schacter, 2004; Wheeler et al., 2006 for evidence of recapitulation during retrieval).

Although the specific regions, and the magnitude of activity within those regions, can vary as a function of the types of details being remembered, there also are a number of regions that seem to be commonly activated across a range of autobiographical retrieval tasks. In addition to the hippocampus, these regions include the medial and lateral prefrontal cortex, the medial and lateral parietal cortex, the amygdala, and sensory cortices within the occipital and temporal lobes (for a meta-analysis, see Svoboda, McKinnon, \& Levine, 2006; for reviews, see Cabeza \& St. Jacques, 2007; Fink et al., 1996; Maguire, 2001). It has been proposed that each of these regions contribute unique processes to the recovery of autobiographical experiences. The medial prefrontal cortex is believed to be tied to the feeling of autonoetic consciousness which Tulving (1985) proposed to be a critical component of episodic memory (Buckner \& Wheeler, 2001; Gilboa, 2004; Wheeler et al., 1997). Lateral prefrontal regions are believed to be associated with more strategic memory search and post-retrieval monitoring processes (e.g., Fletcher \& Dolan, 1999), and together these prefrontal processes may lead to the confident feeling that an experience is dated to one's personal past (see also Daselaar et al., 2008). The regions within the parietal cortex likely help to orient attention to internal representations (Wagner, Shannon, Kahn, \& Buckner, 2005) and may underlie the feeling of recollection or re-experience that typically accompanies autobiographical retrievals (reviewed in Cabeza \& St. Jacques, 2007; see Figure 1 for schematic of the regions commonly activated during autobiographical retrieval).

These regions share extensive overlap with a "default network" (Gusnard \& Raichle, 2001; Buckner et al., 2008) or "core network" (Addis et al., 2008; Vincent et al., 2006) of regions, which are active not only when individuals think about their personal past but also when they think about themselves in other ways (Buckner \& Carroll, 2007; Szpunar \& McDermott, 2008; Saxe et al., 2006; Spreng \& Grady, 2009). As noted above, our ability to 
remember our personal past is essential for our sense of self. It is perhaps not surprising, then, that there is extensive overlap between the regions that we engage during autobiographical retrieval and the regions that are more generally engaged whenever we think about ourselves. Yet this realization has led to a shift from thinking about these regions as an "autobiographical memory network" to thinking of them as regions that support more general cognitive abilities which - although necessary for autobiographical memory - are not specific to it. It is still debated what these more general abilities may be: they could include self-referential processing (Buckner \& Carroll, 2007), cognitive-affective simulation of possible outcomes (Mar \& Oatley, 2008), mind-wandering (Mason et al., 2007) or the (re)construction of spatial contexts (Hassabis et al., 2007).

As researchers have begun to appreciate that this "core network" may not be specific to the domain of autobiographical retrieval but might serve more domain-general purposes (see review by Schacter, Addis, \& Buckner, 2007), it has led to the realization that the reconstructive nature of autobiographical memory may be best thought of not as a maladaptive byproduct but rather as a beneficial and hallmark characteristic of the function of this "core network." In fact, reconstruction may allow the retrievals guided by this network to be useful in a variety of circumstances. If we think about the purpose of remembering past events, it is not simply to allow us to re-experience those events. Rather, it is to help us draw on those past experiences to guide our current behavior and to allow us to plan for the future by using our knowledge of the past (Dudai \& Carruthers, 2005). As stated by Daniel Schacter and Donna Addis, two proponents of this constructivist framework “...future events are not exact replicas of past events, and a memory system that simply stored rote records would not be well-suited to simulating future events. A system built according to constructive principles may be a better tool for the job...Such a system will occasionally produce memory errors, but it also provides considerable flexibility" (Schacter \& Addis, 2007, pg. 27).

Although autobiographical events are always reconstructed, the way in which they are assembled may vary depending on the content of the experience and the context in which it is recalled. In the next sections, we examine how the emotional content of an experience can influence the accuracy and malleability with which it is remembered (Section 3), and we discuss how our current emotional state or goals can influence the way in which past emotions and past events are reconstructed (Section 4).

\section{Emotional Content and the Retention of Autobiographical Memory}

When we think back on our personal past, not all memories come to mind with equal ease or with the same level of detail. The past we recall often consists primarily of moments imbued with emotion; these are the occasions we seem to remember most vividly and durably (see Berntsen \& Rubin, 2002; Buchanan, 2007 for reviews). It feels like we will never forget our college graduation or our wedding day, or less pleasant events like a car crash or the unexpected death of a loved one. As Brown and Kulik (1977) reported in their seminal paper on "flashbulb memories", there is something subjectively special about events that contain powerful emotional significance; the details of these occurrences seem to stay as part of our personal narrative long after more mundane experiences have been forgotten. Indeed, research has confirmed that even years after an emotional experience has occurred, its existence can be remembered vividly. For instance, Brown and Kulik (1977) demonstrated that even a decade after the assassination of John F. Kennedy, most people remembered the personal circumstances in which they had learned the news: people knew where they were, who they were with, and what they were doing. Winograd and Killinger (1983) confirmed that, years later, nearly everyone who had been older than approximately 6 years of age at 
the time of the assassination (in 1963) remembered their whereabouts at the moment they learned of the news.

\subsection{The Affective Characteristics that Modulate Memory}

Although memory for the assassination of John F. Kennedy is often used as the quintessential example of a "flashbulb memory," in fact there have been many public events that have led individuals to retain these types of vivid memories (see Table 1). The occurrence of vivid memories is not limited to the domain of public events, either; individuals can retain vivid memories of personal events as well (e.g., Blackburne-Stover, Belenky, \& Gilligan, 1982;Pillemer, Koff, Rhinehart, \& Rierdan, 1987;Pillemer et al., 1988;Rubin \& Kozin, 1984; Yuille \& Cutshall, 1986). For instance, individuals vividly recall injuries that they sustained (Peterson \& Bell, 1996;Peterson \& Whalen, 2001). These studies reveal that it is not the public or shared nature of the event that is the essential contributor to the vividness of the memory; rather, vivid memories seem to result from factors that can be shared by both public and private experiences. As we will see, emotional arousal and personal involvement in an event seem to be two factors that have a large impact on the likelihood that a vivid memory can be maintained over time.

3.1.1 The Importance of Arousal and Personal Involvement-An inherent component of Brown \& Kulik's (1977) argument was that the emotional significance of the event - which they proposed included both the arousal evoked by the event as well as the consequentiality of the event - would be a key determinant of whether the details of the event were retained. To test this hypothesis, they examined how well people remembered the personal circumstances in which they had learned of the assassination of Martin Luther King Jr., an event which they believed would have greater consequentiality and higher arousal for Black Americans than for White Americans. Consistent with an influence of emotional significance in enhancing memory, they found that the Black Americans' memories were more detailed than were the White Americans' memories.

Although there may be other explanations for the group differences revealed by Brown and Kulik (1977), studies conducted since that initial investigation have corroborated the important role that arousal plays in the maintenance of detailed memories. The presence of arousal appears to trigger a cascade of neurochemical interactions, the end of result of which is the formation of a particularly durable memory (reviewed by McGaugh, 2004). Events that elicit physiological responses and the release of glucose and adrenal hormones into the bloodstream often result in an improved ability to remember information (Anderson et al., 2006; McGaugh, 2004). These benefits can be particularly pronounced when examining a person's ability to remember information over long delays (Quevado et al., 2003; Revelle \& Loftus, 1992), likely because of the cumulative effects of emotion on both the encoding and also the consolidation phases of memory, a point to which we will return later in the article (Section 3.4).

Subsequent research also has confirmed that events with high personal involvement or selfrelevance, concepts closely tied to the idea of "consequentiality" described by Brown and Kulik (1977), are more likely to be remembered than events with less personal relevance (Rogers, Kuiper, \& Kirker, 1977; Symons \& Johnson, 1997). For instance, when information is encoded in a self-referential fashion - when people focus on how information relates to them and on how information makes them feel - there are distinct mechanisms engaged which boost the strength of the encoded memory and may make it more resilient to forgetting (Kelley et al., 2002; Macrae et al., 2004; Mitchell et al., 2004). Similarly, when people are actors in an event, they appear to retain better memory for that event than when they have less personal involvement in an event (e.g., Pezdek, 2003). 
The role of personal involvement was an important consideration for Brown and Kulik (1977), because they understood that the ability to learn of news through secondhand sources was likely not the situation in which specialized memory mechanisms would have evolved. As they stated, "But what if there were no informant, then or now, no separation between the event and the circumstances in which one learned of it? You are in a startling and serious automobile accident, or you narrowly miss being struck by lightning." (Brown \& Kulik, pg. 98). Although they posed the question in 1977, only recently has research begun to examine the potential role that personal involvement may play in the formation and retention of autobiographical memories. This research has confirmed that memory is more vivid for events in which a person is directly involved than for those events in which a person was a bystander. For instance, hockey players remember the game details in which they were directly involved (e.g., the events leading up to a penalty they received) more vividly than they remember game events that they watched from afar (e.g., watching a teammate score a goal; Muscatell, Addis, \& Kensinger, in press; see also Pezdek, 2003; Sharot et al., 2007).

Research has, therefore, made clear that arousal and consequentiality are two factors that contribute to the retention of autobiographical memories. It has been less understood whether these factors are independent, or whether they reflect overlapping processes. Some conceptions of arousal equate it with the personal importance of an experience (Clore \& Schnall, 2005; Frijda, Ortony, Sonnemons \& Clore, 1992; Simon, 1967), suggesting that an arousal response acts both implicitly (through adrenergic and cortisol responses) and explicitly (through conscious elaboration) to increase the importance of an experienced event (see Clore \& Storbeck, 2005). But the relation could also flow in the opposite direction: personal involvement in an event could influence the arousal elicited. It would make sense that experiencing an event directly would elicit more arousal than hearing about the news second-hand, and indeed many have purported that personal involvement modulates memory because of the additional arousal elicited by a personally experienced event (e.g., Christianson, 1992; Gold, 1992; Sharot et al., 2007). In one experiment to examine the effect of personal involvement on emotional memory, Sharot et al. (2007) asked individuals to recall autobiographical details from September 11, 2001 and from the prior summer, in response to cue words (e.g., walking, reading, family). They recruited participants who had been in close proximity to the World Trade Center on September 11, and those who, while still in Manhattan, had been further away from the location of the attacks. They found that those closer to the World Trade Center reported an enhanced "recollective experience" for the memories from September 11 as compared to those who were further away. Furthermore, only those individuals who were in close proximity showed exaggerated amygdala activity during the recall of events from September 11 as compared to events from the prior summer. The amygdala plays a key role in processing the arousal of experiences (Amaral et al., 1992), and so the ability for personal involvement to modulate amygdala activity led the authors to the conclusion that "[a]lthough simply hearing about shocking public events may result in arousal, the strength of this response likely varies depending on the individual's personal experience with the events. The effect of personal experience on arousal is proposed to underlie the observed correlation" (Sharot et al., 2007, pg. 393).

It may not always be the case, however, that personal involvement exerts its influence via modulation of arousal. Instead, there may be instances in which personal involvement influences memory via distinct mechanisms from arousal. Muscatell, Addis, \& Kensinger, (in press) asked hockey players to retrieve memories about specific events - penalities, plays, goals - that had occurred throughout the season. Some memories were of events in which the player had been personally involved while others referred to events that the player had watched from across the rink or from the bench. The neuroimaging analyses revealed 
that there were important differences in neural connectivity between the two types of events (see Figure 2). Two circuits - one connecting the left hippocampus to the medial prefrontal cortex and the other connecting the medial prefrontal cortex to the right amygdala - were in synchrony only during recall of events in which the players had been directly involved.

Although these results are generally consistent with those of Sharot et al., 2007, in suggesting that the amygdala is a key region that can be modulated based on the personal involvement that a person has with an event, the two studies differ in their suggestion of how personal involvement exerts that influence. While the results of Sharot et al., 2007 can be interpreted as suggesting that personal involvement influences memory via its effects on arousal, it is not clear how the results of Muscatell, Addis, and Kensinger (in press) could be consistent with that interpretation. For one, the hockey players did not rate the events in which they were personally involved as more arousing than the ones for which they were bystanders; thus, there is no evidence that personal involvement exerted an influence on arousal. Second, even if personal involvement did enhance arousal, it does not clarify why this would alter the connectivity among different memory networks, rather than simply increasing activity or connectivity within a single network. The dissociation in connectivity revealed by the study instead suggests that there may be something about personal involvement with an event that fundamentally changes the way in which the event is retrieved.

Based on the existing evidence, a viable hypothesis is that personal involvement changes the types of details that are re-experienced during retrieval. The hippocampus is known to support the retrieval of autobiographical memories with rich contextual detail; activity in the hippocampus corresponds with the ability to remember the spatial and temporal context in which life experiences occurred (e.g., Addis et al., 2004; Maguire, 2001; Svoboda et al., 2006). By contrast, amygdala engagement during retrieval does not seem to correspond with the retrieval of these types of contextual details (e.g., Sharot et al., 2004) but instead seems to reflect the processing of affectively-rich, "internal" information (reviewed by Buchanan, 2007; Phan, Wager, Taylor, \& Liberzon, 2004). These systems - likely akin to the "cold" and "hot" processing systems (Metcalfe \& Jacobs, 1996) - may work together to integrate internal and external details, but only when information is high in personal involvement. This is a point that we will return to later (Section 3.3), when we discuss the effects of emotion on different types of event details.

\subsubsection{Consideration of Factors Beyond Arousal and Personal Involvement-}

Studies have also revealed that arousal and personal importance may not be the only affective characteristics to influence how vividly a memory is remembered. Affective experiences are often considered to be described by a two-dimensional space consisting of valence (how negative or positive) and arousal (how exciting/agitating or soothing/ subduing; see Feldman Barrett \& Russell, 1999; Russell, 1980). Experiences can exist anywhere within this space, being high in arousal and positive (feelings of excitement or euphoria), high in arousal and negative (feelings of agitation or anxiety), low in arousal and positive (feelings of calmness or serenity), or low in arousal and negative (feelings of depression or hopelessness). Evidence is accumulating to suggest that the valence of an experience can influence how likely an autobiographical memory is to be remembered (Berntsen \& Rubin, 2002) and can also influence the accuracy with which an event is remembered (Kensinger, 2009a).

In many studies of autobiographical memory, positive events seem to come to mind more readily than negative ones (see Levine \& Bluck, 2004 for review). Some of this mnemonic benefit for positive events may stem from the effects of valence on the self-referential processes already discussed: Because most people's self-schemas are generally positive, 
positive experiences may be more likely to be self-relevant and may also be more easily integrated into a person's conception of themselves (see Matlin \& Stang, 1978). Consistent with this notion, the memory advantage for positive information seems to be particularly strong when information is self-relevant (Hardin \& Banaji, 1990). When individuals are focused instead on other-perception rather than on self-referential processing (e.g., Dreben, Fiske, \& Hastie, 1979; Skowronski \& Carlston, 1987), or when individuals are depressed and therefore have a more negative self-concept (Dalgleish \& Watts, 1990), they are more likely to remember negative experiences than to remember positive ones (see also Section 4.2).

Although the findings discussed so far suggest that the differential effects of valence may be mediated by effects in other domains (e.g., the self-relevance of the events), there is other evidence to suggest that the valence of an event may directly influence the way in which it is remembered. According to the "affect as information" framework (e.g., Schwarz \& Clore, 1983, 1988, 1996; Clore, et al, 2001), the way we feel can alter the way that we process information and the manner in which we go about solving problems: "Positive affect promotes interpretive or "relational" processing; negative affect leads to detailed, stimulus bound, or "referential" processing." (Clore \& Storbeck, 2006, pg. 128). As the authors of that framework explain, our perception of the world results from a continual tug-of-war between top-down and bottom-up processes. The top-down "schemas" (Mandler, 1984; Rumelhart, 1980) that we have activated will influence how we attend to information, while the information to which we attend will affect which schemas are most active (Clore \& Storebeck, 2006). The emotions that we experience can bias the strength of each of these influences, dictating the type of processing that will win out in the tug-of-war. When we are in a negative mood, the details of the world around us seem to matter a lot, and so we will focus on those details and analyze them. Our attention may be narrowed (Schwarz, 1990; Wegner \& Vallacher, 1986), enabling us to process the minutia of an experience but sometimes causing us to miss the bigger picture. By contrast, when we are in a positive mood, we are more likely to process information in reference to our activated schemas and to notice the more global and heuristic characteristics of information rather than their details (e.g., Clore et al., 2001; Fiedler, 2001). As we will discuss in the next section, these effects of emotion on processing have important downstream impacts on the way in which positive and negative events are remembered, and this framework appears to explain many of the valence-based effects on emotional memory.

It should be noted that valence is not likely to be the only (or perhaps even the predominant) factor which will influence the way in which emotional memories are maintained. Whether stimuli are evolutionarily relevant, or whether the emotions evoked by stimuli motivate us to act or reflect an achieved goal, are likely to modulate the way that emotion affects memory (see Levine \& Edelstein, 2009). Personality traits may also influence which of these dimensions play the most important role in influencing memory. Our focus on the valence of an event is not intended to dismiss the importance of the other factors but rather to emphasize that considering only the arousal and the personal involvement of an experience, without taking other factors into account, is likely to lead to an incomplete understanding of how the emotional content of information impacts the way in which it is remembered (see Hamann, 2009; Kensinger, 2009a; Kensinger 2009b; Larsen \& Steuer, 2009; Mather \& Sutherland, 2009 for further discussion).

\subsection{Memory Consistency and Confidence}

In 1932, Sir Frederick Bartlett published a text, Remembering, in which he stated that "[r]emembering is not the re-excitation of innumerable fixed, lifeless and fragmentary traces. It is an imaginative reconstruction..." (Bartlett, 1932, pg. 213). This conclusion was reached after he asked students to recall a set of narratives. In contrast to many of the 
popular views of memory as a literal representation of a past experience, he found that students' recalls were not exact replications of the stories. Rather, their narrative recalls had omissions and embellishments. These changes did not appear to be random but instead seemed to make the story more coherent with the students' cultural beliefs and pre-existing knowledge. Based on these data, Bartlett proposed that our recollections are not always verbatim repetitions of past experiences; rather, our recollections can be shaped by our existing context and our current beliefs (see Ost \& Costall, 2002 for discussion of Bartlett's contributions).

Narratives from our past are no exception to this memory-as-reconstruction rule, and it is therefore not surprising that although emotional autobiographical memories - including socalled "flashbulb" memories (Brown \& Kulik, 1977) - are remembered vividly, they are not always remembered consistently over time. For instance, Neisser and Harsch (1992) asked university students to indicate the personal context in which they had learned of the explosion of the Challenger space shuttle (on January 28, 1986). Approximately 30 months later, students filled out another survey, in which they were asked the same questions about their personal context. The intriguing finding was that although students often believed that they remembered the details vividly, and were highly confident in their memory, the details they recalled were often inconsistent across the two surveys. A study conducted a decade later, regarding the terrorist attacks of September 11, 2001, similarly reported many inconsistencies in the recalls of the personal context in which university students had heard the news; in fact, there was no difference in the memory consistency for the terrorist attacks and for an everyday event (e.g., a party, an exam) that had occurred around the same time as the terrorist attacks (Talarico \& Rubin, 2003). Yet what did differ across the events was the vividness and confidence in the recollection; these subjective qualities were markedly enhanced for the terrorist attacks as compared to the everyday events. The title of that manuscript nicely summarizes the view that is now accepted by many: "Confidence, not consistency, characterizes flashbulb memories" (Talarico \& Rubin, 2003).

It has been purported that it is the arousal of an experience which leads to this distinction between memory confidence and memory accuracy. Phelps \& Sharot (2008) argue that emotional arousal enhances the "subjective feeling of remembering" but has little impact on the ability to accurately retrieve the episodic features of an experience. In one study, they found that arousing items were more likely to be vividly "remembered" after a 24-hour delay, but that arousal did not improve the ability to retain information about the task performed during encoding (Sharot \& Yonelinas, 2008). Based on this type of evidence, they have argued that for emotional experiences, the subjective feeling of remembering may be tied to memory for just a few key details; by contrast, for neutral experiences, the subjective feeling of remembering may be linked to the ability to retrieve a broader array of contextual details (Phelps \& Sharot, 2008). This conclusion is generally consistent with evidence that arousal enhances suggestibility (Porter, Spencer, \& Birt, 2003) and increases the likelihood that false memories are endorsed (Corson \& Verrier, 2007): Individuals may assume that because they can remember one aspect of an event in a detailed and accurate fashion, their memory for the other details of an experience is similarly accurate (see Kensinger, 2009a for further discussion). This type of heuristic may lead individuals to be particularly prone to false endorsements or to become lax in monitoring the accuracy of the details that they retrieve about emotional events.

Although Sharot, Phelps and colleagues have not systematically examined what aspect of the experience affects the ability for emotion to intensify the feeling of recollection, they propose that the arousal elicited by the experience may be the key predictor. Arousal has been related to the boost in "remember" responses for emotional items (e.g., Dolcos et al., 2005; Kensinger \& Corkin, 2004), and it would therefore make sense that it would be the 
arousal dimension that would inflate the subjective vividness with which an emotional memory was recollected.

Sharot, Phelps and colleagues further propose that it may be amygdala engagement at retrieval which leads to the arousal-mediated disconnect between memory confidence or vividness and memory accuracy. Amygdala engagement corresponds with memory for only a subset of episodic details (e.g., Kensinger \& Schacter, 2007; discussed in more detail in Section 3.3), yet when it is engaged at retrieval, it may bias people to believe that they have retained a particularly vivid memory of a past event that includes more accurate detail than it actually holds (Sharot et al., 2004; Phelps \& Sharot, 2008). This interpretation could explain why amygdala activity or volume is sometimes found to relate only to the subjective vividness of a memory, and not to its accuracy (e.g., Sharot et al., 2004; Dougal et al., 2007), while in other instances amygdala activity (Kensinger \& Schacter, 2005; Kensinger \& Schacter, 2007) or gray matter density (Marchewka, Jednorog, Nowicka, Brechmann, \& Grabowska, 2009) has been linked to the accuracy of the memory. The amygdala may relate to memory for only a select subset of episodic details; if those details are assessed, then the amygdala will show a correspondence to memory accuracy, but if other details are examined, then the amygdala will relate only to subjective vividness and not to memory for the episodic features.

Another potential reason for the inconsistent findings may relate to the fact that - as we noted earlier (Section 3.1.2) - many different features contribute to the development of a vivid emotional memory, including not only arousal but also more specific features of the affective experience elicited by the event, including its valence or the specific emotion experienced. Research that has teased apart the effects of negative and positive emotion on memory has revealed that negative emotion in particular is more likely to enhance the vividness of a memory (e.g., Mickley \& Kensinger, 2009) and to increase the likelihood of endorsing an item (e.g., Budson et al., 2006; Dougal \& Rotello, 2007; Sharkawy et al., 2008). Sometimes this effect of negative emotion seems to result from an influence on a person's willingness to attribute an event to their past (Brainerd, Stein, Silveira, Rohenkohl, \& Reyna, 2008; Dougal \& Rotello, 2007), reflecting an influence on response bias rather than on memory accuracy. But in other instances, the effects of negative emotion may lead to a more accurate or durable representation of a past experience.

Convincing evidence that valence influences the consistency of autobiographical memory has come from studies that have examined how memory for the same event differs in those who perceive the event to be negative as compared to those who perceive the event to be positive. This design is particularly elegant because it assures that the event characteristics are held constant across both groups and reduces the likelihood that factors such as event distinctiveness, arousal, semantic clustering, or personal relevance are confounded with valence. A number of studies have now used this approach, examining memory for the verdict in the O.J. Simpson trial (Levine \& Bluck, 2004), the Red Sox-Yankees championship game (Kensinger \& Schacter, 2006b), and the fall of the Berlin Wall (Bohn \& Berntsen, 2007; see also see Baker-Ward et al., 2005 for an investigation of children's memories for a soccer tournament that was either won or lost). Across all studies, positive emotion was associated with a greater propensity for memory distortion than negative emotion, yet the individuals who were pleased with the event were at least as confident in their memory as those who were unhappy with the event outcome.

Studies that have induced participants into positive or negative moods within a laboratory setting generally have corroborated these findings. Participants are more liberal in endorsing items as ones that they have studied when they are in a good mood, and they are more susceptible to false memories when in that pleasant state (Bless et al., 1996; Park \& Banaji, 
2000; Storbeck \& Clore, 2005). Negative mood, by contrast, makes individuals more conservative in endorsing items and reduces the propensity to inaccurately endorse items that are related (but not identical) to studied items (Storbeck \& Clore, 2005).

There are a few explanations for these effects of valence on memory. The first explanation hangs on the "affect-as-information" framework (Schwarz \& Clore, 1983, 1988, 1996; Clore, et al, 2001; also discussed in Section 3.1.2). This framework purports that affect serves as a source of information about our implicit responses and unconscious appraisals to stimuli. The theory further postulates that affective reactions can promote particular modes of information processing (see Clore \& Storebeck, 2006), with positive affect encouraging heuristic and relational processing among many items and negative affect leading instead to detailed and item-specific processing. By encouraging a relational and heuristic mode of processing, positive affect could increase reconstructive memory errors, whereas by encouraging a focus on the specific details of information, negative affect might lead to more accurate memories for at least some types of details (though perhaps not for all details, as we will discuss in Section 3.3).

A related, goal-relevance model (Levine \& Pizarro, 2004), proposes that it is essential to consider that a positive emotion like happiness reflects the attainment of a goal and therefore promotes a top-down form of processing in which information is assimilated with existing world knowledge. Negative emotions, by contrast, reflect a failure to attain a goal and therefore invoke bottom-up processing so that the details that led to the goal failure might be recorded - but the particular details attended may differ depending on whether the thwarted goal is related to loss, a potential threat, or an obstacle. This framework suggests that it is not the valence of the emotion that leads to different modes of processing; rather, it is what the emotion signals with regard to whether a goal has been obtained or forgone.

Another explanation relates not to the way in which affective information is processed but instead to the frequency with which it is encountered. Because positive events are generally more frequent than negative events, there may be more related events that interfere with the accurate retention of any single positive experience. Remembering the location of last year's birthday party might be difficult because there have been many other parties that could interfere with the retention of that one event. Remembering the location of last year's car wreck hopefully would not be met with the same level of interference from other wrecks. The more frequent nature of positive events may also make them more susceptible to binding errors. It might be relatively easy to merge the spatial context of one birthday with the temporal context of another, leading to a false memory for the details of a particular party, whereas it is less likely that a person would have experienced two similar car accidents that could lead to this type of binding error.

Because positive events are not only more frequent than negative events but also are more expected, interference could also arise between anticipated details of a positive event and actual occurrences. We might confuse the location where we thought we would be dining on our birthday with the location where we were pleasantly surprised to be taken. It is well known that individuals can have difficulty distinguishing the details that they've imagined from those which they've experienced (e.g., Johnson \& Raye, 1981), and this difficulty may contribute to the propensity for positive event details to be remembered confidently, but with low accuracy.

In cases where it is not just the details of an event that are misremembered, but the occurrence of the entire event which is fabricated, another factor may be at play. Individuals may be biased to believe that positive events have occurred previously, whereas they may not show the same propensity to believe that negative events have occurred. This bias to 
incorporate positive experiences into our personal narrative more liberally than negative experiences may have beneficial effects on our mental health. A few studies have revealed that older adults - who generally report better moods than young adults - are more likely to falsely endorse positive items as ones that they've seen before (e.g., Fernandes et al., 2008; Piguet et al., 2008), and within a sample of young adults, the likelihood of falsely recalling happiness-related events correlates with scores on the Satisfaction With Life Scale (Koo \& Oishi, 2009). These studies suggest that it may be adaptive to view our past through rosecolored glasses.

Although we have focused on the differences between positive and negative emotions, it is unclear whether a split by valence is sufficient to explain the effects of emotion on memory accuracy or whether it is necessary to further subdivide affective space. For instance, higharousal negative emotions such as the experiences of fear or anger may have different effects on memory than low-arousal negative emotions such as sadness or melancholy (see Corson \& Verrier, 2007; Levine \& Edelstein, 2009 for further discussion). The direction of any interaction between valence and arousal remains uncertain, however, and as we discuss in the next section, part of this inconsistency may be related to differences across studies with regard to the types of details that participants are asked to remember.

\section{3 "Memory Trade-offs" and "Tunnel Memory" for Emotional Experiences}

An often forgotten part of Brown and Kulik's manuscript reveals their recognition that not all aspects of an emotional experience are equally likely to be remembered. "An actual photograph, taken by flashbulb, preserves everything within its scope; it is altogether indiscriminate. Our flashbulb memories are not... a flashbulb memory is only somewhat indiscriminate and is very far from complete. In these respects, it is unlike a photograph." (Brown \& Kulik, 1977, pg. 75). This quote emphasizes that the effects of emotion on memory can be uneven. Emotion can help us to remember some aspects of an event clearly, but it may have no beneficial effect - and in fact may hinder - our ability to retain other event details.

In a real-world context, this effect of emotion has been referred to as a "weapon focus" effect, where witnesses to a crime remember details about the weapon used but not about more peripheral event features (reviewed by Kihlstrom, 2006; Heuer \& Reisberg, 2007). Laboratory studies have confirmed that memory can be narrowed onto the emotional aspects of an event (reviewed by Reisberg \& Heuer, 2004; Levine \& Edelstein, 2009) and that autobiographical memories for emotional experiences often contain only select details (e.g., Peterson \& Whalen, 2001; Bahrick, Parker, Fivush, \& Levitt, 1998; Wagenaar \& Groeneweg, 1990). As thoughtfully reviewed by Levine \& Edelstein (2009), there has been extensive discussion about which types of details are remembered best. These details have been described as those that capture attention, that are perceptually, temporally, or conceptually integral to the emotional event, or that are goal-relevant (see Levine \& Edelstein, 2009, Table 1, pg. 13).

The particular types of details that are remembered can vary based upon a person's perspective on an event. Pezdek (2003) revealed that people tend to remember those details which are most pertinent to their experience of an event. If people feel directly involved in an event, they are more likely to remember event details, whereas if they feel more removed from an event, they are more likely to retain personal autobiographical details. When examining people's memory for the 9/11 terrorist attacks, she found that those living in New York, who were directly involved in the day's events, retained more event details than autobiographical details. By contrast, those living in California or Hawaii, who were less personally involved in the day's events, retained more autobiographical details (Pezdek, 2003). Similar findings were revealed by Smith, Bibi, \& Sheard, 2003, and by Tekcan et al., 
2003, who assessed the memories for 9/11 in individuals living in Canada and Turkey, respectively: Individuals in both countries retained personal details more consistently than event details.

These findings may also help to explain one of the initial surprises about "flashbulb memories": that individuals would remember the personal context in which they learned about the event. These features seemed to be inconsequential as compared to the details of the event itself, and so it was unclear why these personal details would be retained over time. Yet as Brown and Kulik (1977) state, and as the research by Pezdek (2003) later would appear to confirm, "What is relatively new is telecommunication which makes an informant a necessity and creates the sharp separation between news and circumstances of hearing the news...Probably the same "Now print!" mechanism accounts both for the enduring significant memories in which one has played the role of protagonist and those in which one has only been a member of an interested audience of millions." (Brown \& Kulik, 1977; pgs. 98-99). In other words, there probably are not separate mechanisms for remembering event details and personal context; either can be remembered, depending on which subset contains the most personal relevance in the moment. For someone directly experiencing an event, those details are likely to be ones regarding the event itself. But for someone hearing about an event indirectly, those details may be the personal circumstances in which the news was transmitted.

Although these studies have focused on the ability for emotion to enhance memory for external contextual details (either event-based or of a more personal nature), emotion - and perhaps negative emotion in particular - also seems to enhance the ability to remember internal details including the feelings and thoughts elicited by the event (Mickley \& Kensinger, 2009). People tend to remember more about what they felt during an intense emotional experience than during a more moderately emotional event (Fivush et al., 2008) and importantly, they tend to remember their reactions to a negatively emotional event in a fairly consistent fashion, even over long delays (Fivush et al., 2004). As we will discuss later (Section 4.1), people are prone to make errors in the way in which they recall the emotions that they experienced during an event. Yet a few studies have revealed that adults show consistency in how they remember the feelings experienced during intensely emotional events such as the terrorist attacks of 9/11 or a sexual assault (Fivush et al., 2004; Bohanek, Mennuti-Washburn, Fivush, \& Koss, 2005).

These studies emphasize that not all aspects of an emotional experience will be remembered equally well. They also reveal that there is no single answer for the types of details onto which emotion will narrow a memory. Instead, these findings suggest that the types of details that are enhanced, or impaired, by emotion may have less to do with features of the details themselves and more to do with how those details relate to the person experiencing the event.

\subsection{Neural Mechanisms Underlying Autobiographical Memories for Emotional Experiences}

As the prior sections have described, emotion can enhance our ability to remember some but not all - details of autobiographical experiences. Yet the way in which emotion exerts these effects has been a topic of much debate. It was initially proposed that emotion triggered a specialized cascade of processes which led to the representation of the event in memory (e.g., Brown \& Kulik, 1977; Conway, 1996; Kvavilashvili et al., 2003). Other research, however, began to draw into question whether there was a specialized memory mechanism that supported emotional memory, suggesting instead that memories for emotional experiences might be supported by the same processes - and might be prone to the same types of errors of commission and omission - as memories for nonemotional experiences (Christianson, 1989; Crombag et al., 1996 and see Schacter, 1999 for discussion 
of memory errors). Although a cleverly-designed behavioral study can shed light on whether emotional memories are supported by specialized processing, neuroimaging provides a particularly robust method for clarifying whether the mechanisms that support memory for neutral experiences are the same as those that support memory for emotional experiences. If there is a specialized system that supports memory for emotional experiences, then it should be possible to find neural processes that correspond with the ability to remember emotional memories but not neutral ones. Another advantage of neuroimaging over behavioral studies is that it can isolate the processes that act during different phases of memory. It is commonly agreed upon that in order for an event to be remembered it must be encoded into memory, it must be consolidated into a stable memory representation, and it must be retrieved successfully. These phases are difficult to separate through behavioral testing, because the only way that a memory can be assessed behaviorally is through its retrieval. Although behavioral manipulations can target the encoding or consolidation phases, they still rely on measurements that occur at the time of retrieval, thereby making it difficult to ascertain the specific phase of memory at which emotion (or any other variable) exerts its influence. Neuroimaging can isolate these different stages, as can cleverly designed studies with patient populations. It is therefore these types of studies that we focus on in this section, describing the insights they have yielded regarding memory for emotional experiences.

3.4.1 Neural Activity and Connectivity During Encoding-To investigate how emotion modulates memory encoding, most neuroimaging studies have used an eventrelated, subsequent memory design (see Figure 3). In this design, encoding activity is sorted based on whether items presented during the neuroimaging phase can later be remembered. Regions that show greater activity for items later remembered than for those later forgotten are considered to be linked to the successful encoding of information (see Paller et al., 1987;Paller \& Wagner, 2002). It is important to note that these studies have not examined how individuals form contextually rich and detailed autobiographical memories, at least in part because of the logistical difficulties of asking participants to encode many of these types of experiences while undergoing a neuroimaging scan. Instead, researchers have focused on the encoding of more simplistic "events" (often single presentations of a picture or a word). Consistent with extensive animal research (see LeDoux, 2000;LeDoux, 2007; McGaugh, 2000, 2004 for reviews), these neuroimaging studies have emphasized the importance of the amygdala in the creation of emotional memories. When amygdala activity is strong during encoding, emotional events are likely to be remembered (reviewed by Dolcos \& Denkova, 2008;Hamann, 2001;LaBar \& Cabeza, 2006). Yet unlike other regions that are tied to subsequent memory, the relation between amygdala activity and subsequent memory is specific to emotional events. It is not the case that the amygdala shows a general relation to the ability to encode information; rather, the amygdala seems to be particularly involved in the encoding of an emotional experience (see Weiskrantz, 1956;Scoville \& Milner, 1957 for early discussion of the role of the amygdala in memory).

Although amygdala activity enhances the likelihood that a person can remember that an emotional experience has occurred, amygdala activity does not lead to enhanced memory for all details of that emotional experience. Engagement of the amygdala can boost retention of some event details (Kensinger \& Schacter, 2005), have no effect on retention of other details (Dougal et al., 2007; Kensinger \& Schacter, 2006a; Onoda et al., 2009) and impair memory for other types of information (Strange et al., 2003). From the extant data, it seems as though amygdala activity leads to the types of memory trade-offs discussed in Section 3.3:

Amygdala activity can simultaneously predict good memory for some critical aspects of an emotional event and poor memory for less relevant features (Waring \& Kensinger, unpublished data). 
Despite these mixed relations between amygdala activity and subsequent memory for event details, amygdala activity at encoding seems to predict the retention of a memory that will seem vivid and in which people will be highly confident (Mickley \& Kensinger, submitted; Atapattu \& Kensinger, 2009). Amygdala activity during encoding corresponds with the likelihood that people will claim to vividly "remember" an event (Dolcos et al., 2004; Kensinger \& Corkin, 2004; Mickley \& Kensinger, 2008) and amygdala activity parametrically varies with the vividness that people will later ascribe to an emotional memory (Atapattu \& Kensinger, 2009). The reason for this strong connection remains a topic of ongoing investigation, but one possibility is that individuals ascribe vividness and confidence on the basis of their memory for only a subset of details, so that by enhancing memory for select details, amygdala activity may also be enhancing the confidence or vividness with which people will later re-experience an emotional event (discussed by Phelps \& Sharot, 2008).

Although a lot of research has focused on the relation between amygdala activity and the successful encoding of emotional experiences, the amygdala acts as part of a larger network of regions. There is extensive research to suggest that the amygdala exerts many of its effects on memory through its modulation of hippocampal processes (e.g., Dolcos et al., 2004; Kensinger \& Corkin, 2004; Richardson et al., 2004), and regions beyond the hippocampus seem to be modulated based on the emotional content of information as well (e.g., Mickley Steinmetz \& Kensinger, 2009). For instance, the orbitofrontal cortex shows a strong correspondence to successful encoding of emotional experiences (discussed by LaBar \& Cabeza, 2006) and its activity can correspond with the vivid "remembering" of these experiences (Mickley \& Kensinger, 2008). Regions within temporo-occipital cortices can be modulated by emotion as well (Vuilleumier \& Driver, 2007).

The affective characteristics of an experience seem to have a large impact on how neural processes are modulated. The amygdala-mediated modulatory effects of emotion on memory seem to be tied to noradrenaline release: when given before or during an event, adrenergic agonists enhance memory for emotional material (Soetens, Casaer, D'Hooge, \& Hueting, 1995), while adrenergic blockade reduces memory for emotional material (Cahill, Prins, Weber \& McGaugh, 1994; Strange \& Dolan, 2004; Strange, Hurlemann \& Dolan, 2003). The effects of adrenergic modulation on memory are particularly pronounced for emotional information - and in fact often are absent for neutral information - likely because adrenaline modulates amygdala modulation of the hippocampus in situations in which the amygdala is already active. Indeed, it appears that this adrenergic release is necessary for amygdala modulation of hippocampal activity; amygdala activity in the absence of noradrenaline release seems to be insufficient to modulate hippocampal activity (Anderson et al., 2006; see also Onoda et al., 2009, for evidence that the typical modulation of hippocampal processes may not occur when information is not sufficiently arousing to elicit an amygdalar response).

Even when there is not this arousal response, however, there can still be enhanced retention of emotional information. In these circumstances, it is likely that the non-arousing emotional information is retained not because of any emotion-specific processes (e.g., those mediated by the amygdala) but rather due to the engagement of more domain-general processes (e.g., elaboration, rehearsal) which can enhance the encoding of any type of information (discussed in Kensinger, 2004). fMRI evidence has suggested that for nonarousing information, successful encoding may be tied to the implementation of prefrontal processes tied to semantic elaboration and self-referential processing - regions that are recruited when we try to understand the meaning of information or to consider how the information relates to ourselves - rather than to the engagement of amygdala-hippocampal interactions (Kensinger \& Corkin, 2004). Event-related potentials have also revealed a distinction 
between the time course of responses to higher arousal versus lower arousal stimuli, with lower arousal stimuli eliciting greater slow-wave activity, perhaps reflecting the additional engagement of elaborative encoding processes (Koenig \& Mecklinger, 2008).

The engagement of these prefrontal elaborative processes may be particularly robust when information is both low in arousal and of a positive valence (Koenig \& Mecklinger, 2008; Mickley \& Kensinger, 2008; Mickley Steinmetz \& Kensinger, 2009). In fact, Mickley \& Kensinger (2009) found that for positive and low-arousal information, prefrontal activity was the strongest predictor of subsequent memory. By contrast, memory for negative and arousing information was tied to activity increases within temporo-occipital cortices tied to a more visuo-sensory analysis of information (Mickley \& Kensinger, 2008), and activity within those regions was the strongest predictor of subsequent memory performance for the negative items (Mickley Steinmetz \& Kensinger, 2009).

Although these studies emphasize that the valence as well as the arousal of an experience can modulate the association between encoding activity and subsequent memory, the particular effect of valence may vary depending on a person's perspective on an event. Touryan et al. (2008) found that activity in the posterior cingulate cortex and in the parahippocampal cortex were greater when the information that people were encoding was consistent with their self-referential focus. If participants were asked to focus on their hopes and aspirations, these regions showed greater activity during the processing of positive items. But if participants were asked to focus on their duties and obligations, the same regions were more active during the processing of negative items. Similar valence-based differences in responding have been noted in comparisons of young and older adults. Older adults, who tend to focus more on positive self-regulatory goals, show greater activity within medial prefrontal and parietal regions (including the precuneus) during the processing of positive as compared to negative information, whereas young adults often show the opposite pattern (reviewed by Kensinger \& Leclerc, 2009), underscoring the importance of considering the influence of self-referential processing on emotional memory. Although it is still an open question why these particular regions are the ones that most often show valence-based responses that vary depending on a person's perspective or goals, one possibility is that these regions are connected to self-referential processing and their recruitment is therefore sculpted by a person's motivations.

A theme that has run throughout this review has been the importance of considering the affective characteristics of an event, as well as a person's involvement in an event. This section has revealed that these factors remain important for understanding the effects of emotion on successful encoding. The enhanced retention of a wide variety of affective experiences can be traced back to the way in which those events were encoded. Yet the particular processes that guide their encoding can differ based on their arousal and their valence. Moreover, the particular way in which valenced information is encoded - and thus remembered - can be influenced by a person's goals as they process the information.

3.4.2 Effects of Emotion on Memory Consolidation-To become part of our personal narrative, encoded information must be represented in a stabilized form that can be accessed at future time-points. The maintenance of a memory is therefore not a static process but rather is one that continues in the hours, days, and years following an experience (see early discussion by Mueller \& Pilzecker, 1890 and more recent discussion by Moscovitch \& Nadel, 1998). There is evidence that emotional memories can be maintained fairly consistently, even after multi-year delays (Kvavilashvili et al., 2009; although see Schmolck et al., 2000; Horn, 2001 for discussion of this issue), and emotional events may be forgotten more slowly than other events (see discussion by Budson et al., 2007; Kleinsmith \& Kaplan, 1964; Phelps et al., 1997; LaBar \& Phelps, 1998). 
It was initially believed that emotional events might be maintained over time because they were constantly being rehearsed. It is well known that rehearsing information can make it less prone to passive decay over time (although see recent discussions by Nader, Schafe, \& LeDoux, 2000). If emotional experiences are more likely to become part of our personal narratives, then the enhanced rehearsal given to these events could explain their improved retention (Neisser et al., 1996). Although it is often true that arousing events are thought about more frequently than other events (Betz \& Skowronski, 1995), a number of studies now suggest that rehearsal is not sufficient to explain the retention of emotional experiences. Vivid memories can be maintained even when frequent rehearsal has not occurred (Conway et al., 1994; Rubin \& Kozin, 1984; Sheingold \& Tenney, 1982; Winograd \& Killinger, 1983) and the strength of an emotional reaction has been shown to correspond with the likelihood of remembering an autobiographical event, even while the frequency of rehearsal does not (Pillemer et al., 1988; see also Pillemer et al., 1986).

If emotional events are not remembered better simply because they are thought about more often, then what might be the factor contributing to their enhanced retention? It appears that emotional experiences may enjoy enhanced consolidation at the cellular and systems levels. Extensive research in animals has revealed that interactions between the amygdala and the hippocampus serve not only to boost the initial encoding of emotional information but also to increase the likelihood that emotional information becomes stabilized in memory (McGaugh, 2004). The consolidation framework suggests that emotional events should be less prone to forgetting or decay over time than nonemotional information because there should be little that stands in the way of remembering that emotional information which was successfully encoded.

Memory consolidation is a difficult phase to isolate within human memory, however, because it refers to a set of processes that unfolds over time, and therefore there is no single point in time when a snapshot of consolidation can be acquired. To investigate the influence of consolidation processes, a number of studies have capitalized on the fact that sleep appears to provide ideal conditions for consolidation to occur (Stickgold, 2005; Payne et al., 2008b). By measuring the effects of sleep deprivation, or of providing sleep during a delay period, on memory, researchers can gain leverage on the connection between memory consolidation and subsequent memory retrieval.

If emotional memories ${ }^{1}$ are selectively consolidated, then manipulations that enhance sleep (serving as a proxy for manipulations that enhance consolidation processes) should have a larger impact on emotional memories than on nonemotional ones. Although relatively little research has examined the link between sleep and emotional memory, the extant data support this conclusion. A number of studies have demonstrated that sleep provides a greater benefit to memory for emotional information than for neutral information (Hu et al., 2006;Payne et al., 2008a; Wagner et al., 2001,2006), particularly when there is sufficient time spent in rapid eye movement sleep (Wagner et al., 2001). In fact, in these studies, sleep-dependent preservation of memory was apparent only for emotional items and not for neutral items. This selective benefit for emotional material has been revealed not only when emotional and neutral items are temporally segregated, but also when emotional and neutral information is shown at the same time. For instance, if participants are shown a snake in a forest, their memory for the snake will be quite good after a night of sleep, whereas their memory for the forest will be particularly bad. In other words, the "memory trade-off" described earlier (Section 3.3) appears to become exaggerated when individuals sleep

\footnotetext{
${ }^{1}$ The studies looking at the effects of sleep on emotional memory have mostly focused on negative information (see Atienza \& Cantero, 2008 for one exception). Therefore, it is not clear if the consolidation effects extend equally to all types of affective experiences.
} 
during the intervening delay (Payne et al., 2008a). It appears that sleep-mediated consolidation can selectively maintain memory for emotional information while allowing the rest of the information to dissolve from memory.

The effects of sleep on emotional memory can be strikingly long-lasting. Wagner et al. (2006) asked participants to study narratives that contained either emotional or neutral content. Some participants then took a three-hour nap, while others remained awake. The benefits of sleep were still apparent four years later, and those benefits were selective to the emotional narratives. The participants who had slept were more likely to remember the topic of an emotional narrative than were those who remained awake, whereas sleep conveyed no benefit for remembering the topic of a neutral narrative.

To further clarify the processes that may be altered by the presence of sleep, Sterpenich and colleagues asked participants to view emotional and neutral pictures and then assessed the retrieval-related activity after both a 3 day (Sterpenich et al., 2007) and 6 month interval (Sterpenich et al., 2009). Critically, half of the participants were sleep-deprived after viewing the images while the other half were allowed to maintain their usual sleep schedule. Sterpenich et al. (2009) found that when emotional memories were retrieved after a 6-month delay, those participants who had been sleep-deprived showed reduced retrieval-related activity in the amygdala, ventromedial prefrontal cortex, and occipital cortex as compared to those who had been allowed to sleep after studying the emotional information. Sleep deprivation also reduced the functional connectivity among these regions, suggesting that sleep may enrich the coherence of the emotional-memory network, allowing emotional experiences to be durably maintained. Consistent with this proposal, a recent study (Payne \& Kensinger, submitted) asked participants to retrieve emotional and nonemotional information after a 12-hour delay that either included a night of sleep or a day spent awake (Critically, no participants were sleep deprived). The results revealed that the hippocampus was activated during successful retrieval of negative objects regardless of whether participants had slept during the delay, suggesting a stable "hub" to the memory retrieval network regardless of the efficiency of consolidation processes. However, sleep led to a shift away from a diffuse memory network (including lateral prefrontal and parietal cortices) and toward a more refined and integrated network of limbic regions (consisting of the amygdala and ventromedial prefrontal cortex). Despite the very different methods of Sterpenich et al (2009) and Payne and Kensinger (submitted), the two studies seem to converge on the finding that sleep enhances the activity and coherency of the emotional memory network; it may be this neural signature that enables the durable maintenance of emotional memories.

3.4.3 Neural Activity and Connectivity During Retrieval-The section above revealed how retrieval-related activity can differ depending on the way in which information was consolidated. Therefore, although neuroimaging methods can isolate changes in neural processes that arise during the retrieval phase of memory, these effects could reflect the downstream consequence of effects manifest during encoding or consolidation. For instance, events which are encoded more strongly, or consolidated more stably, may be retrieved in a different fashion from those events which have a weaker memory trace (e.g., Rugg et al., 2008). This caveat will be important to keep in mind while considering the studies that have focused on the effects of emotion on memory retrieval: some of the differences present during retrieval may be linked to earlier differences in the processing or consolidation of the emotional experiences.

Because the influence of emotion at retrieval has been thoughtfully reviewed elsewhere (Buchanan, 2007), and we have already discussed the role of personal involvement in autobiographical retrieval (Section 3.1.1), here we focus on how the factors of arousal and valence affect the neural processes used to retrieve autobiographical events. Although it 
initially was unclear whether the amygdala was activated during the retrieval of arousing events (see Damasio et al. 2000; Piefke et al. 2003), a number of studies have now revealed a link between amygdala engagement and retrieval of arousing experiences (Daselaar et al., 2008; Dolcos et al., 2005; Fink et al. 1996; Markowitsch et al. 2000; Greenberg et al. 2005). More specifically, when retrieved events are arousing in nature, there appears to be enhanced connectivity between the amygdala and the hippocampus (Dolcos et al., 2005; Greenberg et al., 2005; Sharot et al., 2004; see also Addis et al., 2004). This enhanced connectivity may guide retrieval search efforts or the initial stages of memory reconstruction (Daselaar et al., 2008; see also Markowitsch et al., 2000). For instance, in a study that distinguished the initial recovery of a memory from the further elaboration of that memory, amygdala activity occurred early on, even before people retrieved a memory in full. These findings indicate that amygdala activity may guide the retrieval search process and increase the likelihood that an arousing experience is recalled (Daselaar et al., 2008). Yet the role of the amygdala may extend beyond that initial stage, to help with recovery of episodic detail or to enhance the feeling of re-experience (Sharot et al., 2004; Smith et al., 2005). Amygdala activity can correspond with the retrieval of accurate episodic detail (Smith et al., 2005; Kensinger \& Schacter, 2005; Markowitsch et al., 2000), suggesting that the amygdala guides the reconstruction of details from past experiences. Amygdala activity also can correspond with the magnitude of the experienced emotion or with the sense of re-experience (Sharot et al., 2004; Sharot et al., 2007) and so in some instances amygdala activity may reflect the "recapitulation" of emotion felt during the event's original occurrence. Just as remembering a sound can re-activate auditory cortex (e.g., Buckner \& Wheeler, 2001) so might remembering an emotion re-activate the amygdala.

A study that investigated emotional memory in patients with amygdala damage supports the conclusion that the amygdala is involved in both memory search and also in the "recapitulation" of emotion. In that study, remote memory was assessed in amnesic patients with medial temporal-lobe damage (Buchanan et al., 2005). In some patients, the damage included the amygdala and in other patients it spared the region. All patients were asked to recall events that had occurred prior to their brain damage. Because the medial temporallobes had been intact at the time of the event and for some period of time thereafter, anything atypical about their memory could be connected to the retrieval phase rather than to the encoding or initial consolidation phases. This study revealed that the subset of patients whose lesions included the amygdala showed a different profile for the types of past experiences that they remembered than did those patients whose damage did not include the amygdala. Those with amygdala damage were less likely to retrieve memories of unpleasant events, and when they did retrieve those unpleasant events, they rated them as less intense. These findings align well with the neuroimaging research, suggesting that the amygdala may help with the search and recovery of arousing memories (such that amygdala damage reduces the likelihood that arousing events will be remembered) and also may participate in the re-experience of emotion during retrieval (such that the intensity of re-experienced affect will be reduced if the amygdala is damaged).

Although these studies have focused on the role of the amygdala in emotional autobiographical memory retrieval, the retrieval of arousing events also may boost activity within visual cortices (Piefke et al., 2003; Muscatell et al., in press; see also Van Strien et al., 2009), perhaps reflecting the recovery of sensory information, and in frontal regions, perhaps reflecting the thematic elaboration or online maintenance and reliving of the event (see Daselaar et al., 2006; Greenberg et al., 2005 for more discussion). The particular modulation of these regions may vary depending upon the valence of an event. Across a few studies, frontal regions have been more active during retrieval of positive autobiographical memories whereas posterior regions have been more active during retrieval of negative events (Piefke, et al, 2003; Markowitsch, et al, 2003). This distinction could be tied to the 
effects of valence discussed earlier (Section 3.1.2), with negative memories associated with more sensory detail and positive memories associated with a more thematic and heuristic form of recall. The differences could also reflect other motivations that differ during the recall of positive versus negative events; for instance, some of the medial frontal regions that are disproportionately engaged for positive events are tied to self-referential processing. It is possible that individuals are more apt to consider positive (vs. negative) life experiences in reference to their self-concept, and so this self-referential mode of processing could explain the additional prefrontal recruitment during the retrieval of positive autobiographical events. Indeed, as we will discuss in the next section (Section 4), individuals are motivated to maintain a positive sense of self (Ross, 1989; Greenwald, 1980; Conway, 2005), and people may re-experience past events in a manner that allows them to achieve that goal.

\section{Effect of Emotion and Emotional Goals on Autobiographical Retrieval}

In the preceding section, we examined how the emotional content of an event can influence the way in which its spatial, temporal and contextual details are remembered. We now shift our attention away from assessments for these types of details and towards memory for the emotions experienced during a event. We discuss how memory for these emotions can often be reconstructed and how the emotions and emotion-regulation goals experienced at the time of retrieval can influence the affective flavor with which prior experiences are remembered.

\subsection{Reconstruction of memory for emotions}

Although some have suggested that implicit memory for emotions experienced at the time of an event is indelible (e.g., LeDoux, 1996), a wealth of research suggests that explicit memory for emotion is reconstructed in the same manner as other event details (e.g., Levine $\&$ Pizarro, 2004). Some have even gone so far as to suggest that retrospective reports of emotion are usually inaccurate (e.g., Thomas \& Diener, 1990; Christianson \& Safer, 1996). Emotions experienced at the time of an event might be viewed as a type of event specific knowledge in the self-memory system proposed by Conway and Pleydell-Pearce (2000), similar to other sensory and perceptual details of an event. Given that event specific knowledge is not thought to be stored in the self-memory system, or at least is not stored in an organized fashion, memory for emotions - like memory for these other details - would theoretically have to be reconstructed at the time of event retrieval.

A good deal of research has demonstrated that individuals' explicit memories for emotion can be biased in reliable ways (for reviews, see Levine, Safer, \& Lench, 2006; Levine \& Pizarro, 2004; Levine \& Safer, 2002). The reconstruction of memory for emotions is evident based on both internal states (such as expectations) and external factors (such as cultural values in emotional experience). Coming to an understanding of how memory for emotions is reconstructed is critical given that our memories for past experiences guide decisionmaking for future experiences, possibly even more than the experienced emotions themselves (e.g., Wirtz, Kruger, Scollon \& Diener, 2003). In this section, we will review evidence for the factors influencing reconstruction of past emotions from behavioral and neuroimaging studies as well as the potential mechanisms for these biases. We also will discuss how this reconstruction can be viewed as functional.

4.1.1. Behavioral evidence for reconstruction-Several lines of behavioral research provide evidence that the emotions we experience at the time of an event are not recalled verbatim each time we retrieve the details of that event. One technique for demonstrating these biases is to ask participants to rate their emotions as they are being experienced and then to later recall what emotions were experienced during an event. By comparing the reported on-line emotional experiences to the retrospective reports of those experiences, a measure of reconstruction can be obtained. In using this technique, memory and emotion 
researchers have gleaned a number of factors that seem to influence the reconstruction of memory for emotions. Many of these factors have been reviewed elsewhere (e.g., Robinson $\&$ Clore, 2002), and so we will briefly summarize the research relevant to this topic.

Individuals' expectations about how a specific event will play out are closely related to how they recall the emotional details of that event after it is over. Imagining real and hypothetical future emotional events, including those that are positive (e.g., vacations) or negative (e.g., menstruation), can arouse intense emotions in the present (Van Boven \& Ashworth, 2007). However, we seem to be relatively inaccurate at such affective forecasting and tend to overestimate the emotional impact that future events will have on us (Wilson, Meyers \& Gilbert, 2003). For example, individuals overestimate how positive vacations will be (Mitchell, Thompson, Peterson \& Cronk, 1997; Wirtz et al., 2003), as evidenced in comparisons of prospective and on-line emotion ratings. Shortly after those vacations end, however, retrospective ratings of emotion are more in line with the prospective ratings than with actual experience (Mitchell et al., 1997). In other words, individuals expect a highly positive trip, experience somewhat of a less positive trip than they expected (e.g., due to disappointments, bad weather, etc.), but remember a highly positive trip; this has been termed the "rosy view" phenomenon (Mitchell et al., 1997). A similar phenomenon holds for individuals' beliefs about how negative events like menstruation (McFarland, Ross, \& DeCourville, 1989) or the experience of Mondays (Stone, Hedges, Neale \& Satin, 1985; Areni \& Burger, 2008) will make us feel. We expect these experiences to be very negative, experience them as less negative than we anticipated, but remember them as more negative than they actually were. Thus, our remembered emotional experiences might be reconstructed in part by how we anticipate feeling prior to an event, even if our prior estimates are incorrect.

Our cultural beliefs about the emotionality of events can further bias memory reconstruction for emotional details. For instance, the types of emotions that are valued in our culture (affect valuation; Tsai, Knutson \& Fung, 2006) can influence how individuals remember experienced emotions. In one experiment, the more that American students valued the cultural ideal of high-arousal positive affect, the more positive affect they recalled feeling over the past week, regardless of their online emotion ratings (Scollon, Howard, Caldwell, \& Ito, 2009). Similar memory biases have been demonstrated based on cultural expectations of the emotions experienced by men and women. Although men and women report no differences in on-line measures of emotions, women retrospectively report feeling more emotions than men (Robinson, Johnson, \& Shields, 1998; Feldman Barrett, Robin, Pietromonaco \& Eyssell, 1998), in line with widely held cultural views that women are the more emotional sex (Feldman Barrett et al., 1998).

Individual differences also play a role in the reconstruction of memory for emotions. Feldman Barrett (1997) asked individuals to rate their on-line emotions over the course of 90 days, and then to recall their emotions from that time period at the end of the study. Fivefactor models of personality variables suggest that extraversion is associated with greater levels of positive affectivity, and neuroticism with greater levels of negative affectivity (Costa \& McCrae, 1980). Individuals' memories for how they felt over the 90-day study were biased in the direction that would be expected based on these models of personality. Those scoring high in extraversion recalled feeling more positive affect than they reported on a daily basis, whereas those scoring high in neuroticism recalled feeling more negative affect. A similar pattern of memory bias was evident for individual differences in selfesteem (as reviewed by Robinson \& Clore, 2002). Individuals scoring high on a self-esteem measure biased their memories about specific autobiographical events in a positive direction, whereas the reverse was true for those with lower self-esteem (Christensen, Wood \& Feldman Barrett, 2003). It is possible that personality variables like the ones described 
above provide information to individuals about their beliefs regarding emotions, which in turn bias reconstruction of emotional experiences (Robinson \& Clore, 2002). Interestingly, the biases in recalling emotions may also contribute to the development of individual differences (Safer \& Keuler, 2002).

So far we have seen that our expectations about the emotions that will be experienced during an event, whether driven by prior expectations, individual differences in personality, or culturally-held beliefs, can be powerful in molding how we recall the emotions that we experience during such events. These are not the only factors that can influence our reconstructions for previously experienced emotions. It is also true that knowledge acquired after an event, and changes in our feelings toward and appraisals about an event, can lead to biases in how we recall emotional details (reviewed by Levine \& Safer, 2002). For instance, Levine (1997) showed systematic biases in individuals' memories for how they felt when U.S. presidential candidate Ross Perot dropped out of the 1992 election; these biases were based on individuals' current feelings following the election. In particular, individuals who remained Perot supporters tended to underestimate their initial feelings of anger and sadness and overestimate their initial feelings of hope upon learning of his withdrawal, whereas those who went on to support other candidates only underestimated their initial sadness and hope. A similar pattern of findings was evident when individuals were asked to recall their emotions regarding the outcome of the O.J. Simpson trial (Levine et al., 2001). The more that individuals' beliefs in Simpson's guilt or innocence changed in the months and year following the verdict, the more their memories for emotions experienced at the time when they learned the outcome were biased toward their current appraisals. Coping mechanisms in dealing with emotional disappointment, such as in Ross Perot's withdrawal from the presidential race, can also influence memory for emotions (Levine \& Bluck, 1997). Older adults were less likely than younger adults to remain engaged in the election, but those who did were more likely than younger adults to underestimate their initial sadness in regards to Perot's withdrawal. This might have reflected an age-related change in regulatory strategies that led older adults to downplay the extent of their initial negative reaction (and see Carstensen et al., 1999, for related discussion).

Before closing this section, it is important to note that the reviewed variables found to influence memory reconstruction for emotions do not necessarily act independently of one another. For example, in one study undergraduate students reported their emotions about a midterm exam both before and after the exam was finished (Safer, Levine, \& Drapalski, 2002). Critically, some students learned their grade on the exam before being asked to recall how they felt before taking the exam, whereas others recalled their pre-exam emotions prior to learning the outcome. All students were generally accurate in recalling which emotions they felt prior to the exam. However, those students who learned that they had achieved high grades before recalling their emotions underestimated how anxious they felt before taking the exam, whereas those who learned they had received low grades overestimated how anxious they had felt. These memory biases were also affected by individual differences: Those scoring high on a neuroticism scale were most likely to overestimate their pre-exam anxiety at retrieval. Memory distortions in this study extended to a month following the exam, suggesting that knowledge acquired after an event, in combination with personality variables, can create long-lasting biases in memory for emotions.

\subsubsection{Mechanisms underlying the reconstruction of memory for emotions-}

Given the vast literature demonstrating that emotional details are reconstructed at the time of memory retrieval, it is perhaps not surprising that several hypotheses have been put forth to explain why this reconstruction occurs. As noted in the Introduction, one key function of autobiographical remembering is to help guide future behavior and decision-making (e.g., Bluck et al., 2005). Given that emotional (vs. neutral) events are most likely to be 
remembered (Talarico, LaBar \& Rubin, 2004) and to guide future behavior toward repeating pleasant events and avoiding aversive events (Levine et al., 2006), it is critical to understand how our reconstructed memories for the emotions associated with events drive our decisions to repeat those events.

One line of work focuses on the idea that when we are asked to recall how we felt during an emotional episode we must summarize across all of the affective moments of that event to give a suitable answer (e.g., Fredrickson, 2000). Additionally, we must be able to quickly evaluate past events to guide our future behavior (e.g., Levine \& Safer, 2002). To this end, two critical time points during specific events may be disproportionately weighted when we consider how we felt during a past episode: the time of highest emotional arousal ("peak" moment) and the end of the episode (reviewed by Fredrickson, 2000). It appears that when trying to summarize all of the "affective moments" that make up an event, individuals tend to disregard the duration of the event (e.g., Fredrickson \& Kahneman, 1993; Kahneman, Fredrickson, Schreiber \& Redelmeier, 1993). For example, Redelmeier and Kahneman (1996) tracked individuals' pain as they underwent medical procedures like colonoscopies. Those on-line measures were then compared to participants' retrospective reports of pain. Perhaps counterintuitively, longer procedures (which should result in greater amounts of pain) were not recalled more negatively than shorter procedures. Instead, the amount of pain recalled was strongly correlated with the most intense pain experienced and the pain experienced during the final moments of the procedure. Further, when a "better ending" is added to the end of an unpleasant experience like holding one's hand in cold water, individuals report stronger preferences to repeat that event than to repeat a shorter trial with a worse ending (Kahneman et al., 1993). This line of research suggests that our reconstructions of emotions at the time of retrieval may depend in particular on the peak and end affect associated with that event, perhaps because those two moments provide a useful heuristic for evaluating an event (Fredrickson, 2000).

Other models have focused more specifically on the memory processes that can lead to reconstructive biases in memory for emotions. For example, Robinson and Clore (2002) proposed a memory accessibility model, which is based on the assumption that past feelings cannot be either stored or recalled. Emotions can be reconstructed based on contextual details like past thoughts through the process of episodic remembering; however, as others (e.g., Conway \& Pleydell-Pearce, 2000; Rubin \& Wenzel, 1996) have suggested, these event specific details quickly fade with time. As a result, we are left to rely on semantic memory to reconstruct past emotions. Semantic memory is comprised of many of the factors found to bias memory that were reviewed above, including personality variables and beliefs about emotions, as well as culturally-based theories that dictate how we should feel during particular events (Robinson \& Clore, 2002).

Still other theories highlight the importance of maintaining a positive, coherent sense of self (Ross, 1989; Greenwald, 1980; Conway, 2005) and posit that memory reconstruction occurs at least in part to serve this goal. Ross (1989) suggested that memory retrieval is biased in the service of either exaggerating the consistency or enhancing the difference between the past and present feelings, depending on whether an individual wants to perceive consistency or improvement over time; we will return to this point in section 4.1.4. More recently, Conway (2005) reviewed evidence that the content of autobiographical memories can be rendered either more or less accessible at retrieval by the working self, with the ultimate goal of maintaining a coherent sense of self and downplaying information inconsistent with one's self-view. One powerful example of how memory for emotions can be reconstructed by the self-memory system is in post-traumatic stress disorder (PTSD). Conway (2005) reviewed a case of a witness to the 9/11 terrorist attacks in New York City who 
misremembered having a calm vantage point above the twin towers, presumably as a way to protect herself from the intense anger and fear she felt as an observer on the ground.

It is proposed that the central executive, likely supported by prefrontal areas, may be responsible for reconstructing memory for emotions in the self-memory system (Conway \& Pleydell-Pearce, 2000; Conway, 2005). This hypothesis is a logical one, given the essential role of these prefrontal processes in generative retrieval and in mnemonic search (e.g., Badre \& Wagner, 2002; Gilboa, 2004; Addis \& McAndrews, 2006). Next, we will review neuropsychological and neuroimaging evidence that may shed further light on the neural underpinnings of reconstructive processes involved in memory for emotion.

\subsubsection{Neuropsychological and neuroimaging evidence for reconstruction-}

Some have argued for a distinction between a memory system for event details and a memory system for emotions (e.g., Zajonc, 1980). Christianson and Safer (1996) reviewed neuropsychological evidence showing that amnesics demonstrate intact memory for emotional information despite having impaired memory for the episodic and contextual information presented with the emotional information. For instance, Johnson, Kim, and Risse (1985) showed that Korsakoff amnesics displayed a preference for a face that had been paired with a narrative that portrayed him as a "good" individual (e.g., one who performed noble acts) as compared to one who had been portrayed as a "bad" (e.g., immoral) individual, despite the fact that the patient could remember no specific details about either narrative. A study by Tranel and Damasio (1993) revealed a similar dissociation between the ability to remember the affective meaning of information and its episodic and contextual content. In their study, an amnesic patient showed a preference for an experimenter who had been nice on several prior testing sessions compared to an experimenter who had been less pleasant. These studies with amnesic patients emphasize that affective meaning can be retained even when event details cannot, and they indicate that the ability to maintain affective meaning can exist even without medial-temporal lobe function or conscious retrieval of the information.

Complementary to the work with amnesic patients, a dual-representation model of PTSD also posits separate memory systems for verbal and non-verbal, affective information; information from both systems is combined when memory is constructed (Brewin, Dalgleish, \& Joseph, 1996; also reviewed in Conway \& Pleydell-Pearce, 2000). Similar to the proposed division of event details and affective information based on work with amnesic patients, Brewin et al. (1996) liken verbally accessible details to conscious, explicit memory and affective information to unconscious, implicit memory. In both models, affective information is inaccessible for conscious retrieval and is only brought into consciousness given appropriate situational or context cues [e.g., the presence of the experimenter in Tranel \& Damasio (1993) or the presence of trauma-related cues in Brewin et al. (1996)]. Although the Brewin et al. (1996) model was hypothesized in regards to PTSD, the broader implication of such a model is that affective information is represented separately from other event details and can be selectively retrieved (Conway \& Pleydell-Pearce, 2000). Further, an important prediction of this dual-representation approach is that affective information may be partially or completely inhibited by the verbal system to avoid the interruption of cognitive processes by the re-experiencing of emotions (Conway \& Pleydell-Pearce, 2000).

In line with Brewin et al.'s (1996) model, patient and neuroimaging evidence suggests that the affective memory system may be preferentially right-lateralized, in contrast to the leftlateralized verbal memory system (see also Conway \& Pleydell-Pearce, 2000). Patients with right hemisphere damage produce autobiographical memories that are impoverished in emotional content and specificity but not in other cognitive content (Cimino, Verfaellie, Bowers \& Heilman, 1991). Similarly, epilepsy patients undergoing a Wada Test (in this 
case, with the right cortical hemisphere anesthetized) showed a marked reduction compared to baseline in the emotional details used to describe emotional autobiographical memories; factual details remained largely unchanged (Ross, Homan, \& Buck, 1994).

More recent evidence indicates that damage to the hippocampus, amygdala, and nearby cortical areas (but not to the hippocampus alone) attenuates the number of negative affective autobiographical memories recalled, the number of negative words used to describe those memories, and the phenomenological ratings of emotional intensity and vividness (Buchanan, Tranel \& Adolphs, 2005); these effects are especially evident in patients with right-lateralized anteromedial temporal lobe damage (Buchanan, Tranel \& Adolphs, 2006). This patient evidence converges nicely with neuroimaging evidence that amygdala activity is associated with emotional intensity in autobiographical memory retrieval (Addis et al., 2004; Daselaar et al., 2008; Greenberg et al., 2005). Taken together, these studies suggest that the reconstruction of emotional and non-emotional details may be dissociable processes that engage slightly different medial temporal lobe structures. The reconstruction of past emotions may be especially reliant on the amygdala and also may be preferentially rightlateralized (at least for negative emotions; see Davidson, 1992; Demaree et al., 2005; Liotti \& Tucker, 1995 for discussion of valence-based laterality effects). That feeling states and non-affective information can be recalled separately allows for the possibility that recall can exist without the re-experiencing of past affect (Conway \& Pleydell-Pearce, 2000).

\subsubsection{The function of reconstructing memory for emotion-Evidence for} reconstructive memory for emotions in autobiographical memory is often couched in negative terminology, such as memory "biases" and "distortions" (as noted by Levine, 1997; Levine \& Safer, 2002; Levine et al., 2006). This may be an unfair evaluation of memory for emotion in light of the function of remembering how past experiences made us feel. For example, if one of the main purposes of remembering emotional experiences is to guide future behavior and help us decide whether to repeat or avoid events, it would make sense if our memories for emotions were updated based on more recent knowledge and appraisals (Levine, 1997; Levine \& Safer, 2002). Levine and Safer (2002) liken reconstructive memory for emotion to updating a map based on new information and current feelings about a situation.

One arena for which this "map updating" analogy is particularly relevant is that of wellbeing. A primary goal in remembering emotions is to find meaning in emotional events and to incorporate them into one's sense of self so that a coherent life narrative can be formed (Fivush et al., 2008). An equally important goal in autobiographical remembering is to maintain a coherent and consistent view of the self over time (Greenwald, 1980; Conway, 2005). The reconstructive nature of memory nicely lends itself to both of these goals. As mentioned previously, Conway (2005) notes that reconstructing factual details of an emotional event, such as in the case of the 9/11 survivor, is sometimes critical to managing PTSD symptoms. Reconstructing how we feel about a particular event is also important for well-being. As one example, Pennebaker and colleagues have repeatedly demonstrated the therapeutic benefits of writing about past negative or traumatic emotional events (e.g., Pennebaker, Mayne \& Francis, 1997; Pennebaker \& Seagal, 1999). Written narrative accounts of highly positive and negative events include a greater proportion of positive and negative emotion words, respectively (Bohanek, Fivush \& Walker, 2005). Repeated disclosures of the same negative emotional events are associated with a reduction of negative emotion words. In turn, a reduction in negative emotion words is associated with positive outcomes ranging from healthier immune functioning to decreased absenteeism from work to increased grade point averages among students (reviewed by Frattaroli, 2006). A meta-analysis by Frattaroli (2006) suggests that repeated recalling of past negative emotions leads to the extinction of the negative thoughts and feelings associated with 
negative events. This proposed exposure and extinction hypothesis might be likened to a form of "map updating," repeatedly recalling emotions allows individuals to reconstruct how they feel about past events, thereby allowing them to integrate negative events into the self-schema (Frattaroli, 2006).

As we noted previously (Section 4.1.2), sometimes we reconstruct past events (e.g., menstruation) in such a way as to make them seem more negative than they actually were. This form of reconstruction may be beneficial to well-being because it creates the perception of improvement over time (Ross, 1989). One domain in which such an effect has been demonstrated is that of romantic relationships, in which feelings of love and satisfaction are perceived to increase over time even though the reported feelings remain relatively stable (Sprecher, 1999). Karney and Coombs (2000) asked wives to rate their current feelings and recall their past feelings regarding their marriage over a 20 year longitudinal study. The authors found that both 10 and 20 years into their marriages, the wives remembered their past ratings as being more negative than they actually were. Even more interestingly, the degree to which the wives showed this negative biasing of the past 10 years into the marriage was positively correlated with marital satisfaction after 20 years. In a similar vein, individuals may construe their romantic partners' faults into virtues (e.g., reframing "stubbornness" as "integrity") as a way to cope with uncertainty in their relationships (Murray \& Holmes, 1993), perhaps suggesting a mechanism (i.e., construal or reinterpretation of negative feelings to positive feelings) by which reconstructive memory for past emotions might serve its functional purpose.

Research on age-related changes in memory for past emotions also sheds light on the potential benefits of the reconstructive nature of memory. Socio-emotional selectivity theory suggests that emotion and emotion regulation goals become more salient with age as time is perceived as more limited (e.g., Carstensen \& Turk-Charles, 1994, 1998). A wealth of research (see Mather, 2006, for a review) shows that older adults are more likely to forget negative events or the negative feelings associated with them more quickly (Berntsen \& Rubin, 2002; Levine \& Bluck, 1997), to reconstruct negative events in a more positive light (Comblain, D'Argembeau \& Van der Linden, 2005), and to recall the past as more positive than it was (Kennedy, Mather \& Carstensen, 2004). Remembering the past with an emphasis on positive emotions may help explain why aging is associated with increased subjective well-being and decreased incidence of mental health problems (Erskine et al., 2007). Indeed, guided reminiscence of autobiographical memory with an emphasis on recalling positive memories and reframing details in a more positive manner is offered as a therapeutic measure for older adults (reviewed by Bluck \& Levine, 1998).

\subsection{Mood Congruent Memory}

Only a portion of our vast autobiographical knowledge stores is available to us at any given time (e.g., Woike \& Polo, 2001; Sanitioso, Kunda \& Fong, 1990; Conway, 2005; Woike, 2008) and memories can be made more or less accessible by our current mood states. An often studied phenomenon in cognitive research is that of mood congruency, which refers to the finding that information congruent in valence to one's present mood is more likely to be perceived, attended to, stored, retrieved, and factored into judgments and decision-making than mood incongruent information (for reviews see Blaney, 1986; Rusting, 1998). Others have reviewed evidence for mood congruent memory (MCM) on laboratory explicit memory tasks such as list-learning and free recall tasks (e.g., Singer \& Salovey, 1988; see Barry, Naus \& Rehm, 2004, for a review of mood congruent implicit memory); here we will mostly focus on work showing the MCM effect to be robust in autobiographical memory tasks. In this section we will review behavioral evidence for autobiographical MCM, describe its characteristics, and discuss different theories that have been put forth to explain its existence. We will end with a review of recent neuroimaging studies aimed at delineating 
the neural networks that underlie MCM. Note that although mood congruency can lead to superior encoding as well as retrieval of mood congruent information, our focus will be on retrieval since mood at the time when autobiographical memories are being encoded is often unknown (Matt, Vazquez \& Campbell, 1992).

4.2.1. Behavioral Evidence for Mood Congruent Memory-A broad range of studies using varied mood induction techniques has demonstrated the MCM effect in regards to autobiographical memory (for reviews, see Bower, 1981; Blaney, 1986; Singer \& Salovey, 1988). Moods have been induced with video clips (e.g., Josephson, Singer \& Salovey, 1996), music (e.g., Miranda \& Kihlstrom, 2005), reading mood-inducing statements (Velten, 1968), adopting an emotion-related body stance (Dijkstra, Kaschak \& Zwaan, 2007), hypnosis (Maccallum et al., 2000), and by neurochemical means such as tryptophan depletion (Klaassen et al., 2002). All of these mood induction techniques have broadly led to MCM, with memories rated as more positive, or less negative, following a happy mood induction vs. a depressed mood induction (Madigan et al., 1982, Exp. 1; Mathews \& Bradley, 1983; Snyder \& White, 1982). In addition to influencing the affect associated with an autobiographical memory, mood can also influence the amount of time it takes to retrieve emotional memories. For example, sad memories take longer to retrieve when in a happy mood, whereas happy memories take longer to retrieve when in a sad mood (e.g., Riskind, 1983; Lloyd \& Lishman, 1975; but see Teasdale \& Fogerty, 1979 for evidence that retrieval latencies hold only for positive memories retrieved in sad moods). Finally, mood congruency is evident in the numbers of positive and negative autobiographical memories reported following a mood induction, with a greater number of positive memories retrieved following a positive mood induction and more negative memories retrieved following a negative mood induction (e.g., Teasdale, Taylor \& Fogarty, 1980; Natale \& Hantas, 1982; Eich, Macaulay \& Ryan, 1994, Experiment 2). Although MCM is generally evident in autobiographical memory, its effects are often asymmetric in nature, with positive moods leading to MCM more reliably than negative moods (see Rusting, 1998; Singer \& Salovey, 1988; Brewin, Andrews \& Gotlib, 1993, for reviews; see also Matt et al., 1992, for a meta-analysis of non-autobiographical memory findings).

The ecological validity of studying MCM with the use of induced moods has been called into question (e.g., Perrig \& Perrig, 1988; Blaney, 1986), leading some to turn to naturallyoccurring mood states, such as depression, to examine MCM (e.g., Clark \& Teasdale, 1982). Generally speaking, autobiographical MCM in depression is a robust phenomenon (Blaney, 1986; Hertel, 2004) and the extent to which depressives recall negative life events is correlated with the severity of their symptoms (Fogarty \& Hemsley, 1983). Although clinical depression is often related to memory impairments, these deficits are usually confined to memory for positive autobiographical events (see Burt, Zembar \& Niederehe, 1995, for a meta-analysis; Lamogne et al., 2006), which suggests a mood congruency effect in that negatively-valenced memories are often more accessible than positive or neutral memories when individuals are in a depressed state.

More recently, researchers in the MCM domain have turned their attention to the interaction of moods with long-standing personality traits, citing evidence for certain personality variables enhancing or diminishing the effect (Rusting, 1998). For example, individuals scoring high on measures of extraversion and positive affectivity show increased mood congruent recall for positive information on a number of memory and judgment tasks (Rusting, 1999); individuals high on scales of neuroticism and negative affectivity show enhanced mood congruent recall for negative information on those same tasks (Bradley et al., 1993; Rusting, 1999). MacLeod et al. (1994) showed similar interactions between personality trait and mood in the latency to retrieve positive and negative autobiographical memories, with positive memories retrieved faster by those scoring highest on measures of 
positive affectivity and vice-versa for those scoring highest on negative affectivity. The directionality of this correlation is ambiguous: The personality trait could influence the ease with which memories are retrieved, or alternately, the ease with which different types of memories are recalled might influence how individuals answer the questions on personality trait assessments. In contrast to these congruency effects, Rusting and DeHart (2000; see Exp. 1 for an autobiographical memory task) showed that individuals who believed most in their ability to regulate negative moods were most likely to recruit positive (mood incongruent) memories following a negative mood induction, a point we will return to in the next section of the review.

4.2.2. Underlying Mechanisms for Mood Congruent Memory-The most popular explanation for MCM focuses on a network theory of affect (Bower, 1981; Clark \& Isen, 1982), which presupposes that specific emotions and events are represented as different nodes in memory. Events that elicit a particular emotion become linked with that emotion's node in memory during encoding. The result is that future activations of an emotion node (e.g., through an experimental mood induction) lead to a spreading activation of the event nodes linked with that emotion node. This spreading activation leads to an increased accessibility of mood congruent information and memories at retrieval and has the potential to create a "cognitive loop" in which mood congruent memories serve as affective cues for the retrieval of additional mood congruent memories, thereby maintaining current mood (e.g., Isen, 1978, 1987).

Rather than focusing on particular emotion and event cognitive nodes, schema models of mood congruent memory rely on the notion of stable cognitive constructs that contain knowledge about the self and one's past experiences (reviewed by Rusting, 1998). Similar to the way nodes can become activated in associative network theories, particular life events can trigger particular self-schemas. When a particular schema is activated, information is perceived and interpreted in manners consistent with the knowledge contained in that schema; this includes the retrieval of memories that are congruent with the schema. Most influential in this domain are Beck's cognitive models of depression and anxiety (e.g., Beck, 1976; Beck \& Clark, 1988). These models predict that particular life events (e.g., those that are sad or threatening) activate depression- or threat-related schemas, thereby making schema-related-including mood congruent-memories more accessible and elongating the activation of those schemas (similar to the cognitive loop proposed by associative network theories).

Although they take slightly different approaches to explaining the underlying mechanisms of MCM, associative network and schema theories have provided broad and influential frameworks for making predictions about autobiographical MCM (Rusting, 1998). Before moving on, we will briefly note that other approaches have provided more specific explanations and predictions about MCM. For example, the Affect Infusion Model proposed by Forgas (1995) predicts that only heuristic (i.e., "shortcut") and substantive (i.e., complex) processing in making judgments will lead to MCM. In contrast, directly accessing previously stored judgments from memory and motivated processing (i.e., in attempts to achieve some goal such as mood regulation) might lead to mood incongruent processing. As another example, Williams et al. (1997) proposed a process-oriented approach that makes specific predictions about the role of preattentive vs. elaborative information processing in depression, namely that a depressed mood will only lead to explicit, but not implicit, MCM. Approaches like these help refine the broader associative network and schema theories and may help explain inconsistencies in the MCM literature, a point we will return to shortly.

4.2.3. Neural Mechanisms Underlying Mood Congruent Memory-Within the past several years, memory and emotion researchers have turned to neuroimaging to clarify the 
brain mechanisms underlying MCM (Lewis \& Critchley, 2003). One study in particular provides preliminary fMRI evidence for the associative network theory of MCM.

Participants in the Lewis et al. (2005) experiment studied positive and negative words, then underwent either a positive or negative mood induction followed by a recognition memory task. The subgenual cingulate gyrus was active during the encoding of subsequently remembered positive words and reactivated during the retrieval of those words when participants were in a positive mood, whereas posteriolateral orbitofrontal cortex showed the same effect for negative words. The authors suggest that these two regions might represent the general locations for negative and positive "emotion nodes" in the associative memory network.

Another MCM study, this time measuring event related potentials (ERPs) during the encoding of mood-congruent or incongruent words, showed a reduced N400 component when participants encoded positive words while in positive moods (Kiefer et al., 2007). The N400 typically is associated with the need to integrate information into a semantic context, with more difficult integration (e.g., the occurrence of an unexpected word at the end of a clause) leading to increased N400 amplitude (Kutas \& Hillyard, 1980). A reduced N400 component has been associated with mood-congruent semantic processing, plausibly because mood-congruent stimuli are preferentially encoded into existing semantic structures (or nodes) (Kiefer et al., 2007). It makes sense that information well-integrated within semantic memory stores could receive a mnemonic benefit, and so this improved semantic integration may be an important factor leading to MCM.

Other imaging work in the domain of MCM has focused on currently and formerly depressed participants. ERP work has shown that there is typically a negative slow-wave component in the left parietal region that becomes more negative with increasing working memory demand (e.g., García-Larrea \& Cézanne-Ber, 1998; Montfort \& Pouthas, 2003). One ERP investigation found that nondepressed individuals have a more-negative slow wave in the left parietal lobe (reflecting storage and retention of information in working memory) when maintaining positive information in working memory, whereas depressed individuals show a more-negative slow wave when maintaining negative information in working memory (i.e., during MCM; Deldin et al., 2001). The more-negative slow wave present in depressed participants holding negative information in working memory may indicate a bias in allocating memory resources to mood congruent information (Deldin et al., 2001).

Ramel et al. (2007) induced a sad mood in their participants and then had them encode positive, negative, and neutral adjectives during a self-referential encoding task. Participants with remitted depression showed a bilateral increase in amygdala activity during the encoding of emotional adjectives when compared to never-depressed individuals. For a subset of the formerly depressed individuals (specifically, those with characteristics associated with higher risk for depressive relapse), the increased amygdala activity during encoding was associated with increased recall of only self-referent negative adjectives (i.e., mood congruent memory). This increased amygdala activity could be due to greater arousal in response to emotional words or to enhanced processing of self-referent information (Ramel et al., 2007). Although a causal role for the amygdala in depressive relapse cannot be established based on this study alone, the amygdala might be part of a larger network whose activity is associated with a vulnerability for relapse (Ramel et al., 2007).

4.2.4. Does Mood Congruent Memory Really Exist?-Before closing this section, it is important to recognize some of the criticisms of MCM research. Although most studies confirm the existence of a mood congruency effect in autobiographical memory, others have found no such effect (see Blaney, 1986), even in naturally-occurring mood states in healthy 
individuals (Hasher et al., 1985; but see Mayer, McCormick \& Strong, 1995). Often times, failures to demonstrate MCM can be explained by turning to the more specific predictions that the AIM (Forgas, 1995) or the process-oriented approach (Williams et al., 1997) make. For example, a failure to find a MCM effect in anxiety (e.g., Levy \& Mineka, 1998) might be attributed to the fact that it is preattentive, rather than elaborative, processing that is biased by anxiety (Williams et al., 1997), whereas MCM may depend upon elaborative processes. Another concern is evidence for mood incongruent memory rather than mood congruency effect (e.g., Parrott \& Sabini, 1990; Josephson et al., 1996). We will discuss mood incongruent memory more in-depth in the following section on memory and emotion regulation, but we will note here that whether a mood elicits congruent or incongruent memories can often be explained by acknowledging individual difference variables (Rusting, 1998), emphasizing the important interaction between MCM and individual differences, some of which we described earlier (Section 4.2.1).

As mentioned previously, some have criticized the use of mood inductions in MCM studies. Perhaps most troubling for MCM theory was a study published by Perrig and Perrig (1988), who demonstrated a mood congruence effect in recall for word lists in the absence of a mood induction. Instead, the authors instructed participants to behave as though they were depressed or happy; they concluded that simply having the knowledge of behaviors associated with a particular mood state is enough to produce MCM. A more recent followup to the Perrigs' study (Eich \& Macaulay, 2000) examined the role of simulated mood in autobiographical memory recall and found similar effects, with the caveat that mood simulations led to striking symmetrical MCM (i.e., participants simulating both happy and depressed moods demonstrated the effect), in contrast to the more typical asymmetrical MCM noted above. It appears that actual changes in mood are not necessary to obtain a mood congruency effect in memory, but that congruency achieved in simulated moods is qualitatively different from that demonstrated in real moods (Eich \& Macaulay, 2000).

\subsection{Emotion Regulation Goals and Autobiographical Retrieval}

In the previous section, we reviewed evidence for the role of emotional states at the time of autobiographical memory retrieval. Since we do not usually adopt passive roles in experiencing our moods, and indeed often try to manipulate or regulate our emotions, it is equally important to acknowledge the role of emotion regulation goals in autobiographical retrieval. As noted in the Introduction, autobiographical memory serves a number of important functions in daily life, including those that are key for social, self, and directive goals (Bluck et al., 2005). Emotion regulation is one perhaps omnipresent use of autobiographical memory that potentially transcends the boundaries between these three broad functions, yet receives curiously little attention from memory researchers (Pasupathi, 2003; see also Koole, 2009). Emotion regulation refers to the processes by which we can alter our emotional experience and/or expression (Gross, 1998). We can probably all think of anecdotal evidence for a time when we recruited an autobiographical memory to achieve emotion regulation, such as when we remembered a great talk we once gave to calm our nerves before a presentation. In this section we will review evidence for emotion regulation through autobiographical remembering, relying primarily on the literatures covering mood incongruent memory, instrumental emotion regulation goals, and overgeneral autobiographical memory.

4.3.1. Mood incongruent recall-In the previous section of this review, we noted that some researchers have found evidence for mood incongruent recall, or the tendency to recall information that is opposite in valence to one's current mood. An often-cited example is a series of experiments performed by Parrott and Sabini (1990), who showed that under "natural" mood conditions such as learning one's grade on an exam or experiencing good vs. 
bad weather, individuals had an easier time recalling autobiographical events opposite in valence to their mood. Although Parrott and Sabini (1990) found evidence for mood incongruence in both happy and sad individuals, mood incongruent recall often occurs in sad moods, possibly explaining the asymmetrical mood congruency effect (e.g., Blaney, 1986; Isen, 1985). A popular explanation for mood incongruent recall is that individuals are undertaking mood repair to avoid prolonging a negative emotional state (Isen et al., 1978; Isen, 1984). In support of this idea is evidence for a delay in incongruency ("first congruency, then incongruency;" Sedikides, 1994). For example, participants who were induced into sad moods via music tended to recall negative (mood congruent) autobiographical events first in order, followed by positive autobiographical events (Josephson, Singer \& Salovey, 1996). When asked to provide justification for why they recalled the events in the order that they did, participants who had recalled a positive event second in order cited mood repair. Mood congruent memory may reflect relatively automatic processes, with mood incongruent memory representing controlled attempts at mood regulation (e.g., Josephson et al., 1996).

Mood incongruency in autobiographical memory appears to be modulated by individual differences, lending further support to its role in emotion or mood regulation. Individuals scoring high (vs. low) in positive affectivity are most likely to demonstrate mood incongruent recall following a negative mood induction (Rusting, 1999), as are those who believe most in their ability to regulate their moods (Rusting \& DeHart, 2000), those who are high in measures of self-esteem (Setliff \& Marmurek, 2002), and those who adopt a reflective, rather than ruminative, self-focus when in negative moods (McFarland \& Buehler, 1998). The ability to regulate mood using autobiographical memory may have important implications for well-being: Individuals scoring high in depression were least likely to recall second positive memories in Josephson et al.'s (1996) study, which may reflect a general inability to use positive memories for mood regulation in depression (Joorman \& Siemer, 2004). Similarly, the tendency of dysphorics to generate more negative autobiographical events when induced to ruminate (rather than reflect) on their negative moods may indicate a mechanism by which depression is perpetuated (Lyubomirsky, Caldwell \& Nolen-Hoeksema, 1998).

\subsubsection{Instrumental emotion regulation goals and autobiographical recall-It is} generally accepted that individuals are usually motivated to regulate their emotions in a hedonic direction (see Tamir, 2009; Tamir, Chiu \& Gross, 2007, for reviews), but more recent research on what have been termed instrumental emotion regulation goals may shed further light on how individuals use their memories to regulate their emotions. Although we frequently regulate our emotions to make ourselves feel more positive, we are sometimes motivated to feel unpleasant emotions, if those emotions help us achieve some future goal (Tamir, 2009). Social interactions are one domain in which this instrumental motivation is evident, such as when individuals feel motivated to either neutralize their own moods or even match the mood of an emotional individual they are expecting to meet (Erber, Wegner \& Therriault, 1996).

Studies examining instrumental emotion regulation goals provide evidence that individuals may recruit their autobiographical memories to achieve these goals. In one study, individuals were told that they would be playing either a confrontational or nonconfrontational video game at the end of their appointment (Tamir, Mitchell \& Gross, 2008). Before playing the game, participants were asked to rate their preferences for recalling different emotional events from their pasts. Those individuals who expected to play a confrontational (vs. non-confrontational) video game showed higher preferences for recalling angry events; moreover, those who did show such a preference showed enhanced performance on the video game. Similar to the findings in the mood incongruent memory 
literature, these effects are modulated by individual differences; extraverts are more likely to prefer recalling positive autobiographical memories in effortful contexts, such as preparing to give a speech or taking a test (Tamir, 2009).

Taken together, research from the mood incongruent memory and instrumental emotion regulation goal traditions suggests that individuals can and do select to recall particular memories to achieve emotion regulation goals, and that their propensity to do so is related to individual differences in personality. The reconstructive nature of autobiographical remembering might make it particularly suitable for emotion regulation processes, as memories can be constructed in such a way as to accentuate positive or negative details (Pasupathi, 2003). Research from our lab provides evidence that individuals may bias the emotional details of past events when expecting to meet with an emotional individual. Individuals who thought they would be meeting with a sad individual increased the amount of negative emotional language they used in reporting past events, in comparison to a baseline recall of the same events; those who thought they would be meeting with a happy individual demonstrated the opposite trend (Holland, Tamir \& Kensinger, submitted). This effect was related to differences in extraversion, with those scoring high on that trait less likely to increase their negative emotional language prior to a supposed meeting with a sad individual. Further, the effect was confined to an autobiographical event recalled second in order, lending additional support to the notion that regulatory processes using autobiographical memory might take time and be attributed to controlled processes (e.g., Sedikides, 1994; Josephson et al., 1996). This research suggests that emotion regulation goals influence not only what memories we recall, but also the details we recall about those memories as well.

\subsubsection{Overgeneral autobiographical memory and affect regulation-Affect} regulation might also occur (intentionally or not) when events are recalled at a general rather than specific level. As we noted in the Introduction, autobiographical events can be arranged hierarchically and vary in their specificity. When we attempt to retrieve a memory in response to some cue (i.e., generative retrieval), our search begins at the intermediate level of general memories; with the aid of a central executive, we narrow our search to a unique episode (Conway \& Pleydell-Pearce, 2000). Individuals suffering from affective disorders including subclinical and clinical levels of depression (e.g., Williams \& Broadbent, 1986; Kuyken \& Brewin, 1995; Brewin, Reynolds \& Tata, 1999; Watkins \& Teasdale, 2001), seasonal affective disorder (Dalgleish et al., 2001), eating disorders (Dalgleish et al., 2003), and post-traumatic stress disorder (Dalgleish et al., 2008) all show reduced specificity in their recall of autobiographical events; they tend to recall a greater proportion of repeated or categorical events than healthy individuals. This has been termed the overgeneral memory effect (for reviews, see Williams, 1996; Williams et al., 2007; Williams, 2006).

One mechanism proposed to underlie the overgeneral memory effect is functional avoidance, or the idea that remaining at a general level of specificity during autobiographical retrieval allows for the avoidance of recalling specific, negative and painful details (reviewed by Williams et al., 2007). Over time, repeated avoidance of painful memories leads one to adopt a retrieval style that involves moving across the level of general memories in the autobiographical knowledge hierarchy, rather than from top to bottom; this style has been termed mnemonic interlock (Williams, 1996). Correlational evidence between the amount of intrusions and avoidance following stressful events (measured by the Impact of Event Scale and other tests of cognitive avoidance and suppression) with measures of autobiographical memory specificity seems to confirm the functional avoidance hypothesis; the more that individuals reported avoidance behaviors, the less specific they were on an autobiographical memory cue word task (reviewed by Williams et al., 2007). A more recent test lends further support to the idea that there is a 
relationship between affect regulation and overgeneral memory. Raes et al. (2003) attempted to induce feelings of frustration in participants with the use of a puzzle task. Those individuals who reported the greatest amount of negative affect following the task were the same individuals who were most specific on an autobiographical memory cue word test. These findings are consistent with those discussed in Section 3.1.2, revealing that negative affect can be tied to recovery of some episodic details. Although Section 3.1.2 primarily conceptualized of the results as an effect of negative affect on memory specificity, if the link also exists in the opposite direction - as an effect of memory specificity on the intensity of negative affect - then it would follow that individuals who wish to minimize their negative affect may attempt to do so by retrieving general, rather than specific, autobiographical memories (Williams et al., 2007).

As this discussion highlights, much of the evidence for a tie between negative affect and memory specificity - including the study by Raes et al. (2003) - is based on correlational evidence between reported emotion on one task and memory specificity on a separate task (discussed by Philippot et al., 2004). Although these studies tend to suggest that there is an association between specific autobiographical retrieval and enhanced negative affect, the results may not always exist in that direction. A recent memory model of emotion regulation proposes that overgeneral memory style can increase negative affect (Philippot et al., 2004). Influenced by Conway and Pleydell-Pearce's (2000) self-memory system, Philippot et al. (2004) proposed two distinct levels of emotion: (a) a schematic system that contains implicit knowledge about emotions and acts relatively automatically and unconsciously (e.g., a startle response upon hearing a loud noise), and (b) a propositional system that contains explicit knowledge about emotions and allows us to identify and communicate our emotion states to others. According to this model, regulation of the schematic system must occur so that automatic emotional responses do not disrupt more thoughtful responses based on the propositional system. One of the ways that this regulation can occur is through the elaboration of emotional information, which is posited to interrupt schematic processing. Even though individuals seem to believe that elaborating on their feeling states will intensify their emotional experience (Philippot et al., 2004), empirical evidence showed that individuals primed to retrieve general (vs. specific) autobiographical memories actually experienced more emotional intensity in a subsequent task in which they mentally re-lived an emotional experience (Philippot, Schaefer \& Herbette, 2003). Therefore, it seems that adopting a specific autobiographical retrieval mode and elaborating on the emotions associated with such memories might reduce subsequent emotional intensity (Philippot et al., 2004). A separate literature has suggested that verbal elaboration can be an effective emotion regulation strategy, perhaps because the top-down processes needed for such elaboration effectively serve to dampen the responses within the limbic system (see Berkman \& Lieberman, in press, for discussion). Similar processes may be at work when individuals retrieve specific autobiographical memories.

4.3.4. Neural correlates of emotion regulation-Much of the work examining the neural correlates of emotion regulation has focused on the regulation of emotional responses to visual stimuli (Kross et al., 2009). A great deal has been learned in the past several years about the neural structures engaged during the reappraisal of the meaning and significance of emotional stimuli. Reappraisal seems to reflect influences of the prefrontal, orbitofrontal, and cingulate cortices on regions associated with emotional responding, including the amygdala and insula (see Ochsner \& Gross, 2005, 2008, for reviews). In particular, it seems that amygdala activity can be modulated by prefrontal areas to increase or decrease depending on whether one is trying to up- or down-regulate negative emotions, respectively (Ochsner et al., 2004). 
To date, only one study has examined the neural correlates of regulating emotions associated with autobiographical memories. Kross et al. (2009) asked participants to either focus on the emotions experienced with negative autobiographical events or to cognitively analyze (similar to rumination) or accept (i.e., down-regulate) the negative emotions. Consistent with the broader literature on emotion regulation, all of the regulation strategies engaged leftlateralized prefrontal areas associated with cognitive control. However, activity in the subgenual anterior cingulate cortex (sgACC) and medial prefrontal cortex (regions associated with both autobiographical memory retrieval and emotional experience) was lowest in the accept condition compared to the feel condition; activity in these regions was positively correlated with reported negative emotional experience, leading the authors to suggest that activity in those areas tracks with subjective feelings. Interestingly, depressed individuals show increased sgACC resting activity (Kross et al., 2009), perhaps reflecting rumination on negative experiences similar to the analyze condition in the Kross et al. (2009) study.

\section{Conclusions and Future Directions}

One recurrent theme throughout this review is the constructivist nature of memory. Emotional memories, like all episodic memories, are reconstructed at the time of retrieval, making them prone to memory biases and inconsistencies. The affective characteristics of an event can influence the likelihood that a memory is encoded, stored, and retrieved, but these emotional memories are never perfect representations of our past, and we often remember past experiences - and our emotional reactions to those experiences - through a distorted lens. The emotion that we feel at retrieval, or that we want to feel, can have a particularly strong influence on the way in which we reconstruct past experiences and past emotions. Yet our emotional experience affects memory long before the retrieval phase; emotion affects the information that becomes a part of the memory trace as well as the information that is accessible for recall.

Another broad theme in this review is the function of emotional autobiographical memory. Much work has demonstrated that our personal memories contain inaccuracies or imperfections, even for highly arousing and personally significant events. Although it is tempting to view these distortions as problematic, it is informative to consider these findings in light of the proposed functions of autobiographical memory that we noted in the Introduction and to realize the possible functional and positive outcomes of this reconstructive memory system. For example, remembering our past experiences and behaviors as more positive than they actually were may allow us to maintain a coherent, positive sense of self and to forge positive social relationships. Similarly, the flexibility in the construction of events at retrieval may enable us to direct our future behavior and to regulate our emotions. Although the benefits of the reconstructive nature of memory have been espoused, these discussions generally have focused on memory for neutral events (Schacter \& Addis, 2007); the construction of emotional events and of experienced emotions may provide even wider-ranging benefits.

Many of life's experiences elicit emotions, and this review demonstrates that much has been uncovered about how emotion and autobiographical memory interact, but it also highlights areas where gaps in our knowledge remain. There are a multitude of domains that would benefit from further research, but here we highlight three research directions that we believe will be particularly fruitful and for which we believe that a combination of behavioral and neuroimaging approaches will yield important insights.

As noted in Section 4.2, the literature on mood congruent memory is equivocal as to whether this effect occurs. It seems that individual differences in personality influence mood 
congruent memory (Rusting, 1998), but more work is needed to determine what factors account for the effect. Perhaps even more importantly, further work is needed to clarify whether real mood or simulated mood is sufficient to create a mood congruency effect; the small amount of work (Perrig \& Perrig, 1988; Eich \& Macaulay, 2000) indicating that mood is not a necessary component of mood congruent memory has serious implications for interpretations of this effect and deserves more attention in the literature. Neuroimaging may provide a rich methodology to explore this issue, as research could examine whether the mechanisms that influence memory selection differ when individuals simulate mood rather than experience a particular mood state.

The interaction between autobiographical memory retrieval and emotion regulation goals also deserves more attention (also noted by Pasupathi, 2003). Much of the work in this domain has focused on using mood repair or emotion regulation as an explanation for mood incongruent or overgeneral memory, but it has not focused on the details of how and when memories might be recruited to serve regulatory functions. In a similar vein, most research has focused on which memories are retrieved under different conditions of mood or emotion regulation goals. However, it is also interesting to ask how event specific knowledge and emotional details are reconstructed when the particular memory being retrieved is constrained (e.g., when asking individuals to recall a particular event like high school graduation). We predict that the reconstruction of event specific details can be biased in reliable ways depending on the emotional conditions under which the memory is retrieved; we have some evidence to support this hypothesis (Holland et al., submitted), but more work can be done to delineate how individual differences and different moods or emotion regulation goals influence the reconstruction of event details. It may be particularly useful to investigate whether the reconstructive processes guided by internal regulatory goals mirror those evoked by external, environmental cues; neuroimaging may provide a robust methodology to investigate this type of question.

The use of neuroimaging has begun to elucidate the neural network engaged during emotional autobiographical remembering and during the encoding and retrieval of emotional information. There have now been a number of studies highlighting interactions between structures within the medial temporal lobe (e.g., amygdalar modulation of the hippocampus) and between those structures and the prefrontal and visual cortices (see Section 3.4). In addition, a good deal of work has focused on the functional neuroanatomy of emotional experience (see Phan et al., 2004, for a meta-analysis). Many of the regions implicated in emotional experience are also engaged during autobiographical memory retrieval, including the amygdala, medial prefrontal cortex, and anterior cingulate cortex (Phan et al., 2004). However, the work examining the neural correlates of the interaction between emotional states and goals at the time of memory retrieval (reviewed throughout Section 4) is quite preliminary. More work is needed to determine how the activity present during a particular emotional state or the attempted regulation of that state might modulate the activity during subsequent autobiographical retrieval. These types of investigations could enrich our understanding of the links between emotion and autobiographical memory, and they could provide insight into the ways in which our current emotions and goals can influence the way in which our personal past is remembered.

As we noted at the outset of this review, autobiographical memory represents the intersection between memory, self, and social processes. The integration of behavioral and neuroimaging methods has provided important insights into the nature of this intersection, but as we have highlighted here, there is still much to be learned about the interrelation among these different types of processes. We believe this area of research will continue to be a fruitful and important one, revealing key insights into how memories for our past can sculpt, and be sculpted by, our internal motivations and affective responses. 


\section{Acknowledgments}

Preparation of this manuscript was supported by a National Defense Science and Engineering Graduate fellowship (to A.C.H.), by NIH grant MH080833 (to E.A.K.) and by the Searle Scholars program (to E.A.K.). We thank Donna Rose Addis, Lisa Feldman Barrett, Hiram Brownell, Angela Gutchess, Keely Muscatell, Jessica Payne, and Maya Tamir for helpful discussions about the connections between autobiographical memory, self-referential processing, and emotional experience.

\section{References}

Addis DR, Moscovitch M, Crawley AP, McAndrews MP. Recollective qualities modulate hippocampal activation during autobiographical memory retrieval. Hippocampus 2004;14:752-762. [PubMed: 15318333]

Addis DR, Wong AT, Schacter DL. Age-related changes in the episodic simulation of future events. Psychological Science 2008;19:33-41. [PubMed: 18181789]

Addis DR, McAndrews MP. Prefrontal and hippocampal contributions to the generation and binding of semantic associations during successful encoding. Neuroimage 2006;33:1194-1206. [PubMed: 17023179]

Amaral, DG.; Price, JL.; Pitkanen, A.; Carmichael, ST. The Amygdala: Neurobiological Aspects of Emotion, Memory, and Mental Dysfunction. Aggleton, JP., editor. Wiley-Liss; New York: 1992. p. $1-66$.

Anderson D, Shimizu H. Factors shaping vividness of memory episodes: Visitors' long-term memories of the 1970 Japan World Exposition. Memory 2007;15:177-191. [PubMed: 17534111]

*. Anderson AK, Yamaguchi Y, Grabski W, Lacka D. Emotional memories are not all created equal: evidence for selective memory enhancement. Learning and Memory 2006;13:711-718. [PubMed: 17101871]

Areni C, Burger M. Memories of "bad" days are more biased than memories of "good" days: Past Saturdays vary, but past Mondays are always blue. Journal of Applied Social Psychology 2008;38:1395-1415.

Atapattu R, Kensinger EA. Valence and arousal influence the encoding of emotional experiences. Society for Neuroscience Abstracts. 2009

Atienza M, Cantero JL. Modulatory effects of emotion and sleep on recollection and familiarity. Journal of Sleep Research 2008;17(3):285-294. [PubMed: 18503512]

Baddeley, A. What is autobiographical memory? In: Conway, MA.; Rubin, DC.; Spinnler, H.; Wagenaar, WA., editors. Theoretical Perspectives on Autobiographical Memory (Boston). 1992. p. 13-29.

Badre D, Wagner AD. Semantic retrieval, mnemonic control, and prefrontal cortex. Behavioral and Cogntive Neuroscience Reviews 2002;1:206-218.

Bahrick LE, Parker JF, Fivush R, Levitt M. The effects of stress on young children's memory for a natural disaster. Journal of Experimental Psychology: Applied 1998;4:308-331.

Baker-Ward L, Eaton KL, Banks JB. Young Soccer Players' Reports of a Tournament Win or Loss: Different Emotions, Different Narratives. Journal of Cognition and Development 2005;6(4):507527.

Barclay CR, Wellman HM. Accuracies and inaccuracies in autobiographical memories. Journal of Memory and Language 1986;25:93-103.

Barry ES, Naus MJ, Rehm LP. Depression and implicit memory: Understanding mood congruent memory bias. Cognitive Therapy and Research 2004;28:387-414.

Barsalou, LW. The content and organization of autobiographical memories. In: Neisser, U.; Winograd, E., editors. Remembering Reconsidered: Ecological and Traditional Approaches to the Study of Memory (New York). 1988. p. 193-243**.

Bartlett, FC. Remembering: A study in experimental and social psychology. Cambridge, England: 1932.

Beck AT, Clark DA. Anxiety and depression: An information-processing perspective. Anxiety Research 1988;1:23-36*. 
Beck, AT. Cognitive therapy and the emotional disorders. International Universities Press; New York: 1976.

Bell, C. Memory for an early school report. In: Conway, MA.; Rubin, DC.; Spinnler, H.; Wagenaar, WA., editors. Theoretical Perspectives on Autobiographical Memory. Boston: 1992. p. 151-171.

Berkman, ET.; Lieberman, MD. Journal of Cognitive Neuroscience. Approaching the bad and avoiding the good: Lateral prefrontal cortical asymmetry distinguishes between action and valence. in press

*. Berntsen D, Rubin DC. Emotionally charged autobiographical memories across the life span: The recall of happy, sad, traumatic, and involuntary memories. Psychology and Aging 2002;17:636652. [PubMed: 12507360]

Berntsen D, Rubin DC. Emotion and vantage point in autobiographical memory. Cognition and Emotion 2006a;20:1193-1215.

Berntsen D, Rubin DC. Flashbulb memories and posttraumatic stress reactions across the life-span: Age-related effects of the German occupation of Denmark during WWII. Psychology and Aging 2006b;21:127-139. [PubMed: 16594798]

Berntsen D, Thomsen DK. Personal Memories for Remote Historical Events: Accuracy and Clarity of Flashbulb Memories Related to World War II. Journal of Experimental Psychology: General 2005;134(2):242-257. [PubMed: 15869348]

Berntsen D. Tunnel memories for autobiographical events: Central details are remembered more frequently from shocking than from happy experiences. Memory and Cognition 2002;20:10101020 .

Blackburne-Stover G, Belenky MF, GiUigan C. Moral development and reconstructive memory: Recalling a decision to terminate an unplanned pregnancy. DevelopmentalPsychology 1982;18:862-870.

Blaney PH. Affect and memory: A review. Psychological Bulletin 1986;99:229-246. [PubMed: 3515383]

Bless H, Clore GL, Schwarz N, Golisano V, Rabe C, Wolk M. Mood and the use of scripts: Does a happy mood really lead to mindlessness? Journal of Personality and Social Psychology 1996;71:665-679. [PubMed: 8888596]

Bluck S. Autobiographical memory: Exploring its functions in everyday life. Memory 2003;11:113123. [PubMed: 12820825]

Bluck S, Levine LJ. Reminiscence as autobiographical memory: A catalyst for reminiscence theory development. Ageing and Society 1998;18:185-208.

*. Bluck S, Alea N, Habermas T, Rubin DC. A tale of three functions: The self-reported uses of autobiographical memory. Social Cognition 2005;23:91-117.

Bohanek, JG.; Mennuti-Washburn, J.; Fivush, R.; Koss, M. Affect and coherence in women's narratives of sexual assault: Relations to psychological wellbeing. Poster presented at the meetings of the International Society for Traumatic Stress Studies; April; 2005.

Bohanek JG, Fivush R, Walker E. Memories of positive and negative emotional events. Applied Cognitive Psychology 2005;19:51-66.

Bohannon, JN.; Symons, VL. Flashbulb memories: Confidence, consistency, and quantity. In: Winograd, E.; Neisser, U., editors. Affect and accuracy in recall: Studies of "flashbulb" memories. Emory symposia in cognition. Vol. 4. New York, NY, US: Cambridge University Press; 1992. p. 65-91.

Bohannon JN. Flashbulb memories for the space shuttle disaster: A tale of two theories. Cognition 1988;29(2):179-196. [PubMed: 3168421]

Bohannon JN, Gratz S, Cross VS. The effects of affect and input source on flashbulb memories. Applied Cognitive Psychology 2007;21(8):1023-1036.

Bohn A, Berntsen D. Pleasantness bias in flashbulb memories: Positive and negative flashbulb memories of the fall of the Berlin Wall among East and West Germans. Memory and Cognition 2007;35:565-577.

***. Bower GH. Mood and memory. American Psychologist 1981;36:129-148. [PubMed: 7224324]

Bower GH, Monteiro KP, Gilligan SG. Emotional mood as a context for learning and recall. Journal of Verbal Learning and Verbal Behavior 1978;17(5):573-585. 
Bradley B, Mogg K, Galbraith M, Perrett A. Negative recall bias and neuroticism: State vs. trait effects. Behavioural Research and Therapy 1993;31:125-127.

Brainerd CJ, Stein LM, Silveira RA, Rohenkohl G, Reyna VF. Does negative emotion cause false memories? Psychological Science 2008;19:919-925**. [PubMed: 18947358]

Brewer, WF. What is recollective memory? In: Rubin, DC., editor. Remembering our past: Studies in autobiographical memory. New York: 1996. p. 19-66.

Brewin CR, Dalgleish T, Joseph S. A dual representation theory of post traumatic stress disorder. Psychological Review 1996;103:670-686. [PubMed: 8888651]

Brewin CR, Andrews B, Gotlib IH. Psychopathology and early experience: A reappraisal of retrospective reports. Psychological Bulletin 1993;113:82-98. [PubMed: 8426875]

Brewin CR, Reynolds M, Tata P. Autobiographical memory processes and the course of depression. Journal of Abnormal Psychology 1999;108:511-517. [PubMed: 10466275]

***. Brown R, Kulik J. Flashbulb memories. Cognition 1977;5:73-99.

Buchanan TW, Tranel D, Adolphs R. Memories for emotional autobiographical events following unilateral damage to medial temporal lobe. Brain 2006;129:115-127. [PubMed: 16291807]

**. Buchanan TW. Retrieval of emotional memories. Psychonomic Bulletin 2007;133:761-779.

*. Buchanan TW, Tranel D, Adolphs R. Emotional autobiographical memories in amnesic patients with medial temporal lobe damage. Journal of Neuroscience 2005;25(12):3151-3160. [PubMed: 15788772]

Buckner RL, Carroll DC. Self-projection and the brain. Trends in Cognitive Sciences 2007;11(2):4957. [PubMed: 17188554]

Buckner RL, Wheeler ME. The cognitive neuroscience of remembering. Nature Reviews Neuroscience 2001;2:624-634.

Buckner RL, Andrews-Hanna JR, Schacter DL. The brain's default network: anatomy, function, and relevance to disease. Annals of the New York Academy of Sciences 2008;1124:1-38. [PubMed: 18400922]

Budson AE, Todman RW, Chong H, Adams EH, Kensinger EA, Krandel TS, et al. False recognition of emotional word lists in aging and Alzheimer's disease. Cognitive and Behavioral Neurology 2006;19:71-78. [PubMed: 16783129]

Budson AE, Simons JS, Sullivan AL, Beier JS, Soloman PR, Scinto LF, et al. Memory and emotions for the September 11, 2001, terrorist attacks in patients with Alzheimer's disease, patients with mild cognitive impairment, and healthy older adults. Neuropsychology 2004;18:315-327. [PubMed: 15099154]

Budson AE, Simons JS, Waring JD, Sullivan AL, Hussoin T, Schacter DL. Memory for the September 11, 2001, terrorist attacks one year later in patients with Alzheimer's disease, patients with mild cognitive impairment, and healthy older adults. Cortex 2007;43:875-888. [PubMed: 17941346]

Burt CDB, Kemp S, Conway MA. Themes, events and episodes in autobiographical memory. Memory and Cognition 2003;31:317-325.

Burt DB, Zembar MJ, Niederehe G. Depression and memory impairment: A meta-analysis of the association, its pattern, and specificity. Psychological Bulletin 1995;117:285-305. [PubMed: 7724692]

*. Cabeza R, St Jacques P. Functional neuroimaging of autobiographical memory. Trends in Cognitive Sciences 2007;11:219-227. [PubMed: 17382578]

Cabeza R, Prince SE, Daselaar SM, Greenberg D, Budde M, Dolcos F, LaBar KS, Rubin DC. Brain activity during episodic retrieval of autobiographical and laboratory events: An fMRI study using a novel photo paradigm. Journal of Cognitive Neuroscience 2004;9:1533-1594.

Cahill L, Prins B, Weber M, McGaugh JL. Beta-adrenergic activation and memory for emotional events. Nature 1994;371(6499):702-704. [PubMed: 7935815]

Candel I, Jelicic M, Merckelbach H, Wester A. Korsakoff patients' memories of September 11. The Journal of Nervous and Mental Disease 2003;191(4):262-265. [PubMed: 12695739]

Carstensen LL, Turk-Charles S. The salience of emotion across the adult life course. Psychology and Aging 1994;9:259-264. [PubMed: 8054174] 
Carstensen LL, Turk-Charles S. Emotion in the second half of life. Current Directions in Psychological Science 1998;7:144-149.

Carstensen LL, Isaacowitz DM, Charles ST. Taking time seriously: A theory of socioemotional selectivity. American Psychologist 1999;54:165-181. [PubMed: 10199217]

Christensen TC, Wood JV, Feldman Barrett L. Remembering everyday experience through the prism of self-esteem. Personality and Social Psychology Bulletin 2003;29(1):51-62. [PubMed: 15272959]

Christianson SA. Flashbulb memories: Special, but not so special. Memory and Cognition 1989;17:435-43.

Christianson SA. Emotional stress and eyewitness testimony: A critical review. Psychological Bulletin 1992;112:284-309. [PubMed: 1454896]

Christianson, S-A.; Safer, MA. Emotional events and emotions in autobiographical memories. In: Rubin, DC., editor. Remembering our past: Studies in autobiographical memory. New York: 1996. p. 218-234.

Christianson SA, Engelberg E. Memory and emotional consistency: The MS Estonia ferry disaster. Memory 1999;7(4):471-482.

Cimino C, Verfaellie M, Bowers D, Heilman KM. Autobiographical memory: influence of right hemisphere damage on emotionality and specificity. Brain and Cognition 1991;15:106-18. [PubMed: 2009169]

Clark DM, Teasdale JD. Diurnal variation in clinical depression and accessibility of memories of positive and negative experiences. Journal of Abnormal Psychology 1982;91:87-95. [PubMed: 7200102]

Clark, MS.; Isen, AM. Toward understanding the relationship between feeling states and social behavior. In: Hastorf, AH.; Isen, AM., editors. Cognitive social psychology. New York: 1982. p. 73-108.

Clore, GL.; Schnall, S. The Influences of Affect on Attitude. In: Albarracín, D.; Johnson, BT.; Zanna, MP., editors. Handbook of Attitudes and Attitude Change. Mahwah, NJ: Erlbaum; 2005.

Clore, GL.; Wyer, RS.; Dienes, B.; Gasper, K.; Gohm, C.; Isbell, L. Affective feelings as feedback: Some cognitive consequences. In: Martin, LL.; Clore, GL., editors. Theories of mood and cognition: A user's handbook. Mahwah, NJ: Erlbaum; 2001. p. 27-62.

*. Clore, GL.; Storbeck, J. Affect as information about liking, efficacy, and importance. In: Forgas, J., editor. Hearts and Minds: Affective influences on social cognition and behaviour. New York: Psychology Press; 2006. p. 123-142.

Cohen G, Conway MA, Maylor EA. Flashbulb memories in older adults. Psychology and Aging 1994;9(3):454-463. [PubMed: 7999330]

Colgrove FW. Individual memories. American Journal of Psychology 1899;10:228-255.

Comblain C, D'Argembeau A, Van der Linden M. Phenomenal characteristics of autobiographical memories for emotional and neutral events in older and younger adults. Experimental Aging Research 2005;31(2):173-189. [PubMed: 15981795]

Conway ARA, Skitka LJ, Hemmerich JA, Kershaw TC. Flashbulb memory for 11 September 2001. Applied Cognitive Psychology 2009;23(5):605-623.

**. Conway MA, Pleydell-Pearce CW. The construction of autobiographical memories in the selfmemory system. Psychological Review 2000;107:261-288. [PubMed: 10789197]

***. Conway, MA.; Rubin, DC. The structure of autobiographical memory. In: Collins, AF.; Gathercole, SE.; Conway, MA.; Morris, PE., editors. Theories of memory. Hillsdale, NJ: Erlbaum; 1993. p. 103-139.

**. Conway MA. Memory and the self. Journal of Memory and Language 2005;53:594-628.

Conway, MA. Autobiographical memory: An introduction. Open University Press; Maidenhead, BRK, England: 1990.

*. Conway, MA. Autobiographical knowledge and autobiographical memories. In: Rubin, DC., editor. Remembering our past: Studies in autobiographical memory. New York: 1996. p. 67-93.

Conway MA, Anderson SJ, Larsen SF, Donnelly CM, McDaniel MA, McClelland AG, Rawles RE, Logie RH. The formation of flashbulb memories. Memory and Cognition 1994;22(3):326-343. 
Corson Y, Verrier N. Emotions and false memory: Valence or arousal? Psychological Science 2007;18:208-211. [PubMed: 17444912]

Costa PT, McCrae RR. Influence of extraversion and neuroticism on subjective well-being: Happy and unhappy people. Journal of Personality and Social Psychology 1980;38:668-678. [PubMed: 7381680]

Crombag HFM, Wagennar WA, van Koppen PJ. Crashing memories and the problem of "source monitoring". Applied Cognitive Psychology 1996;10:95-104.

Crovitz HF, Schiffman H. Frequency of episodic memories as a function of their age. Bulletin of the Psychonomic Society 1974;7:61-62.

Cubelli R, Della Sala S. Flashbulb memories: special but not iconic. Cortex 2008;44(7):908-909. [PubMed: 18423432]

Curci A, Lanciano T. Features of autobiographical memory: theoretical and empirical issues in the measurement of flashbulb memory. Journal of General Psychology 2009;136(2):129-150. [PubMed: 19350832]

Curci A, Luminet O, Finkenauer C, Gisle L. Flashbulb memories in social groups: A comparative testretest study of the memory of French President Mitterrand's death in a French and a Belgian group. Memory 2001;9(2):81-101. [PubMed: 11338939]

Curci A, Luminet O. Follow-up of a cross-national comparison on flashbulb and event memory for the September $11^{\text {th }}$ attacks. Memory 2006;14(2006):329-344. [PubMed: 16574589]

D'Argembeau A, Comblain C, Van Der Linden M. Phenomenal characteristics of autobiographical memories for positive, negative, and neutral events. Applied Cognitive Psychology 2003;17:281294.

Dalgleish T, Watts FN. Biases of attention and memory in disorders of anxiety and depression. Clinical Psychology Review 1990;10(5):589-604.

Dalgleish T, Spinks H, Yiend J, Kuyken W. Autobiographical memory style in seasonal affective disorder and its relationship to future symptom remission. Journal of Abnormal Psychology 2001;110:335-340. [PubMed: 11358027]

Dalgleish T, Rolfe J, Golden A, Dunn BD, Barnard PJ. Reduced autobiographical memory specificity and posttraumatic stress: Exploring the contributions of impaired executive control and affect regulation. Journal of Abnormal Psychology 2008;117:236-241. [PubMed: 18266501]

Dalgleish T, Tchanturia K, Serpell L, Hems S, Yiend J, De Silva P, et al. Self-reported parental abuse relates to autobiographical memory style in patients with eating disorders. Emotion 2003;3:211222. [PubMed: 14498792]

Damasio AR, Grabowski TJ, Bechara A, Damasio H, Ponto LL, Parvizi J, Hichwa RD. Subcortical and cortical brain activity during the feeling of self-generated emotions. Nature Neuroscience 2000;3:1049-1056.

*. Daselaar SM, Rice HJ, Greenberg DL, Cabeza R, LaBar KS, Rubin DC. The spatiotemporal dynamics of autobiographical memory: Neural correlates of recall, emotional intensity, and reliving. Cerebral Cortex 2008;18(1):217-229. [PubMed: 17548799]

Davidson PSR, Glisky EL. Is flashbulb memory a special instance of source memory? Evidence from older adults. Memory 2002;10(2):99-111. [PubMed: 11798440]

Davidson PSR, Cook SP, Glisky EL. Flashbulb Memories for September 11th can be Preserved in Older Adults, Aging. Neuropsychology, and Cognition 2006;13(2):196-206.

Davidson RJ. Anterior cerebral asymmetry and the nature of emotion. Brain and Cognition 1992;20(1):125-151. [PubMed: 1389117]

Deldin PJ, Deveney CM, Kim AS, Casas BR, Best JL. A slow wave investigation of working memory biases in mood disorders. Journal of Abnormal Psychology 2001;110:267-281. [PubMed: 11358021]

Demaree HA, Everhart E, Youngstrom EA, Harrison DW. Brain lateralization of emotion processing: Historical roots and a future incorporating "dominance". Behavioral and Cognitive Neuroscience Reviews 2005;4:3-20. [PubMed: 15886400]

Dijkstra K, Kaschak MP, Zwaan RA. Body posture facilitates retrieval of autobiographical memories. Cognition 2007;102:139-149. [PubMed: 16472550] 
*. Dolcos F, Denkova E. Neural Correlates of Encoding Emotional Memories: A Review of Functional Neuroimaging Evidence. Cell Science Reviews 2008;5(2):78-122.

Dolcos F, LaBar KS, Cabeza R. Interaction between the amygdala and the medial temporal lobe memory system predicts better memory for emotional events. Neuron 2004;42(5):855-863. [PubMed: 15182723]

*. Dolcos F, LaBar KS, Cabeza R. Remembering one year later: role of the amygdala and the medial temporal lobe memory system in retrieving emotional memories. Proceedings of the National Academy of Sciences, USA 2005;102:2626-2631.

Dougal S, Rotello CM. "Remembering" emotional words is based on response bias, not recollection. Psychonomic Bulletin and Review 2007;14:423-429. [PubMed: 17874582]

Dougal S, Phelps EA, Davachi L. The role of medial temporal lobe in item recognition and source recollection of emotional stimuli. Cognitive, Affective, and Behavioral Neuroscience 2007;7(3): 233-242.

Dreben EK, Fiske ST, Hastie R. The independence of evaluative and item information: Impression and recall order effects in behavior-based impression formation. Journal of Personality and Social Psychology 1979;37(10):1758-1768.

Dudai Y, Carruthers M. The Janus face of mnemosyne. Nature 2005;434:823-824.

**. Easterbrook JA. The effects of emotion on cue utilization and the organization of behavior. Psychological Review 1959;66:183-201. [PubMed: 13658305]

Edery-Halpern G, Nachson I. Distinctiveness in flashbulb memory: Comparative analysis of five terrorist attacks. Memory 2004;12(2):147-157. [PubMed: 15250180]

Eich E, Macaulay D. Are real moods required to reveal mood-congruent and mood-dependent memory? Psychological Science 2000;11:244-248. [PubMed: 11273411]

Eich E, Macaulay D, Ryan L. Mood dependent memory for events of the personal past. Journal of Experimental Psychology: General 1994;123:201-215. [PubMed: 8014613]

Er N. A new flashbulb memory model applied to the Marmara earthquake. Applied Cognitive Psychology 2003;17(5):503-517.

Erber R, Wegner DM, Therriault N. On being cool and collected: Mood regulation in anticipation of social interaction. Journal of Personality and Social Psychology 1996;70:757-766. [PubMed: 8636896]

Erskine JAK, Kvavilashvili L, Conway MA, Myers L. The effects of age on psychopathology, wellbeing and repressive coping. Aging and Mental Health 2007;11(4):394-404. [PubMed: 17612803]

*. Feldman Barrett L, Russell JA. The structure of current affect: Controversies and emerging consensus. Current Directions in Psychological Science 1999;8:10-14.

Feldman Barrett L. The relationships among momentary emotion experiences, personality descriptions, and retrospective ratings of emotion. Personality and Social Psychology Bulletin 1997;23(10):1100-1110.

Feldman Barrett L, Robin L, Pietromonaco PR, Eyssell KM. Are women the "more emotional" sex? Evidence from emotional experiences in social context. Cognition and Emotion 1998;12(4):555578.

Fernandes M, Ross M, Wiegand M, Schryer E. Are the memories of older adults positively biased? Psychology and Aging 2008;23(2):297-306. [PubMed: 18573004]

Fiedler, K. Affective states trigger processes of assimilation and accommodation. In: Martin, LL.; Clore, GL., editors. Theories of mood and cognition: A user's guidebook. Mahwah, NJ, US: Lawrence Erlbaum Associates Publishers; 2001. p. 85-98.

**. Fink GR, Markowitsch HJ, Reinkemeier M. Cerebral representation of one's own past: Neural networks involved in autobiographical memory. The Journal of Neuroscience 1996;16(13):42754282. [PubMed: 8753888]

Finkenauer, C.; Gisle, L.; Luminet, O. When collective memories are socially shaped: Flashbulb memories of socio-political events. In: Pennebaker, JW.; Paez, D.; Rimé, B., editors. Collective memories of political events: Social and psychological perspectives. Hillsdale, NJ: Erlbaum; 1997. p. 191-208. 
Fitzgerald, JM. Intersecting meanings of reminiscence in adult development and aging. In: Rubin, DC., editor. Remembering our past: Studies in autobiographical memory. New York: 1996. p. 360-383.

Fivush, R.; Reese, E. The social construction of autobiographical memory. In: Conway, MA.; Rubin, DC.; Spinnler, H.; Wagenaar, WA., editors. Theoretical Perspectives on Autobiographical Memory. Boston: 1992. p. 115-132.

Fivush, R.; Bohanek, JG.; Marin, K.; Sales, JM. Emotional memory and memory for emotions. In: Luminet, O.; Curci, A.; Conway, M., editors. Flashbulb memories: New issues and new perspectives. 2008.

Fivush, R.; Haden, C.; Reese, E. Remembering, recounting, and reminiscing: The development of autobiographical memory in social context. In: Rubin, DC., editor. Remembering our past: Studies in autobiographical memory. New York: 1996. p. 341-359.

Fivush R, Sales JD, Goldberg A, Bahrick L, Parker J. Weathering the storm: Children's long-term recall of Hurricane Andrew. Memory 2004;12:104-118. [PubMed: 15098624]

Fletcher PC, Dolan RJ. Right prefrontal cortex responds to item familiarity during a memory encoding task. Memory Special Issue: Neuroimaging and Memory 1999;7(5-6):703-713.

Fogarty SL, Hemsley DR. Depression and the accessibility of memories. British Journal of Psychiatry 1983;142:232-237. [PubMed: 6860876]

*. Forgas JP. Mood and judgment: The affect infusion model (AIM). Psychological Bulletin 1995;117:39-66. [PubMed: 7870863]

Frattaroli J. Experimental disclosure and its moderators: A meta-analysis. Psychological bulletin 2006;132:823-865. [PubMed: 17073523]

Fredrickson BL, Kahneman D. Duration neglect in retrospective evaluations of affective episodes. Journal of Personality and Social Psychology 1993;65(1):45-55. [PubMed: 8355141]

*. Fredrickson BL. Extracting meaning from past affective experiences: The importance of peaks, ends, and specific emotions. Cognition and Emotion: Special Issue: Emotion, cognition, and decision making 2000;14(4):577-606.

Freud, S. Screen memories. In: Strachey, J., editor. Sigmund Freud: Collected papers. London: 1899/1953. p. 47-69.

Frijda, NH.; Ortony, A.; Sonnemans, J.; Clore, GL. The complexity of intensity: Issues concerning the structure of emotion intensity. In: Clark, M., editor. Emotion: Review of Personality and Social Psychology. Vol. 13. Newbury Park, CA: Sage; 1992.

Galton F. Psychometric experiments. Brain 1879;2:149-162.

García-Larrea L, Cézanne-Ber G. P3, slow wave and working memory load: A study on the functional correlates of slow wave activity. Electroencephalography and clinical neurophysiology 1998;108:260-273. [PubMed: 9607515]

Gilboa A. Autobiographical and episodic memory-one and the same? Evidence from prefrontal activation in neuroimaging studies. Neuropsychologia 2004;42(10):1336-1349. [PubMed: 15193941]

Gilboa A, Winocur G, Grady CL, Hevenor SJ, Moscovitch M. Remembering our past: Functional neuroanatomy of recollection of recent and very remote personal events. Cerebral Cortex 2004;14:1214-1225. [PubMed: 15166099]

Gold, PE. Modulation of memory processing: Enhancement of memory in rodents and humans. In: Butters, N.; Squire, LR., editors. Neuropsychology of memory. Guilford Press; New York: 1992. p. $402-414$.

Greenberg DL. President Bush's false 'flashbulb' memory of 9/11/01. Applied Cognitive Psychology 2004;18:363-370.

Greenberg DL, Rice HJ, Cooper JJ, Cabeza R, Rubin DC, LaBar KS. Coactivation of the amygdala, hippocampus, and inferior frontal gyrus during autobiographical memory retrieval. Neuropsychologia 2005;43:659-674. [PubMed: 15721179]

**. Greenwald AG. The totalitarian ego: Fabrication and revision of personal history. American Psychologist 1980;35:603-618.

Gross J. The emerging field of emotion regulation: An integrative review. Review of General Psychology 1998;2:271-299. 
Gusnard DA, Raichle ME. Searching for a baseline: functional imaging and the resting human brain. Nature Reviews Neuroscience 2001;2:685-694.

Habermas T, Bluck S. Getting a life: The emergence of the life story in adolescence. Psychological Bulletin 2000;126:748-769. [PubMed: 10989622]

Hamann S. Cognitive and neural mechanisms of emotional memory. Trands in Cognitive Sciences 2001;5(9):394-400.

Hamann S. Towards understanding emotion's effects on memory. Emotion Review 2009;1(2):114115.

Hardin, C.; Banaji, MR. Affective intensity and valence in memory. Paper presented at the meeting of the American Psychological Association; Boston, MA. 1990.

Hasher L, Rose KC, Zacks RT, Sanft H, Doren B. Mood, recall, and selectivity in normal college students. Journal of Experimental Psychology: General 1985;114:104-118. [PubMed: 3156943]

Hassabis D, Kumaran D, Maguire EA. Using imagination to understand the neural basis of episodic memory. Journal of Neuroscience 2007;26:14365-14374. [PubMed: 18160644]

Hertel, PT. Memory for emotional and nonemotional events in depression: A question of habit?. In: Hertel, PT.; Reisberg, D., editors. Memory and Emotion. Oxford, England: 2004. p. 182-216.

Heuer, F.; Reisberg, D. The memory effects of emotion, stress and trauma. In: Ross, D.; Toglia, M.; Lindsay, R.; Read, D., editors. Handbook of Eyewitness Psychology: Volume 1 - Memory for Events. Mahwah, NJ: Erlbaum Associates; 2007. p. 81-116.

Hirst W, Phelps EA, Buckner RL, Budson AE, Cuc A, et al. Long-term memory for the terrorist attack of September 11: Flashbulb memories, event memories, and the factors that influence their retention. Journal of Experimental Psychology: General 2009;138(2):161-176. [PubMed: 19397377]

Holland, AC.; Tamir, M.; Kensinger, EA. Emotion regulation's influence on the content of autobiographical memory. Manuscript submitted for publication

Horn DB. Confounding the effects of delay and interference on memory distortions: Commentary on Schmolck, Buffalo, and Squire. Psychological Science 2001;12:180-181. [PubMed: 11340930]

Hornstein SL, Brown AS, Mulligan NW. Long-term flashbulb memory for learning of Princess Diana's death. Memory 2003;11(3):293-306. [PubMed: 12908677]

Hu P, Stylos-Allan M, Walker M. Sleep facilitates consolidation of emotional declarative memory. Psychological Science 2006;17:891-898. [PubMed: 17100790]

Isen, AM. Toward understanding the role of affect in cognition. In: Wyer, RS.; Srull, TK., editors. Handbook of social cognition. Erlbaum; Hillsdale NJ: 1984. p. 179-236.

Isen AM. Asymmetry of happiness and sadness in effects on memory in normal college students: Comment on Hasher, Rose, Zacks, Sanft, and Doren. Journal of Experimental Psychology: General 1985; 114:388-391.

Isen, AM. Positive affect, cognitive processes, and social behavior. In: Berkowitz, L., editor. Advances in Experimental Social Psychology. New York: 1987. p. 203-253.

**. Isen AM, Shalker TE, Clark M, Karp L. Affect, accessibility of material in memory, and behavior: A cognitive loop? Journal of Personality and Social Psychology 1978;36(1):1-12. [PubMed: 621625]

Johnson MK, Raye CL. Reality monitoring. Psychological Review 1981;88:67-85.

Johnson MK, Kim JK, Risse G. Do alcoholic Korsakoff's syndrome patients acquire affective reactions? Journal of Experimental Psychology: Learning, Memory, and Cognition 1985;11(1): 22-36.

Joorman J, Siemer M. Memory accessibility, mood regulation, and dysphoria: Difficulties in repairing sad mood with happy memories? Journal of Abnormal Psychology 2004;113:179-188. [PubMed: 15122938]

Josephson BR, Singer JA, Salovey P. Mood regulation and memory: Repairing sad moods with happy memories. Cognition and Emotion 1996;10:437-444.

Kahn I, Davachi L, Wagner AD. Functional-neuroanatomic correlates of recollection: implications for models of recognition memory. Journal of Neuroscience 2004;24:4172-4180. [PubMed: 15115812] 
Kahneman D, Fredrickson BL, Schreiber CA, Redelmeier DA. When more pain is preferred to less: Adding a better end. Psychological Science 1993;4(6):401-405.

Karney BR, Coombs RH. Memory bias in long-term close relationships: Consistency or improvement? Personality and Socail Psychology Bulletin 2000;26(8):959-970.

Kelley WM, Macrae CN, Wyland CL, Caglar S, Inati S, Heatherton TF. Finding the Self? An EventRelated fMRI Study. Journal of Cognitive Neuroscience 2002;14(5):785-794. [PubMed: 12167262]

Kennedy Q, Mather M, Carstensen LL. The role of motivation in the age-related positivity effect in autobiographical memory. Psychological Science 2004;15(3):208-214. [PubMed: 15016294]

Kensinger EA, Schacter DL. Emotional content and reality-monitoring ability: fMRI evidence for the influences of encoding processes. Neuropsychologia 2005;43(10):1429-1443. [PubMed: 15989934]

Kensinger EA, Schacter DL. Reality monitoring and memory distortion: Effects of negative, arousing content. Memory and Cognition 2006a;34:251-260.

Kensinger EA, Schacter DL. When the Red Sox shocked the Yankees: Comparing negative and positive memories. Psychonomic Bulletin and Review 2006b;13:757-763. [PubMed: 17328369]

Kensinger EA, Schacter DL. Remembering the specific visual details of presented objects: Neuroimaging evidence for effects of emotion. Neuropsychologia 2007;45:2951-2962. [PubMed: 17631361]

Kensinger EA, Leclerc CM. Age-related changes in the neural mechanisms supporting emotion processing and emotional memory. European Journal of Cognitive Psychology 2009;21(2-3): 192-215.

Kensinger EA, Corkin S. Two routes to emotional memory: Distinct neural processes for valence and arousal. Proceedings of the National Academy of Sciences, USA 2004;101:3310-3315.

Kensinger, EA.; Corkin, S. Amnesia: Point and Counterpoint. In: Menzel, R.; Byrne, J., editors. Learning Theory and Behavior, Vol. 1 of Learning and Memory - A Comprehensive Reference. Vol. 4. Oxford: Elsevier Press; 2008. p. 259-286.

Kensinger EA. Remembering emotional experiences: The contribution of valence and arousal. Reviews in the Neurosciences 2004;15:241-251. [PubMed: 15526549]

*. Kensinger EA. Remembering the details: Effects of emotion. Emotion Review. 2009a;1:99-113.

Kensinger EA. What factors need to be considered to understand emotional memories? Emotion Review 2009b;1:116-118.

Kensinger EA, Krendl AC, Corkin S. Memories of an emotional and a nonemotional event: Effects of aging and delay interval. Experimental Aging Research 2006;32(1):23-45. [PubMed: 16293567]

Kershaw, TC.; Hemmerich, JA.; Ahmed, S. Flashbulb Memory for September 11 and the Columbia Space Shuttle Disaster. In: Kelley, MR., editor. Applied Memory. Nova Science Publishers, Inc; 2009. p. 129-146.

Kiefer M, Schuch S, Schenck W, Fiedler K. Mood states modulate activity in semantic brain areas during emotional word encoding. Cerebral Cortex 2007;17:1516-1530. [PubMed: 16926240]

Kihlstrom, JF. Trauma and memory revisited. In: Uttl, B.; Ohta, N.; Siegenthaler, AL., editors. Memory and emotions: Interdisciplinary perspectives. New York: Blackwell; 2006.

Klaassen T, Riedel WJ, Deutz NEP, Van Praag HM. Mood congruent memory bias induced by tryptophan depletion. Psychological Medicine 2002;32:167-172. [PubMed: 11885569]

Kleinsmith LJ, Kaplan S. Paired-associate learning as a function of arousal and interpolated interval. Journal of Exprimental Psychology 1963;65:190-193.

Koenig S, Mecklinger A. Elextrophysiological correlates of encoding and retrieving emotional events. Emotion 2008;8(2):162-173. [PubMed: 18410190]

Köhler S, McIntosh AR, Moscovitch M, Winocur G. Functional interactions between the medial temporal lobes and posterior neocortex related to episodic memory retrieval. Cerebral Cortex 1998;8:451-461. [PubMed: 9722088]

Koo M, Oishi S. False memories and the associative network of happiness. Personality and Social Psychology Bulletin 2009;35(2):212-220. [PubMed: 19141625] 
Koole SL. The psychology of emotion regulation: An integrative review. Cognition and Emotion 2009;23:4-41.

Krackow E, Lynn SJ, Payne DG. The death of Princess Diana: The effects of memory enhancement procedures on flashbulb memories, Imagination. Cognition and Personality 2005;25(3):197-219.

Kross E, Davidson M, Weber J, Ochsner K. Coping with emotions past: The neural bases of regulating affect associated with negative autobiographical memories. Biological Psychiatry 2009;65:361366. [PubMed: 19058792]

Kutas M, Hillyard SA. Event-related brain potentials to semantically inappropriate and surprisingly large words. Biological Psychology 1980;11:99-116. [PubMed: 7272388]

Kuyken W, Brewin CR. Autobiographical memory functioning in depression and reports of early abuse. Journal of Abnormal Psychology 1995;104:585-591. [PubMed: 8530760]

Kvavilashvili L, Mirani J, Schlagman S, Kornbrot DE. Comparing flashbulb memories of September 11 and the death of Princess Diana: effects of time delays and nationality. Applied Cognitive Psychology 2003;17:1017-1031.

Kvavilashvili L, Mirani J, Schlagman S, Foley K, Kornbrot DE. Consistency of flashbulb memories of September 11 over long delays: Implications of consolodation and wrong time slice hypotheses. Journal of Memory and Language. 2009 in press.

**. LaBar KS, Cabeza R. Cognitive neuroscience of emotional memory. Nature Reviews Neuroscience 2006;7(1):54-64.

LaBar KS. Co-activation of the amygdala, hippocampus and inferior frontal gyrus during autobiographical memory retrieval. Neuropsychologia 2005;43:659-674. [PubMed: 15721179]

LaBar KS, Phelps EA. Arousal-mediated memory consolidation: Role of the medial temporal lobe in humans. Psychological Science 1998;9:490-493.

Lamogne C, Piolino P, Friszer S, Claret A, Girault N, Jouvent R, Allilaire J-F, Fossati P. Episodic autobiographical memory in depression: Specificity, autonoetic consciousness, and selfperspective. Consciousness and Cognition 2006;15:258-268. [PubMed: 16154765]

Larsen SF, Conway MA. Reconstructing dates of true and false autobiographical memories. European Journal of Cognitive Psychology 1997;9:259-272.

Larsen, SF. Personal context in autobiographical and narrative memories. In: Conway, MA.; Rubin, DC.; Spinnler, H.; Wagenaar, WA., editors. Theoretical Perspectives on Autobiographical Memory. Boston: 1992. p. 53-71.

Larsen CL, Steuer EL. Motivational Relevance as a Potential Modulator of Memory for Affective Stimuli: Can We Compare Snakes and Cakes? Emotion Review 2009;1(2):116-117.

LeDoux JE. Emotion circuits in the brain. Annual Review of Neuroscience 2000;23:155-184.

LeDoux JE. The amygdala. Current Biology 2007;17(20):R868-874. [PubMed: 17956742]

*. LeDoux, JE. The emotional brain: The mysterious underpinnings of emotional life. London: Simon and Schuster; 1996.

Lee PJ, Brown NR. Delay related changes in personal memories for September 11, 2001. Applied Cognitive Psychology 2003;17(9):1007-1015.

**. Levine LJ, Pizarro DA. Emotion and memory research: A grumpy overview. Social Cognition 2004;22:530-554.

Levine LJ, Safer MA. Sources of bias in memory for emotions. Current Directions in Psychological Science 2002;11:169-173.

Levine LJ, Bluck S. Painting with broad strokes: Happiness and the malleability of event memory. Cognition and Emotion 2004;18:559-574.

*. Levine LJ, Edelstein RS. Emotion and memory narrowing: A review and goal-relavance approach. Cognition and Emotion 2009;23(5):833-875.

Levine LJ, Bluck S. Experienced and remembered emotional intensity in older adults. Psychology and Aging 1997;12(3):514-523. [PubMed: 9308098]

Levine LJ. Reconstructing memory for emotions. Journal of Experimental Psychology: General 1997;126:165-177. 
**. Levine, LJ.; Safer, MA.; Lench, HC. Remembering and misremembering emotions. In: Sanna, LJ.; Chang, EC., editors. Judgments Over Time: The Interplay of Thoughts, Feelings, and Behaviors. Oxford University Press; New York: 2006. p. 271-290.

Levine LJ, Prohaska V, Burgess SL, Rice JA, Laulhere TM. Remembering past emotions: The role of current appraisals. Cognition and Emotion 2001;15:393-417.

Levy EA, Mineka S. Anxiety and mood-congruent autobiographical memory: A conceptual failure to replicate. Cognition and Emotion 1998;12:625-634.

Lewis PA, Critchley HD. Mood-dependent memory. Trends in Cognitive Sciences 2003;7:431-433. [PubMed: 14550485]

Lewis PA, Critchley HD, Smith AP, Dolan RJ. Brain mechanisms for mood congruent memory facilitation. NeuroImage 2005;25:1214-1223. [PubMed: 15850739]

Liotti, M.; Tucker, DM. Emotion in asymmetric corticolimbic networks. In: Davidson, RJ.; Hugdahl, K., editors. Brain asymmetry. MIT Press; Cambridge, MA: 1995. p. 389-423.

Lloyd GG, Lishman WA. Effect of depression on the speed of recall of pleasant and unpleasant experiences. Psychological Medicine 1975;5:173-180. [PubMed: 1161955]

Luminet O, Antonietta C, Marsh EJ, Wessel I, Constantin T, Gencoz F, Yogo M. The cognitive emotional, and social impacts of the September 11 attacks: Group differences in memory for the reception context and the determinants of flashbulb memory. Journal of General Psychology 2004;131(3):197-224. [PubMed: 15248591]

Lyubomirsky S, Caldwell ND, Nolen-Hoeksema S. Effects of ruminative and distracting responses to depressed mood on retrieval of autobiographical memories. Journal of Personality and Social Psychology 1998;75:166-177. [PubMed: 9686457]

Maccallum F, McConkey KM, Bryant RA, Barnier AJ. Specific autobiographical memory following hypnotically induced mood state. Clinical and Experimental Hypnosis 2000;48:361-373. [PubMed: 11011497]

Macrae CN, Moran JM, Heatherton TF, Banfield JF, Kelley WM. Medial prefrontal activity predicts memory for self. Cerebral Cortex 2004;14:647-654. [PubMed: 15084488]

MacLeod AK, Anderson A, Davies A. Self-ratings of positive and negative affect and retrieval of positive and negative affect memories. Cognition and Emotion 1994;8:483-488.

Madigan RJ, Bollenbach AK. Effects of induced mood on retrieval of personal episodic and semantic memories. Psychological Reports 1982;50:147-157.

*. Maguire EA. Neuroimaging studies of autobiographical event memory, Philosophical Transactions of the Royal Society of London. Series B. Biological Sciences 2001;356:1441-1451. [PubMed: 11571035]

Maguire EA, Mummery CJ, Buchel C. Patterns of hippocampal-cortical interaction dissociate temporal lobe memory subsystems. Hippocampus 2000;10:475-482. [PubMed: 10985287]

Mandler, JM. Stories, scripts, and scenes: Aspects of schema theory. Hillsdale, NJ: Lawrence Erlbaum; 1984.

Mar RA, Oatley K. The function of fiction is the abstraction and simulation of social experience. Perspectives on Psychological Science 2008;3(3):173-192.

Marchewka A, Jednoróg K, Nowicka A, Brechmann A, Grabowska A. Grey-matter differences related to true and false recognition of emotionally charged stimuli - a voxel based morphometry study. Neurobiology of Learning and Memory 2009;92(1):99-105. [PubMed: 19292997]

Markowitsch HJ, Thiel A, Reinkemeier M, Kessler J, Koyuncu A, Heiss WD. Right amygdalar and temporofrontal activation during autobiographic, but not during fictitious memory retrieval. Behavioral Neuroscience 2000;12:181-190.

Markowitsch HJ, Vandekerckhove MM, Lanfermann H, Russ MO. Engagement of lateral and medial prefrontal areas in the ecphory of sad and happy autobiographical memories. Cortex 39:643-665. [PubMed: 14584547]

Mason MF, Norton MI, Van Horn JD, Wegner DM, Grafton ST, Macrae CN. Wandering minds: the default network and stimulus-independent thought. Science 2007;315(5810):393-395. [PubMed: 17234951] 
Mather, M. Why memories may become more positive as people age. In: Uttl, B.; Ohta, N.; Siegenthaler, AL., editors. Memory and Emotion: Interdisciplinary Perspectives. Blackwell Publishing; 2006. p. 135-159.

Mather M, Sutherland M. Disentangling the effects of arousal and valence on memory for intrinsic details. Emotion Review 2009;1:118-119.

Mathews A, Bradley B. Mood and the self-reference bias in recall, Behavior. Research and Therapy 1983;21:233-239.

Matlin, M.; Stang, DJ. The pollyanna principle. Shenkman Publishing; Cambridge, MA: 1978.

Matt GE, Vazquez C, Campbell WK. Mood-congruent recall of affectively tones stimuli: A metaanalytic review. Clinical Psychology Review 1992;12:227-255.

Mayer JD, McCormick LJ, Strong SE. Mood-congruent memory and natural mood: New evidence. Personality and Social Psychology Bulletin 1995;21:736-746.

McAdams DP. Personality, modernity, and the storied self: A contemporary framework for studying persons. Psychological Inquiry 1996;7:295-321.

McAdams DP, Hoffman BJ, Mansfield ED, Day R. Themes of agency and communion in significant autobiographical scenes. Journal of Personality 1996;64:339-378.

McCloskey M, Wible CG, Cohen NJ. Is there a special flashbuld-memory mechanism? Journal of Experimental Psychology: General 1988;117(2):171-181.

McFarland C, Buehler R. The impact of negative affect on autobiographical memory: The role of selffocused attention to moods. Journal of Personality and Social Psychology 1998;75:1424-1440. [PubMed: 9914662]

McFarland C, Ross M, DeCourville N. Women's theories of menstruation and biases in recall of menstrual symptoms. Hournal of Personality and Social Psychology 1989;57(3):522-531.

*. McGaugh JL. The amygdala modulates the consolidation of memories of emotionally arousing experiences. Annual Review of Neuroscience 2004;27:1-28.

Metcalfe J, Jacobs WJ. A "hot-system/cool-system” view of memory under stress. PTSD Research Quarterly 1996;7:1-8.

Mickley Steinmetz KR, Kensinger EA. The effects of valence and arousal on the neural activity leading to subsequent memory. Psychophysiology 2009;46(6):1190-1199. [PubMed: 19674398]

Mickley KR, Kensinger EA. Emotional valence influences the neural correlates associated with remembering and knowing. Cognitive, Affective, and Behavioral Neuroscience 2008;8:143-152.

Mickley KR, Kensinger EA. Phenomenological characteristics of emotional memories in younger and older adults. Memory 2009;17(5):528-543. [PubMed: 19468956]

Miranda R, Kihlstrom JF. Mood congruence in childhood and recent autobiographical memory. Cognition and Emotion 2005;19:981-998.

Mitchell JP, Macrae CN, Banaji MR. Encoding-specific effects of social cognition on the neural correlates of subsequent memory. Journal of Neuroscience 2004;24:4912-4917. [PubMed: 15163682]

Mitchell TR, Thompson L, Peterson E, Cronk R. Temporal adjustments in the evaluation of events: The "rosy view". Journal of Experimental Social Psychology 1997;33(4):421-448. [PubMed: 9247371]

Montfort V, Pouthas V. Effects of working memory demands on frontal slow waves in time-interval reproduction tasks in humans. Neuroscience Letters 2003;343:195-199. [PubMed: 12770695]

Morse CK, Woodward EM, Zweigenhaft RL. Gender differences in flashbulb memories elicited by the Clarence Thomas hearings. The Journal of Social Psychology 1993;133(4):453-458. [PubMed: 8231123]

Moscovitch M, Nadel L. Consolidation and the hippocampal complex revisited: in defense of the multiple-trace model. Current Opinion in Neurobiology 1998;8:297-30. [PubMed: 9635217]

*. Moscovitch M, Rosenbaum RS, Gilboa A, Addis DR, Westmacott R, Grady C, McAndrews MP, Levine B, Black SE, Winocur G, Nadel L. Functional neuroanatomy of remote episodic, semantic and spatial memory: A unified account based on multiple trace theory. Journal of Anatomy 2005;207:35-66. [PubMed: 16011544] 
Mueller GE, Pilzecker A. Experimentelle Beitrage zur Lehre von Gedachtnis. Z Psychol 1900;1:1300.

Murray SL, Holmes JG. Seeing virtues in faults: Negativity and the transformation of interpersonal narratives in close relationships. Journal of Personality and Social Psychology 1993;65:707-722.

Muscatell KA, Addis DR, Kensinger EA. Self-involvement modulates the effective connectivity of the autobiographical memory network. Social, Cognitive, and Affective Neuroscience. in press.

Nachson I, Zelig A. Flashbulb and factual memories. The case of Rabin's assassination 2003;17(5): 519-531.

Nadel L, Moscovitch M. Memory consolidation, retrograde amnesia and the hippocampal complex. Current Opinion in Neurobiology 1997;7(2):217-227. [PubMed: 9142752]

Nader K, Schafe G, LeDoux JE. The labile nature of consolidation theory. Nature Neuroscience Reviews 2000;1(3):216-219.

Natale M, Hantas M. Effects of temporary mood states on selective memory about the self. Journal of Personality and Social Psychology 1982;42:927-934.

Neisser, U. Snapshots or benchmarks?. In: Neisser, U.; Hyman, IE., editors. Memory observed: Remembering in natural contexts. Worth Publishers; San Fancisco: 1982. p. 68-74.

Neisser, U.; Harsch, N. Phantom flashbulbs: false recollections of hearing the news about Challenger. In: Winograd, E.; Neisser, U., editors. Affect and accuracy in recall: Studies of 'flashbulb' memories. New York: Cambridge University Press; 1992. p. 9-31.

Neisser U, Winograd E, Bergman ET, Schreiber CA, Palmer SE, Weldon MS. Remembering the Earthquake: Direct experience vs. hearing the news. Memory 1996;4(4):337-357. [PubMed: 8817459]

Nelson K, Fivush R. The emergence of autobiographical memory: A social cultural developmental theory. Psychological Review 2004;111:486-511. [PubMed: 15065919]

NiedŸwieńska A. Metamemory knowledge and the accuracy of flashbulb memories. Memory 2004;12(5):603-613. [PubMed: 15615318]

Nigro G, Neisser U. Point of view in personal memories. Cognitive Psychology 1983;15:467-482.

Norris, FH.; Kaniasty, K. Journal of Traumatic Stress. Vol. 5. 1992. Reliability of delayed self-reports in disaster research; p. 575-588.

Nurhan E. A new flashbulb memory model applied to the Marmara earthquake. Applied Cognitive Psychology 2003;17(5):503-517.

Ochsner K, Gross JJ. Cognitive emotion regulation: Insights from social cognitive and affective neuroscience. Current Directions in Psychological Science 2008;17:153-158.

*. Ochsner KN, Gross JJ. The cognitive control of emotion. Trends in Cognitive Sciences 2005;9:242249. [PubMed: 15866151]

Ochsner KN, Ray RD, Cooper JC, Robertson ER, Chopra S, Gabrieli JDE, Gross JJ. For better or for worse: Neural systems supporting the cognitive down- and up-regulation of negative emotion. NeuroImage 2004;23:483-499. [PubMed: 15488398]

Onoda K, Okamoto Y, Yamawaki S. Neural correlates of associative memory: the effects of negative emotion. Neuroscience Research 2009;64(1):50-55. [PubMed: 19428683]

Ost J, Costall A. Misremembering Bartlett: A study in serial reproduction. British Journal of Psychology 2002;93(2):243-255. [PubMed: 12031150]

Otani H, Kusumi T, Kato K, Matsuda K, Kern RP, Widner R, Ohta N. Remembering a nuclear accident in Japan: Did it trigger flashbulb memories? Memory 2005;13(1):6-20. [PubMed: 15724904]

Otten LJ, Henson RNA, Rugg MD. State-related and item-related neural correlates of successful memory encoding. Nature Neuroscience 2002;5(12):1339-1344.

Paller KA, Wagner AD. Observing the transformation of experience into memory. Trends in Cognitive Science 2002;6(2):93-102.

Paller KA, Kutas M, Shimamura AP, Squire LR. Brain responses to concrete and abstract words reflect processes that correlate with later performance on a test of stem-completion priming. Electroencephalogr Clin Neurophysiol Suppl 1987;40:360-365. [PubMed: 3480147] 
Paradis CM, Solomon LZ, Florer F, Thompson T. Flashbulb memories of personal events of 9/11 and the day after for a sample of New York City residents. Psychological Reports 2004;95:304-310. [PubMed: 15460385]

Park J, Banaji MR. Mood and heuristics: The influence of happy and sad states on sensitivity and bias in stereotyping. Journal of Personality and Social Psychology 2000;78(6):1005-1023. [PubMed: 10870905]

Parrott WG, Sabini J. Mood and memory under natural conditions: Evidence for mood incongruent recall. Journal of Personality and Social Psychology 1990;59:321-336.

Pasupathi M. Emotion regulation during social remembering: Differences between emotions elicited during an event and emotions elicited when talking about it. Memory 2003;11:151-163. [PubMed: 12820828]

Payne JD, Swanberg K, Stickgold R, Kensinger EA. Sleep preferentially enhances memory for emotional components of scenes. Psychological Science 2008a;19:781-788. [PubMed: 18816285]

Payne, JD.; Ellenbogen, JM.; Walker, MP.; Stickgold, R. The role of sleep in memory consolidation. In: Byrne, JH., editor. Learning and Memory: A Comprehensive Reference. New York: Elsevier; 2008 b.

Pennebaker JW, Seagal JD. Forming a story: The health benefits of narrative. Journal of Clinical Psychology 1999;55(10):1243-1254. [PubMed: 11045774]

Pennebaker JW, Mayne TJ, Francis ME. Linguistic predictors of adaptive bereavement. Journal of Personality and Social Psychology 1997;72(4):863-871. [PubMed: 9108699]

Perrig WJ, Perrig P. Mood and memory: Mood-congruity effects in absence of mood. Memory and Cognition 1988;16:102-109.

Peterson C, Bell M. Children's memory for traumatic injury. Child Development 1996;67:3045-3070. [PubMed: 9071770]

Peterson C, Whalen N. Five years later: Children's memory for medical emergencies. Applied Cognitive Psychology 2001;15:17-24.

Pezdek K. Event memory and autobiographical memory for the events of September 11, 2001. Applied Cognitive Psychology 2003;17:1033-1045.

*. Phan KL, Wager T, Taylor SF, Liberzon I. Functional neuroanatomy of emotion: A meta-analysis of emotion activation studies in PET and fMRI. NeuroImage 2004;16:331-348. [PubMed: 12030820]

Phelps EA, LaBar KS, Spencer DD. Memory for emotional words following unilateral temporal lobectomy. Brain and Cognition 1997;35:85-109. [PubMed: 9339304]

*. Phelps EA, Sharot T. How (and why) emotion enhances the subjective sense of recollection. Current Directions in Psychological Science 2008;17:147-152.

Philippot P, Schaefer A, Herbette G. Schematic versus propositional processing of emotional information: Impact of generic versus specific autobiographical memory priming on emotion elicitation. Emotion 2003;3:270-283. [PubMed: 14498796]

*. Philippot, P.; Baeyens, C.; Douilliez, C.; Francart, B. Cognitive regulation of emotion: Application to clinical disorders. In: Philippot, P.; Feldman, RS., editors. The regulation of emotion. Lawrence Erlbaum Associates; New York: 2004. p. 71-98.

Piefke M, Weiss PH, Zilles K, Markowitsch HJ, Fink GR. Differential remoteness and emotional tone modulate the neural correlates of autobiographical memory. Brain 2003;126:650-668. [PubMed: 12566286]

Piguet O, Connally E, Krendl AC, Huot JR, Corkin S. False memory in aging: Effects of emotional valence on word recognition accuracy. Psychology and Aging 2008;23(2):307-314. [PubMed: 18573005]

Pillemer DB. Flashbulb memories of the assassination attempt on President Reagan. Cognition 1984;16:63-80. [PubMed: 6540649]

Pillemer DB. Directive functions of autobiographical memory: The guiding power of the specific episode. Memory 2003;11:193-202. [PubMed: 12820831] 
Pillemer DB, Goldsmith LR, Panter AT, White SH. Very long-term memories of the first year in college, Journal of Experimental Psychology: Learning. Memory, and Cognition 1988;14:709_ 715.

Pillemer DB, Rhinehart ED, White SH. Memories of life transitions: The first year in college. Human Learning 1986;5:109-123.

Pillemer DB, Koff E, Rhinehart ED, Rierdan J. Flashbulb memories of menarche and adult menstrual distress. Journal of Adolescence 1987;10:187-199. [PubMed: 3611467]

Pillemer DB, Goldsmith LR, Panter AT, White SH. Very long-term memories of the first year in college, Journal of Experimental Psychology: Learning. Memory, and Cognition 1988;14:709715.

Porter S, Spencer L, Birt AR. Blinded by emotion? Effect of the emotionality of a scene on susceptibility to false memories. Canadian Journal of Behavioural Science 2003;35(3):165-175.

Quevedo J, Sant'Anna MK, Madruga M, et al. Differential effects of emotional arousal in short- and long-term memory in healthy adults. Neurobiology of Learning and Memory 2003;79:132-135. [PubMed: 12591221]

Raes F, Hermans D, de Decker A, Eelen P, Williams JMG. Autobiographical memory specificity and affect regulation: An experimental approach. Emotion 2003;3:201-206. [PubMed: 12899419]

Ramel W, Goldin PR, Eyler LT, Brown GG, Gotlib IH, McQuaid JR. Amygdala reactivity and moodcongruent memory in individuals at risk for depressive relapse. Biological Psychiatry 2007;61:231-239. [PubMed: 16950223]

Redelmeier DA, Kahneman D. Patients' memories of painful medical treatments: Real-time and retrospective evaluations of two minimally invasive procedures. Pain 1996;66(1):3-8. [PubMed: 8857625]

**. Reisberg, D.; Heuer, F. Remembering emotional events. In: Reisberg, D.; Hertel, P., editors. Memory and emotion. New York: Oxford University Press; 2004. p. 3-41.

Revelle, W.; Loftus, D. The implications of arousal effects for the study of affect and memory. In: Christianson, SA., editor. Handbook of emotion and memory. Hillsdale, NJ: Erlebaum; 1992. p. 113-150.

Richardson MP, Strange BA, Dolan RJ. Emotional memory encoding depends on amygdala and hippocampus and their interactions. Nature Neuroscience 2004;7:278-285.

Riskind JH. Nonverbal expressions and the accessibility of life experience memories: A congruence hypothesis. Social Cognition 1983;2:62-86.

*. Ritchey M, Dolcos F, Cabeza R. Role of amygdala connectivity in the persistence of emotional memories over time: An event-related fMRI investigation. Cerebral Cortex 2008;18:2494-2504. [PubMed: 18375529]

Robinson, JA. Perspective, meaning and remembering. In: Rubin, DC., editor. Remembering our past: Studies in autobiographical memory. New York: 1996. p. 199-217.

Robinson JA, Swanson KL. Field and observer modes of remembering. Memory 1993;1:169-184. [PubMed: 7584265]

**. Robinson MD, Clore GL. Belief and Feeling: Evidence for an accessibility model of emotional self-report. Psychological Bulletin 2002;128:934-960. [PubMed: 12405138]

Robinson MD, Johnson JT, Shields SA. The gender heuristic and the database: Factors affecting the perception of gender-related differences in the experience and display of emotions. Basic and Applied Social Psychology 1998;20(3):206-219.

Robinson JA, Swanson JA. Field and observer modes of remembering. Memory 1993;1:169-184. [PubMed: 7584265]

Rogers TB, Kuiper NA, Kirker WS. Self-reference and the encoding of personal information. Journal of Personality and Social Psychology 1977;35(9):677-688. [PubMed: 909043]

Romeu PF. Memories of the terrorist attacks of September 11, 2001: A study of the consistency and phenomenal characteristics of flashbulb memories. The Spanish Journal of Psychology 2006;9(1):52-60. [PubMed: 16673623]

Ross ED, Homan RW, Buck R. Differential hemispheric lateralization of primary and social emotions: Implications for developing a comprehensive neurology for emotions, repression, and the subconscious, Neuropsychiatry. Neuropsychology, and Behavioral Neurology 1994;7(1):1-19. 
**. Ross M. Relation of implicit theories to the construction of personal histories. Psychological Review 1989;96:341-357.

Rubin, DC.; Wenzel, A. Autobiographical memory tasks: Six common methods. In: Wenzel, A., editor. Cognitive Methods and Their Application to Clinical Research. Washington, D.C: 2004. p. 215-218.

Rubin DC, Wenzel AE. One hundred years of forgetting: A quantitative description of retention. Psychological Review 1996;103:734-760.

*. Rubin DC, Kozin M. Vivid memories. Cognition 1984;16(1):81-95. [PubMed: 6540650]

Rubin DC. A basic systems approach to autobiographical memory. Current Directions in Psychological Science 2005;14:79-83.

*. Rubin DC. The basic-systems model of episodic memory. Perspectives on Psychological Science 2006;1:277-311.

*. Rubin DC, Schrauf RW, Greenberg DL. Belief and recollection of autobiographical memories. Memory and Cognition 2003;31:887-901.

Rubin, DC.; Wetzler, SE.; Nebes, RD. Autobiographical memory across the lifespan. In: Rubin, DC., editor. Autobiographical Memory. Cambridge, U.K: 1986. p. 202-221.

Rugg MD, Johnson JD, Park H, Uncapher MR. Encoding-retrieval overlap in human episodic memory: a functional neuroimaging perspective. Progress in Brain Research 2008;169:339-352. [PubMed: 18394485]

Rumelhart, DE. Schemata: the building blocks of cognition. In: Spiro, RJ.; Bruce, BC.; Brewer, WF., editors. Theoretical issues in reading comprehension. New York, NY: Erlbaum; 1980. p. 33-58.

*. Russell JA. A circumplex model of affect. Journal of Personality and social Psychology 1980;39:1161-1178.

Rusting CL, DeHart T. Retrieving positive memories to regulate negative mood: Consequences for mood-congruent memory. Journal of Personality and Social Psychology 2000;78:737-752. [PubMed: 10794377]

**. Rusting CL. Personality, mood, and cognitive processing of emotional information: Three conceptual frameworks. Psychological Bulletin 1998;124:165-196. [PubMed: 9747185]

Rusting CL. Interactive effects of personality and mood on emotion-congruent memory and judgment. Journal of Personality and Social Psychology 1999;77:1073-1086. [PubMed: 10573881]

Safer MA, Keuler DJ. Individual differences in misremembering pre-psychotherapy distress: Personality and memory distortion. Emotion 2002;2(2):162-278. [PubMed: 12899189]

Safer MA, Levine LJ, Drapalski AL. Distortion in memory for emotions: The contributions of personality and post-event knowledge. Personality and Social Psychology Bulletin 2002;28(11): 1495-1507.

Sanitioso R, Kunda Z, Fong GT. Motivated recruitment of autobiographical memories. Journal of Personality and Social Psychology 1990;59:229-241. [PubMed: 2213492]

Saxe R, Moran JM, Scholz J, Gabrieli JDE. Overlapping and non-overlapping brain regions for theory of mind and self reflection in individual subjects, Social. Cognitive, and Affective Neuroscience 2006;1(3):229-234.

*. Schacter DL, Addis DR. The ghosts of past and future: A memory that works by piecing together bits of the past may be better suited to simulating future events than one that is a store of perfect records. Nature 2007;445(7123):27. [PubMed: 17203045]

Schacter DL. The seven sins of memory: Insights from psychology and cognitive neuroscience. American Psychologist 1999;54(3):182-203. [PubMed: 10199218]

Schacter DL, Addis DR, Buckner RL. Remembering the past to imagine the future: The prospective brain. Nature Reviews Neuroscience 2007;8(9):657-661.

Schmidt SR. Autobiographical memories for the September 11th attacks: Reconstructive errors and emotional impairment of memory. Memory and Cognition 2004;32:443-454.

Schmolck H, Buffalo EA, Squire LR. Memory distortions develop over time: Recollections of the O.J. Simpson trial verdict after 15 and 32 months. Psychological Science 2000;11:39-45. [PubMed: 11228841] 
Schwarz ED, Kowalski JM, McNally RJ. Malignant memories: Post traumatic changes in memory in adults after a school shooting. Journal of Traumatic Stress 1993;6(4):545-553.

**. Schwarz M, Clore GL. Mood, misattribution, and judgements of well-being: Informative and directive functions of affective states. Journal of Personality and Social Psychology 1983;45(3): 513-523.

Schwarz, N. Feelings as information: Informational and motivational functions of affective states. In: Higgins, ET.; Sorrentino, RM., editors. Handbook of motivation and cognition: Foundations of social behavior. Vol. 2. New York, NY: Guilford Press; 1990. p. 527-561.

Schwarz, N.; Clore, GL. How do I feel about it? Informative functions of affective states. In: Fiedler, K.; Forgas, J., editors. Affect, cognition, and social behavior. Toronto, Canada: Hogrefe International; 1988. p. 44-62.

Schwarz, N.; Clore, GL. Feelings and phenomenal experiences. In: Higgins, ET.; Kruglanski, A., editors. Social psychology: Handbook of basic principles. New York: Guilford; 1996. p. 433-465.

Scollon CN, Howard AH, Caldwell AE, Ito S. The role of ideal affect in the experience and memory of emotions. Journal of Happiness Studies 2009;10(3):257-269.

Scott D, Ponsoda V. The role of positive and negative affect in flashbulb memory. Psychological Reports 1996;79(2):467-473. [PubMed: 8909069]

***. Scoville WB, Milner B. Loss of recent memory after bilateral hippocampal lesions, Journal of Neurology. Neurosurgery, and Psychiatry 1957;20:11-21.

Sedikides C. Incongruent effects of sad mood on self-conception valence: It's a matter of time. European Journal of Social Psychology 1994;24:161-172.

Setliff AE, Marmurek HHC. The mood regulatory function of autobiographical recall is moderated by self-esteem. Personality and Individual Differences 2002;32:761-771.

Shapiro, L. Remembering September 11th: The role of retention interval and rehearsal on flashbulb and event memory, Memory. Vol. 14. 2006. p. 129-147.

Sharkawy J, Groth K, Vetter C, Beraldi A, Fast K. False memories of emotional and neural words. Behavioural Neurology 2008;19(1-2):7-11. [PubMed: 18413909]

Sharot T, Martorella EA, Delgado MR, Phelps EA. How personal experience modulates the neural circuitry of memories of September 11. Proceedings of the National Academy of Sciences, USA 2007;104:389-394.

*. Sharot T, Delgado MR, Phelps EA. How emotion enhances the feeling of remembering. Nature Neuroscience 2004;12:1376-1380.

Sharot T, Yonelinas AP. Differential time-dependent effects of emotion on the recollective experience and memory for contextual information. Cognition 2008;106:538-547. [PubMed: 17451666]

Sheingold, K.; Tenney, YJ. Memory for a salient childhood event. In: Neisser, U., editor. Memory observed. Freeman; San Francisco: 1982. p. 201-212.

Simon HA. Motivational and emotional controls of cognition. Psychological Review 1967;74:29-39. [PubMed: 5341441]

Singer JA, Salovey P. Mood and memory: Evaluating the network theory of affect. Clincial Psychology Review 1988;8:211-251.

Skowronski JJ, Carlston DE. Social judgement and social memory: The role of cue diagnosticity in negativity, positivity, and extremity biases. Journal of Personality and Social Psychology 1987;52(4):689-699.

Slotnick SD, Schacter DL. A sensory signature that distinguishes true from false memories. Nature Neuroscience 2004;7:664-672.

Smith MC, Bibi U, Sheard DE. Evidence for the differential impact of time and emotion on personal and event memories for September 11, 2001. Applied Cognitive Psychology 2003;17:10471055.

Smith AP, Henson RN, Rugg MD, Dolan RJ. Modulation of retrieval processing reflects accuracy of emotional source memory. Learning and Memory 2005;12:472-479. [PubMed: 16204201]

Snyder M, White P. Moods and memories: Elation, depression, and the remembering of the events of one's life. Journal of Personality 1982;50:142-167. 
Soetens E, Casaer S, D’Hooge R, Hueting JE. Effect of amphetamine on long-term retention of verbal material. Psychopharmacology 1995;119(2):155-162. [PubMed: 7659762]

Sprecher S. "I love you more today than yesterday": Romantic partners' perceptions of changes in love and related affect over time. Journal of Personality and Social Psychology 1999;76(1):46-53. [PubMed: 9972552]

Spreng RN, Grady CL. Patterns of brain activity supporting autobiographical memory, prospection, and theory-of-mind and their relationship to the default mode network. Journal of Cognitive Neuroscience. 2009 in press.

Sterpenich V, Albouy G, Darsaud A, Schmidt C, Vandewalle G, et al. Sleep promotes the neural reorganization of remote emotional memory. Journal of Neuroscience 2009;29:5143-5152. [PubMed: 19386910]

Stickgold R. Sleep-dependent memory consolidation. Nature 2005;437:1272-1278. [PubMed: 16251952]

Stone AA, Hedges SM, Neale JM, Satin MS. Prospective and cross-sectional mood reports offer no evidence of a "blue Monday" phenomenon. Journal of Personality and Social Psychology 1985;49(1):129-134.

Storbeck J, Clore GL. With sadness comes accuracy; with happiness, false memory: Mood and the false memory effect. Psychological Science 2005;16:785-791. [PubMed: 16181441]

Strange BA, Dolan RJ. Beta-adrenergic modulation of emotional memory-evoked human amygdala and hippocampal responses. Proceedings of the National Academy of Sciences 2004;101(31): $11454-11458$.

Strange BA, Hurlemann R, Dolan RJ. An emotion-induced retrograde amnesia in humans is amygdalaand beta-adrenergic-dependent. Proceedings of the National Academy of Sciences 2003;100(23): 13626-13631.

**. Svoboda E, McKinnon MC, Levine B. The functional neuroanatomy of autobiographical memory: A meta-analysis. Neuropsychologia 2006;44(12):2189-2208. [PubMed: 16806314]

Symons CS, Johnson BT. The self-reference effect in memory: A meta-analysis. Psychological Bulletin 1997;121(3):371-394. [PubMed: 9136641]

Szpunar KK, McDermott KB. Episodic future thought and its relation to remembering: Evidence from ratings of subjective experience. Consciousness and Cognition 2008;17:330-334. [PubMed: 17540581]

Talarico JM, Rubin DC. Confidence, not consistency, characterizes flashbulb memories. Psychological Science 2003;14:455-461. [PubMed: 12930476]

Talarico JM, Rubin DC. Flashbulb memories are special after all; in phenomenology, not accuracy. Applied Cognitive Psychology 2007;21(5):557-578.

Talarico JM, LaBar KS, Rubin DC. Emotional intensity predicts autobiographical memory experience. 2004;32:1118-1132.

Tamir M. Differential preferences for happiness: Extraversion and trait-consistent emotion regulation. Journal of Personality 2009;77:447-470. [PubMed: 19220724]

Tamir M, Mitchell C, Gross JJ. Hedonic and instrumental motives in anger regulation. Psychological Science 2008;19:324-328. [PubMed: 18399883]

Tamir M, Chiu CY, Gross JJ. Business or pleasure? Utilitarian versus hedonic considerations in emotion regulation. Emotion 2007;7:546-554. [PubMed: 17683211]

Teasdale JD, Fogerty SJ. Differential effects of induced mood on retrieval of pleasant and unpleasant events from episodic memory. Journal of Abnormal Psychology 1979;88:248-257. [PubMed: 500952]

Teasdale JD, Taylor R, Fogarty SJ. Effects of induced elation-depression on the accessibility of memories of happy and unhappy experiences. Behavior Research and Therapy 1980;18:339-346.

Tekcan AI, Ece B, Gülgöz S, Er N. Autobiographical and event memory for 9/11: Changes across one year. Applied Cognitive Psychology 2003;17:1057-1066.

Tekcan AI, Peynircioglu ZF. Effects of age on flashbulb memories. Psychology and Aging 2002;17(3): 416-422. [PubMed: 12243383] 
Tekcan AI. Recall, consistency, and determinants of flashbulb memories. Dissertation Abstracts International: Section B: The Sciences and Engineering 1999;60(1-B):0385.

Tekcan AI. Flashbulb memories for a negative and a positive event: news of Desert Storm and acceptance to college. Psychological Reports 2001;88:323-331. [PubMed: 11351866]

Terr LC, Bloch DA, Michel BA, Shi H, et al. Children's memories in the wake of Challenger. The American Journal of Psychiatry 1996;153(5):618-625. [PubMed: 8615406]

Thomas DL, Diener E. Memory accuracy in the recall of emotions. Journal of Personality and Social Psychology 1990;59(2):291-297.

Thompson CP, Cowan T. Flashbulb memories: A nicer interpretation of a Neisser recollection. Cognition 1986;22(2):199-200. [PubMed: 3709091]

Thompson RG, Moulin CJA, Ridel GL, Hayre S, Conway MA, Jones RW. Recall of 9.11 in Alzheimer's disease: further evidence for intact flashbulb memory. International journal of geriatric psychiatry 2004;19(5):494-496.

Tinti C, Schmidt S, Sotgiu I, Testa S, Curci A. The role of importance/consequentiality appraisal in flashbulb memory formation: The case of death of Pope John Paul II. Applied Cognitive Psychology 2009;23(2):236-253.

Touryan SR, Johnson MK, Mitchell KJ, Norman F, Cunningham WA, Raye CL. The influence of selfregulatory focus on encoding of, and memory for, emotional words. Social Neuroscience 2006;2:14-27. [PubMed: 18633804]

Tranel D, Damasio AR. The covert learning of affective valence does not require structures in hippocampal system or amygdala. Journal of Cognitive Neuroscience 1993;5(1):79-88.

Tsai JL, Knutson B, Fung HH. Cultural variation in affect valuation. Journal of Personality and Social Psychology 2006;90(2):288-307. [PubMed: 16536652]

***. Tulving, E. Episodic and semantic memory. In: Tulving, E.; Donaldson, W., editors. Organization of memory. New York: 1972. p. 382-402.

**. Tulving, E. Elements of Episodic Memory. Vol. 2. Oxford University Press; New York: 1983.

**. Tulving E. How many memory systems are there? American Psychologist 1985;40:385-398.

Underwood BJ. Intralist similarity in verbal learning and retention. Psychological Review 1954;61:160-166. [PubMed: 13167242]

Underwood BJ. Degree of learning and the measurement of forgetting. Journal of Verbal Learning and Verbal Behavior 1964;3:112-129.

Vaidya CJ, Zhao M, Desmond JE, Gabrieli JDE. Evidence for cortical encoding specificity in episodic memory: Memory- induced re-activation of picture processing areas. Neuropsychologia 2002;40(12):2136-2143. [PubMed: 12208009]

Van Boven L, Ashworth L. Looking forward, looking back: Anticipation is more evocative than retrospection. Journal of Experimental Psychology 2007;136(2):289-300. [PubMed: 17500652]

Van Strien JW, Langeslag SJ, Strekalova NJ, Gootjes L, Franken IH. Valence interacts with the early ERP old/new effect and arousal with the sustained ERP old/new effect for affective pictures. Brain Research 2009;1251:223-235. [PubMed: 19063866]

Velten E. A laboratory task for induction of mood states. Behavior Research and Therapy 1968;6:473482.

Vincent JL, Snyder AZ, Fox MD, Shannon BJ, Andrews JR, Raichle ME, Buckner RL. Coherent spontaneous activity identifies a hippocampal-parietal mnemonic network. Journal of Neurophysiology 2006;6:3517-3531. [PubMed: 16899645]

Vuilleumier P, Driver J. Modulation of visual processing by attention and emotion: windows on causal interactions between human brain regions. Philosophical Transactions of the Royal Society of London, B Series. Biological Sciences 2007;362:837-855. [PubMed: 17395574]

Wagenaar WA, Groeneweg J. The memory of concentration camp survivors. Applied Cognitive Psychology 1990;4(2):77-87.

Wagenaar WA. My memory: A study of autobiographical memory over six years. Cognitive Psychology 1986;18:225-252.

Wagner AD, Shannon BJ, Kahn I, Buckner RL. Parietal lobe contributions to episodic memory retrieval. Trends in Cognitive Sciences 2005;9(9):445-453. [PubMed: 16054861] 
Wagner U, Gais S, Born J. Emotional memory formation is enhanced across sleep intervals with high amounts of rapid eye movement sleep. Learning and Memory 2001;8:112-119. [PubMed: 11274257]

Wagner U, Hallschmid M, Rasch B, Born J. Brief sleep after learning keeps emotional memories alive for years. Biological Psychiatry 2006;60:788-790. [PubMed: 16806090]

Watkins E, Teasdale JD. Rumination and overgeneral memory in depression: Effects of self-focus and analytic thinking. Journal of Abnormal Psychology 2001;110:353-357. [PubMed: 11358029]

Weaver CA, Krug KS. Consolidation-like effects in flashbulb memories: Evidence from September 11, 2001. American Journal of Psychology 2004;117(4):517-530. [PubMed: 15605956]

Weaver CA. Do you need a 'flash' to form a flashbulb memory? Journal of Experimental Psychology: General 1993;122:39-46.

Wegner, DM.; Vallacher, RR. Action identification. In: Sorrentino, RM.; Higgins, ET., editors. Handbook of motivation and cognition: Foundations of social behavior. Guilford; New York: 1986. p. 550-582.

Weiskrantz L. Behavioral changes associated with ablation of the amygdaloid complex in monkeys. Journal of comparative and physiological psychology 1956;49:381-91. [PubMed: 13345917]

Wheeler ME, Buckner RL. Functional-anatomic correlates of remembering and knowing. NeuroImage 2004;21:1337-1349. [PubMed: 15050559]

Wheeler ME, Stuss DT, Tulving E. Toward a theory of episodic memory: The frontal lobes and autonoetic consciousness. Psychological Bulletin 1997;121:331-354. [PubMed: 9136640]

Wheeler ME, Buckner RL. Functional Dissociation among Components of Remembering: Control, Perceived Oldness, and Content. The Journal of Neuroscience 2003;23(9):3869-3880. [PubMed: 12736357]

Wheeler ME, Shulman GL, Buckner RL, Miezin FM, Velanova K, Petersen SE. Evidence for separate perceptual reactivation and search processes during remembering. Cerebral Cortex 2006;16(7): 949-959. [PubMed: 16162854]

Wheeler ME, Petersen SE, Buckner RL. Memory's echo: vivid remembering reactivates sensoryspecific cortex. Proceedings of the National Academy of Sciences, USA 2000;97:11125-11129.

Williams JMG, Broadbent K. Autobiographical memory in suicide attempters. Journal of Abnormal Psychology 1986;95:144-149. [PubMed: 3711438]

Williams, JMG. Depression and the specificity of autobiographical memory. In: Rubin, DC., editor. Remembering our past: Studies in autobiographical memory. New York: 1996. p. 244-267.

Williams, JMG.; Watts, FN.; MacLeod, C.; Mathews, A. Cognitive psychology and emotional disorders. 2. Wiley; Chichester, UK: 1997.

*. Williams JMG, Barnhofer T, Crane C, Hermans D, Raes F, Watkins E, Dalgleish T. Autobiographical memory specificity and emotional disorder. Psychological Bulletin 2007;133:122-148. [PubMed: 17201573]

Williams JMG. Capture and rumination, functional avoidance, and executive control (CaRFAX): Three processes that underlie overgeneral memory. Cognition and Emotion 2006;20:548-568.

Wilson TD, Meyers J, Gilbert DT. "How happy was I, anyway?” A retrospective impact bias. Social Cognition 2003;21(6):421-446.

Wilson TD, Meyers J, Gilbert DT. Lessons from the past: Do people learn from experience that emotional reactions are short-lived? Personality and Social Psychology Bulletin 2003;27(12): $1648-1661$.

Winningham RG I, Hyman E, Dinnel DL. Flashbulb memories? The effects of when the initial memory report was obtained. Memory 2000;8(4):209-216. [PubMed: 10932791]

Winograd E, Killinger WA Jr. Relating age at encoding in early childhood to adult recall: development of flashbulb memories. Journal of Experimental Psychology: General 1983;112:413-422.

Wirtz D, Kruger J, Napa Scollon C, Diener E. What to do on spring break? The role of predicted, online, and remembered experience in future choice. Psychological Science 2003;14(5):520-524. [PubMed: 12930487] 
Woike B, Gershkovich I, Piorkowski R, Polo M. The role of motives in the content and structure of autobiographical memory. Journal of Personality and Social Psychology 1999;76:600-612. [PubMed: 10234847]

Woike BA, Polo M. Motive-related memories: Content, structure, and affect. Journal of Personality 2001;69:391-415. [PubMed: 11478731]

Woike BA. A functional framework for the influence of implicit and explicit motives on autobiographical memory. Personality and Social Psychology Review 2008;12:99-117. [PubMed: 18453474]

Wolters G, Goudsmit JJ. Flashbulb and Event Memory of September 11, 2001: Consistency, Confidence and Age Effects. Psychological Reports 2005;96(3):605-619. [PubMed: 16050611]

Wright, D.; Gaskell, G. The construction and function of vivid memories. In: Conway, MA.; Rubin, DC.; Spinnler, H.; Wagenaar, WA., editors. Theoretical Perspectives on Autobiographical Memory. Boston: 1992. p. 275-292.

Wright DB, Gaskell GD, O’Muircheartaigh CA. Flashbulb memory assumptions: Using national surveys to explore cognitive phenomena. British Journal of Psychology 1998;89:103-121. [PubMed: 9532725]

Wright DB. Recall of the Hillsborough disaster over time: Systematic biases of "flashbulb" memories. Applied Cognitive Psychology 1993;7(2):129-138.

Yarmey AD, Bull MP. Where were you when President Kennedy was assassinated? Bulletin of the Psychonomic Society 1978;11(2):133-135.

Yaron-Antar A, Nachson I. Collaborative remembering of emotional events: The case of Rabin's assassination. Memory 2006;14(1):46-56. [PubMed: 16423741]

Yuille JC, Cutshall JL. A case study of eyewitness memory of a crime. Journal of Applied Psychology 1986;71(2):291-301. [PubMed: 3722079]

Zajonc RB. Feeling and thinking: Preferences need no inferences. American Psychologist 1980;35(2): $151-175$. 


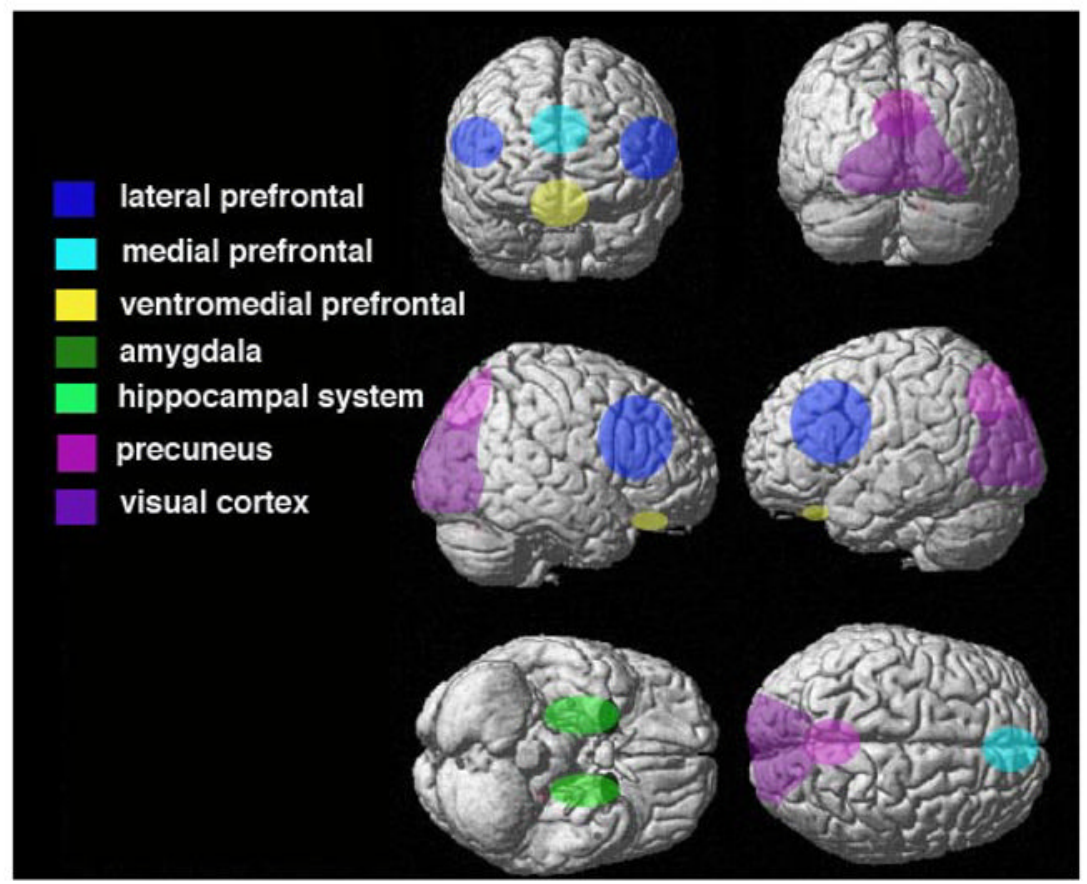

Figure 1.

A schematic of the regions commonly activated during autobiographical retrieval. The regions depicted here are those reviewed by Cabeza \& St. Jacques (2007) and discussed in the meta-analysis by Svoboda et al. (2006). 


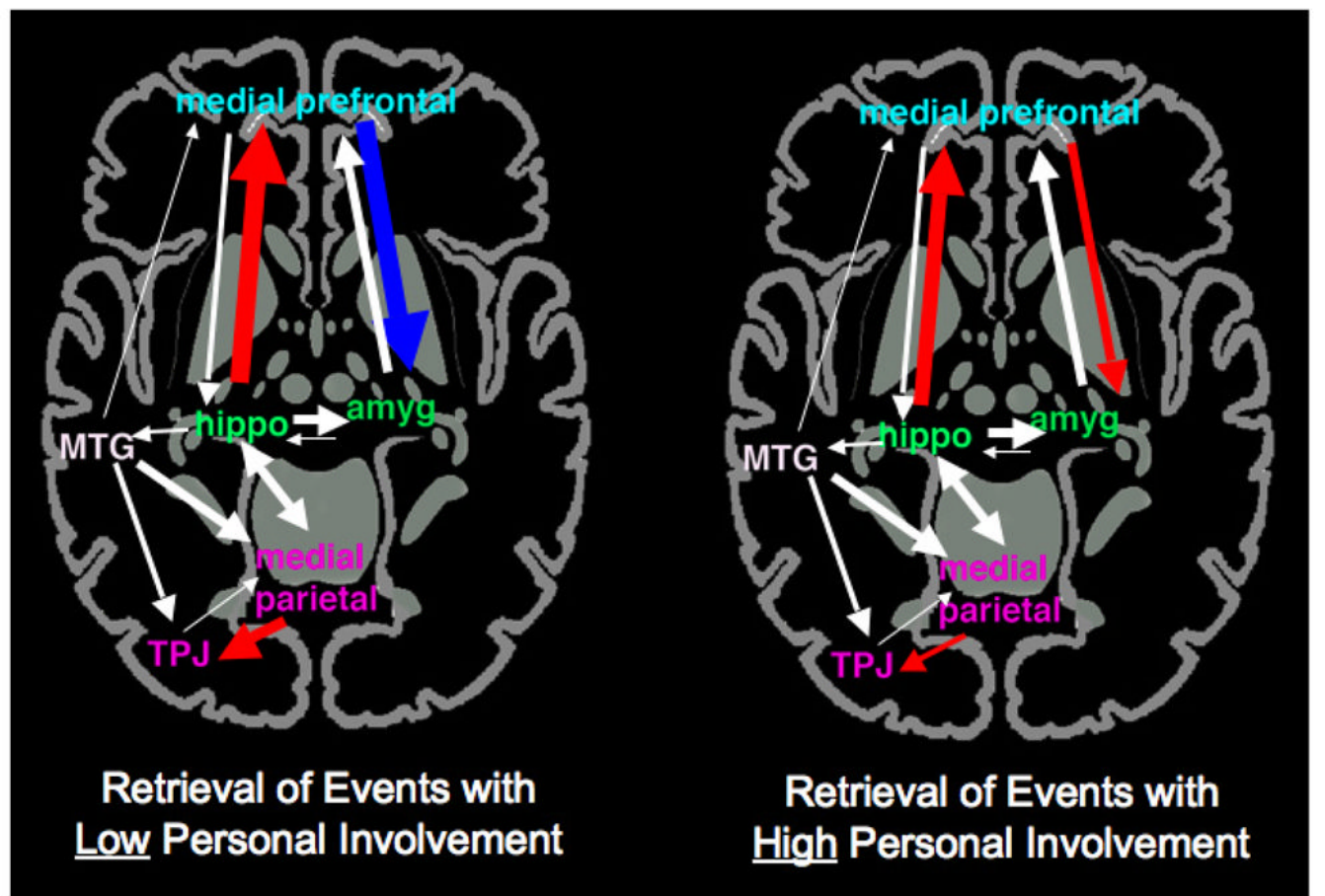

Figure 2.

A schematic representation of how the effective connectivity within an autobiographical retrieval network varies based on the level of personal involvement with a past event. Colored lines indicate conditions that differ significantly between the two types of events, with red lines indicating significantly positive connections and blue lines indicating significantly negative connections. Connections which did not differ between the conditions are depicted in white. The thickness of the line represents the strength of the connection. Adapted from Muscatell et al. (in press). Hippo = hippocampus; Amyg = amygdala; TPJ = temporo-parietal junction; MTG = middle temporal gyrus. Region names are color-coded to match those depicted in Figure 1. 


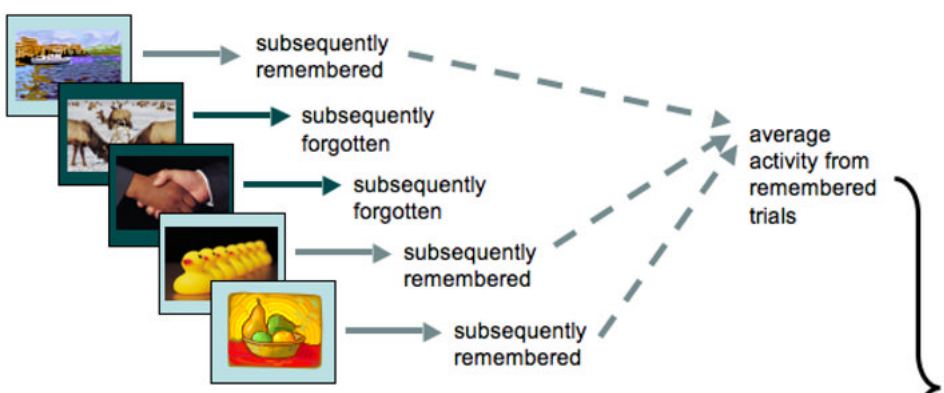

Difference in response to memory ( $\mathrm{Dm}$ or subsequent memory effect) results when activity in a region is greater for the remembered trials than for the forgotten trials

$\square$ Remembered $\square$ Forgotten
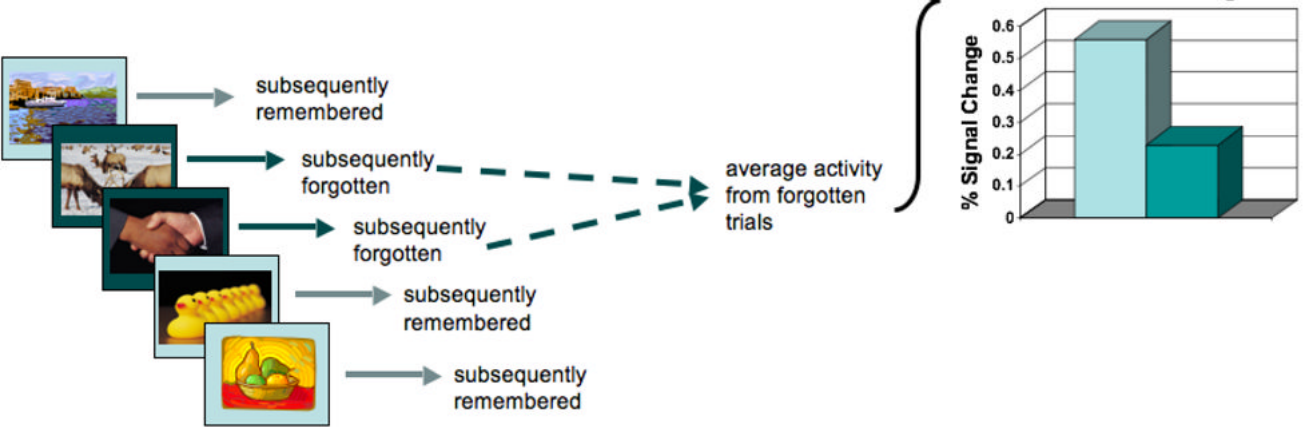

Figure 3.

A schematic of the event-related, subsequent-memory design, often used in neuroimaging studies to assess the successful encoding of information. 
Table 1

A list of studies examining adults' retention of public events.

\begin{tabular}{|c|c|c|c|}
\hline Event Type & Event Valence & Event Description (Year) & Relevant Studies \\
\hline \multirow[t]{8}{*}{ Space Shuttle Explosion } & Negative & Challenger (1986) & Bohannon, 1988 \\
\hline & & & Bohannon \& Symons, 1992 \\
\hline & & & Bohannon, Gratz, \& Cross, 2007 \\
\hline & & & McCloskey, Wible, \& Cohen, 1988 \\
\hline & & & Neisser \& Harsch, 1992 \\
\hline & & & Terr et al., 1996 \\
\hline & Negative & Columbia (2003) & Kensinger, Krendl, \& Corkin, 2006 \\
\hline & & & Kershaw, Hemmerich, \& Ahmed, 2009 \\
\hline \multirow[t]{5}{*}{ Man-made disaster } & Negative & Hillsborough soccer field disaster (1989) & Wright, 1993 \\
\hline & & nuclear accident in Japan (1999) & Otani et al., 2005 \\
\hline & & school shooting (1988) & Schwarz, Kowalski \& McNally, 1993 \\
\hline & & MS Estonia Ferry Disaster (1994) & Christianson \& Engelberg, 1999 \\
\hline & & Train station bombing in Bologna (1980) & Cubelli \& Della Sala, 2008 \\
\hline \multirow[t]{5}{*}{ Natural disaster } & Negative & Earthquake in Loma Prieta (1989) & Neisser et al., 1996 \\
\hline & & Hurricane Andrew (1992) & Bahrick, Parker, Fivush, \& Levett, 1998 \\
\hline & & Hurricane Hugo (1989) & Norris \& Kaniasty, 1992 \\
\hline & & Marmara earthquake & Er, 2003 \\
\hline & & & Nurhan, 2003 \\
\hline \multirow[t]{14}{*}{ World Events } & Either & German invasion of Denmark (1940) & Berntsen \& Rubin, 2006b \\
\hline & & German withdrawal from Denmark & Berntsen \& Thomsen, 2005 \\
\hline & Negative & Beginning of the Gulf War (1990) & Bohannon, Gratz, \& Cross, 2007 \\
\hline & & & Tekcan, 2001 \\
\hline & & & Weaver, 1993 \\
\hline & Negative & Bombing of Pearl Harbor (1941) & Neisser, 1982 \\
\hline & & & Thompson \& Cowan, 1986 \\
\hline & & Resignation of Margaret Thatcher (1990) & Cohen et al., 1994 \\
\hline & & & Conway et al., 1994 \\
\hline & & & Wright, Gaskell, \& O’Muircheartaigh, 1998 \\
\hline & Either & Fall of the Berlin Wall (1989) & Bohn \& Berntsen, 2007 \\
\hline & & & Scott \& Ponsoda, 1996 \\
\hline & Positive & Japan World Exposition (1970) & Anderson \& Shimizu, 2007 \\
\hline & & $\begin{array}{l}\text { Change in national borders of Turkey } \\
\text { (1939) }\end{array}$ & Tekcan \& Peynircioglu, 2002 \\
\hline \multirow[t]{4}{*}{ Assassination } & Negative & $\begin{array}{r}\text { Swedish Prime Minister Olof Palme } \\
\text { (1986) }\end{array}$ & Christianson, 1989 \\
\hline & & Attempted, President Reagan (1981) & McCloskey et al., 1988 \\
\hline & & & Pillemer, 1984 \\
\hline & & & Rubin \& Kozin, 1984 \\
\hline
\end{tabular}

Phys Life Rev. Author manuscript; available in PMC 2011 March 1. 


\begin{tabular}{|c|c|c|c|}
\hline Event Type & Event Valence & Event Description (Year) & Relevant Studies \\
\hline & & President Lincoln (1865) & Colgrove, 1899 \\
\hline & & President John F. Kennedy (1963) & Brown \& Kulik, 1977* \\
\hline & & & Christianson, 1989 \\
\hline & & & Winograd \& Killinger, 1983* \\
\hline & & & Yarmey \& Bull, 1978 \\
\hline & & $\begin{array}{r}\text { Israel's Prime Minister, Yitzhak Rabin } \\
\text { (1995) }\end{array}$ & Yaron-Antar \& Nachson, 2006 \\
\hline & & & Nachson \& Zelig, 2003 \\
\hline \multirow{12}{*}{$\begin{array}{r}\text { Death of famous } \\
\text { individual }\end{array}$} & Negative & Belgian king Baudouin (1995) & Finkenauer, Gisle, \& Luminet, 1997 \\
\hline & & Princess Diana (1997) & Bohannon, Gratz, \& Cross, 2007 \\
\hline & & & Davidson \& Glisky, 2002 \\
\hline & & & Hornstein, Brown, \& Mulligan, 2003 \\
\hline & & & Krackow, Lynn, \& Payne, 2005 \\
\hline & & & $\begin{array}{r}\text { Kvavilahvili, Mirani, Schlagman, \& Kornbrot, } \\
2003\end{array}$ \\
\hline & & Mother Theresa (1997) & Davidson \& Glisky, 2002 \\
\hline & & $\begin{array}{r}\text { Turgut Özal, 8th President of Turkey } \\
\text { (1993) }\end{array}$ & Tekcan \& Peynircioglu, 2002 \\
\hline & & & Tekcan, 1999 \\
\hline & & $\begin{array}{r}\text { Mustafa Kemal Atatürk, first president } \\
\text { of Turkey (1938) }\end{array}$ & Tekcan \& Peynircioglu, 2002 \\
\hline & & $\begin{array}{r}\text { Francois Mitterrand, former president of } \\
\text { France (1996) }\end{array}$ & Curci, Luminet, Finkenauer, \& Gisle, 2001 \\
\hline & & Pope John Paul II (2005) & Tinti et al., 2009 \\
\hline \multirow[t]{3}{*}{ Courtroom trial } & Either & O.J. Simpson verdict (1995) & Schmolck, Buffalo, \& Squire, 2000 \\
\hline & & & Winningham et al., 2000 \\
\hline & Negative & Clarence Thomas hearings & Morse, Woodward, \& Zweigenhaft, 1993 \\
\hline \multirow[t]{2}{*}{ Terrorist Attacks } & Negative & September $11(2001)$ & Budson et al., 2004 \\
\hline & & & Budson et al., 2007 \\
\hline
\end{tabular}

Candel, Jelicic, Merckelbach, \& Wester, 2003

Conway, Skitka, Hemmerich, \& Kershaw, 2009

Curci \& Lanciano, 2009

Curci \& Luminet, 2006

Davidson, Cook, \& Glisky, 2006

Greenberg, 2004

Hirst et al., 2009

Kvavilahvili, Mirani, Schlagman, \& Kornbrot, 2003

Kvavilashvili, Mirani, Schlagman, Foley, \&

Kornbrot, 2009

Lee \& Brown, 2003

Luminet et al., 2004

NiedŸwieńska, 2004 


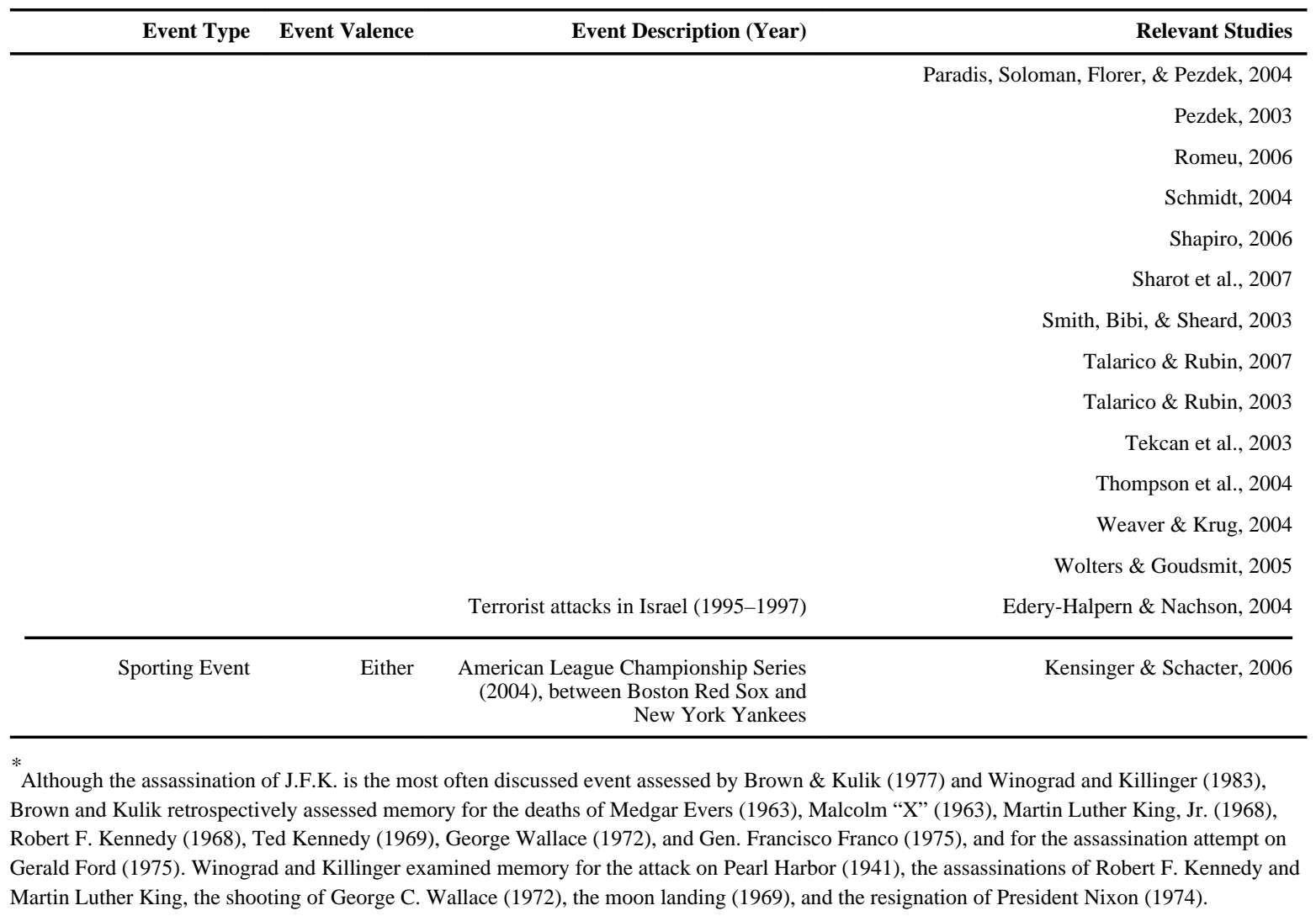

